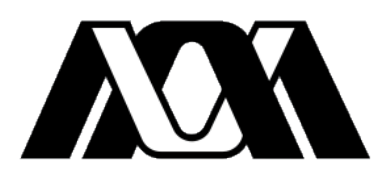

Casa abierta al tiempo
UNIVERSIDAD AUTÓNOMA METROPOLITANA

DIVISIÓN DE CIENCIAS BIOLÓGICAS Y DE LA SALUD

UNIDAD IZTAPALAPA

POSGRADO EN BIOLOGÍA EXPERIMENTAL

\title{
"Actividad cicatrizante y caracterización química del látex de Jatropha neopauciflora en un modelo experimental de diabetes"
}

\section{TESIS}

QUE PARA OBTENER EL GRADO DE:

DOCTORA EN BIOLOGÍA EXPERIMENTAL

PRESENTA:

M. en C. ANA BERTHA HERNÁNDEZ HERNÁNDEZ

\section{DIRECTORES:}

DRA. MARÍA MARGARITA CANALES MARTÍNEZ

DR. FRANCISCO JAVIER ALARCÓN AGUILAR

\section{ASESOR:}

DR. MARCO AURELIO RODRÍGUEZ MONROY 
"El Programa de Doctorado en Biología Experimental de la Universidad Autónoma Metropolitana pertenece al Programa Nacional de Posgrados de Calidad (PNPC) del CONACYT, registro 001482, en el Nivel Consolidado, y cuenta con apoyo del mismo consejo, clave DAFCYT-2003IDPTNNN0020" Número de registro de la beca otorgada por CONACYT: 376294 


\section{MIEMBROS DEL JURADO Y LAS FORMAS CORRESPONDIENTES (ANEXO XII)}

El jurado designado por la Comisión Académica del Posgrado en Biología Experimental de la División de Ciencias Biológicas y de la Salud de la Universidad Autónoma Metropolitana Unidad Iztapalapa, aprobó la tesis titulada "Actividad cicatrizante y caracterización química del látex de Jatropha neopauciflora en un modelo experimental de diabetes" que presentó la M. en C. Ana Bertha Hernández Hernández el día 12 de enero de 2018.

Presidente: Dr. Mario García Lorenzana Profesor Titular C Laboratorio de Neurobiología Tisular Departamento de Biología de la Reproducción Universidad Autónoma Metropolitana-Iztapalapa

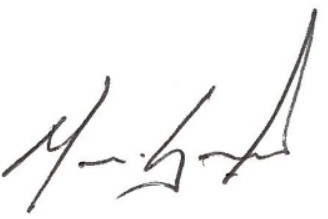

Secretario: Dr. Marco Aurelio Rodríguez Monroy Profesor Titular A Laboratorio de Inmunobiología

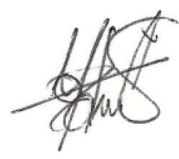

Carrera de Médico Cirujano. Facultad de Estudios Superiores Iztacala Universidad Nacional Autónoma de México

Vocal: Dr. Manuel Jiménez Estrada

Profesor Investigador Titular C Laboratorio de Productos Naturales Instituto de Química

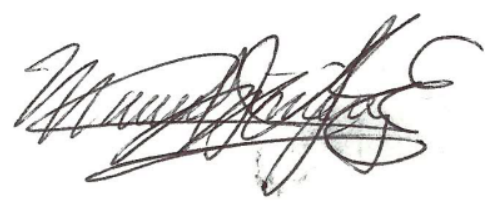

Universidad Nacional Autónoma de México

Vocal: Dr. Gerardo Blancas Flores

Profesor Asociado D

Laboratorio de Farmacología DCBS

Universidad Autónoma Metropolitana - Iztapalapa

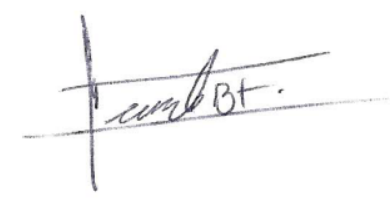




\title{
MIEMBROS DEL COMITÉ DE TUTORES
}

\author{
Dr. Francisco Javier Alarcón Aguilar \\ Director de Tesis \\ Profesor Titular C \\ Laboratorio de Farmacología DCBS \\ Universidad Autónoma Metropolitana - Iztapalapa \\ aaaf@xanum.uam.mx
}

Dra. María Margarita Canales Martínez

Directora de Tesis

Profesor Titular C

Laboratorio de Farmacognosia UBIPRO FES-I

Universidad Nacional Autónoma de México

dra.margaritacanales@gmail.com

Dr. Marco Aurelio Rodríguez Monroy

Asesor

Profesor Titular A

Laboratorio de Inmunobiología, Carrera de Médico Cirujano FES-I

Universidad Nacional Autónoma de México

dr.marcorodriguez@gmail.com 


\title{
AGRADECIMIENTOS
}

\section{Al Posgrado en Biología Experimental, Universidad Autónoma Metropolitana} Unidad Iztapalapa, Universidad Nacional Autónoma de México

Este trabajo fue realizado en el laboratorio de Farmacognosia ubicado en la Unidad de Biotecnología y Prototipos, perteneciente a la División de Investigación y Posgrado de la Facultad de Estudios Superiores Iztacala, UNAM y financiado por el proyecto PAPIIT-UNAM IN212317, en colaboración con el Laboratorio de Farmacología DCBS, UAM- Iztapalapa.

\author{
A los Miembros del Jurado: \\ Dr. Mario García Lorenzana. \\ Dr. Marco Aurelio Rodríguez Monroy. \\ Dr. Manuel Jiménez Estrada. \\ Dr. Gerardo Blancas Flores.
}




\section{AGRADECIMIENTOS}

A mis directores de Tesis, Dra. Ma. Margarita Canales Martínez y Dr. Francisco Javier Alarcón Aguilar por haberme guiado en la realización de este trabajo, por la confianza, por todo el apoyo y por todos los conocimientos que me transmitieron.

A mi Asesor, Dr. Marco Aurelio Rodríguez Monroy, por todas sus observaciones y sugerencias, por todo el apoyo recibido durante todos estos años y sobre todo por el cariño y confianza que ha depositado en mí.

A los miembros del Jurado:

Dr. Mario García Lorenzana, por todos sus consejos, observaciones y sugerencias que ayudaron a concluir este trabajo.

Dr. Manuel Jiménez Estrada y Dr. Gerardo Blancas Flores por los comentarios y sugerencias realizadas en este trabajo.

De la FES Iztacala quiero agradecer:

Al Dr. Cesar Mateo Flores Ortiz y al M. en C. Luis Barbo Hernández Portilla, por la ayuda otorgada en el análisis de las muestras por HPLC en el laboratorio de Biogeoquímica. 


\section{DEDICATORIAS}

A mis padres y hermanos quienes siempre me han apoyado y amado de una manera incondicional, muchas gracias por todo, los amo.

A mi hermosa Andrea, por ser lo más importante en mi vida y por apoyarme siempre, eres mi fortaleza, te amo.

A todos mis amigos y compañeros del laboratorio de Farmacognosia e Inmunobiología, gracias a todos por apoyarme y hacer que mis días sean más amenos. 


\section{ÍNDICE GENERAL}

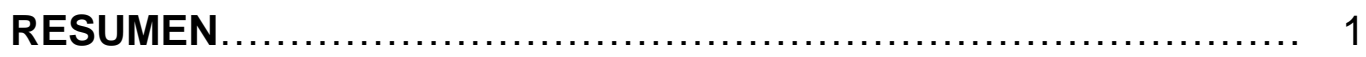

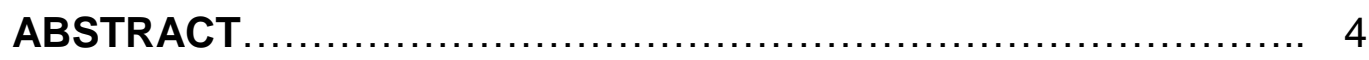

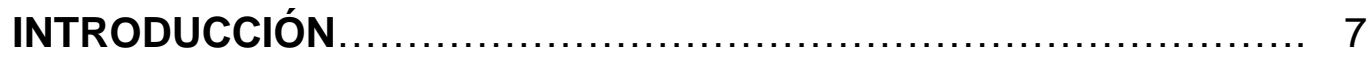

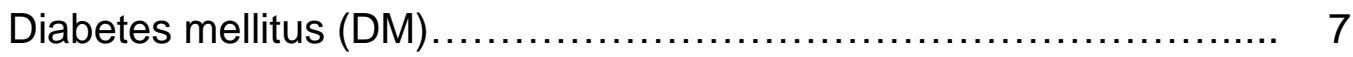

Disfunción inmunológica en DM 8

Lesiones ulcerosas y amputaciones en pacientes con DM............. 9

La piel........................................................... 10

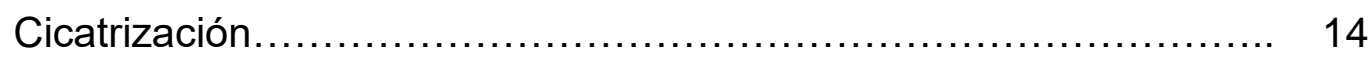

Tratamiento farmacológico actual de las heridas...................... 17

México, medicina tradicional, biodiversidad vegetal y endemismo..... 19

Plantas medicinales utilizadas como cicatrizantes.................... 20

Familia Euphorbiaceae........................................... 21

El género Jatropha................................................. 22

Jatropha neopauciflora............................................ 23

JUSTIFICACIÓN.................................................... 24

PREGUNTA DE INVESTIGACIÓN................................. 25

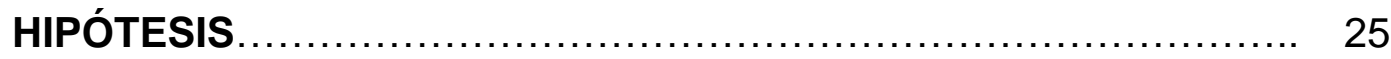

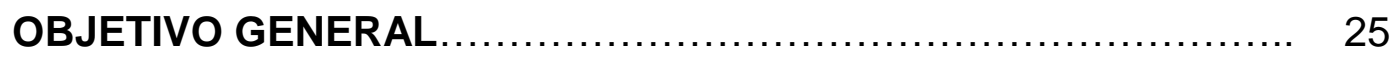

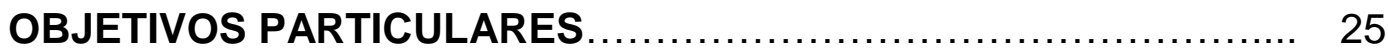

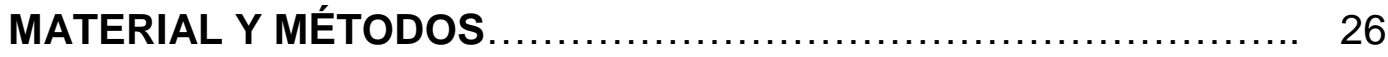

Evaluación tensiométrica de la eficacia cicatrizante del látex de J. 26 neopauciflora en ratones sanos.

Evaluación morfológica de la eficacia cicatrizante del látex de $\mathrm{J}$. neopauciflora en ratones sanos...................................... 27

Inducción de diabetes en ratones............................... 27

Evaluación morfológica de la eficacia cicatrizante del látex en ratones con diabetes. 
Evaluación de la proliferación y la migración celular en fibroblastos 3T3-L1

Evaluación de la citotoxicidad del látex de J. neopauciflora en fibroblastos 3T3 -L1 y macrófagos P-388.

Evaluación de la capacidad antioxidante in vitro del látex de $\mathrm{J}$. neopauciflora. 29

Caracterización química del látex de J. neopauciflora

Determinación de fenoles totales en el látex de J. neopauciflora por el método modificado de Singleton y Rosi

Determinación de flavonoides totales en el látex de J. neopauciflora por el método de Dowd.

Cuantificación de carbohidratos en el látex de J. neopauciflora por la técnica de Nelson-Somogyi

Determinación de carbohidratos por cromatografía líquida de alta resolución (HPLC).

Cuantificación de proteínas en el látex de J. neopauciflora por el método de Bradford. 32

Fraccionamiento biodirigido del látex de J. neopauciflora.............. 32 ANÁLISIS ESTADÍSTICO ......................................... 33

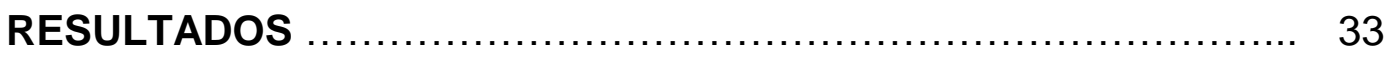

Eficacia cicatrizante del látex de J. neopauciflora....................... 33

Eficacia cicatrizante del látex por el método tensiométrico en ratones sanos. 33

Eficacia cicatrizante del látex en ratones sanos: estudio morfológico. 35

Eficacia cicatrizante del látex en ratones con diabetes inducida con

STZ: estudio morfológico 39

Evaluación de la proliferación y migración de fibroblastos .............. 45

Evaluación de la capacidad antioxidante............................. 47

Caracterización química del látex de J. neopauciflora 49

Fenoles totales ...................................................... 49 


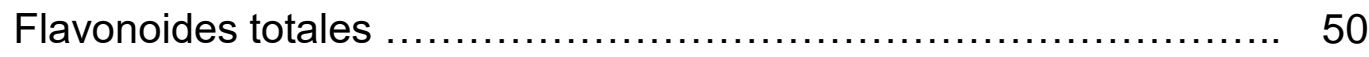

Proteínas ......................................................... 50

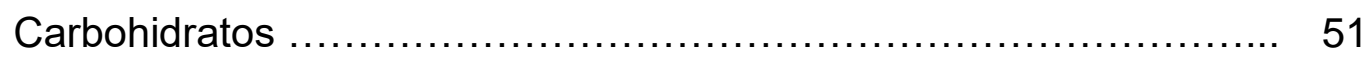

Determinación de carbohidratos por cromatografía líquida de alta

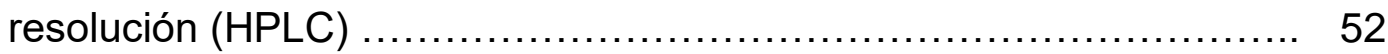

Cromatografía de exclusión en gel ................................. 52

DISCUSIÓN ......................................................... 54

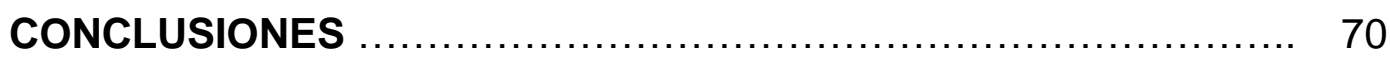

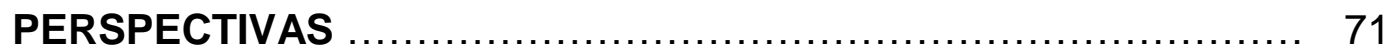

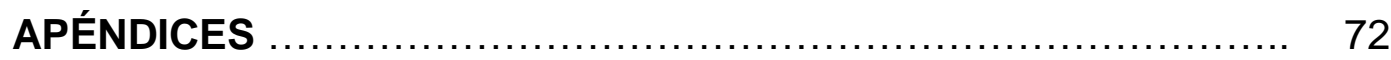

Apéndice 1. Zona de colecta ...................................... 72

Apéndice 2. Método Tensiométrico (Vaisberg et al., 1989) ............. 75

Apéndice 3. Técnica histológica .................................... 76

Apéndice 4. Inducción de diabetes con estreptozotocina (STZ) ....... 80

Apéndice 5. Proliferación y migración celular ........................... 83

Apéndice 6. Método de reducción del radical 2,2-difenil-1-picrilhidracil (DPPH•) (Murillo, 2006) 85

Apéndice 7. Conteo de fenoles totales (CFT) (Método modificado de Singleton et al., 1999)

Apéndice 8. Contenido de flavonoides totales Método Down

(Ramamoorthy y Bono, 2007)

Apéndice 9. Cuantificación de carbohidratos (Método de Nelson -

Somogy) 94

Apéndice 10. Cuantificación de proteínas por el método de Bradford. 96

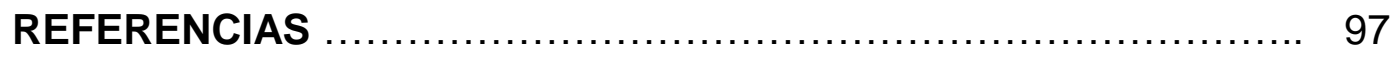

PUBLICACIÓN: Antimicrobial and anti-inflammatory activities, woundhealing effectiveness and chemical characterization of the latex of Jatropha neopauciflora Pax 


\section{ÍNDICE DE FIGURAS}

Figura 1. Organización morfológica de la piel ............................... 11

Figura 2. Capas de la epidermis ............................................ 12

Figura 3. Fases de la cicatrización ........................................ 16

Figura 4. Jatropha neopauciflora Pax .................................. 23

Figura 5. Eficacia cicatrizante de los diferentes tratamientos................ 34

Figura 6. Eficacia cicatrizante del látex de J. neopauciflora por el método tensiométrico ........................................................... 34

Figura 7. Microfotografías de piel de ratones sanos, tinción H\&E ........... 36

Figura 8. Fibroblastos activos en cada grupo experimental de ratones sanos

Figura 9. Microfotografías de piel de ratones sanos. Tinción tricrómica de Masson 39

Figura 10. Eficacia cicatrizante de los diferentes tratamientos............. 40

Figura 11. Microfotografías de piel de ratones diabéticos, tinción H\&E.....

Figura 12. Fibroblastos activos en cada grupo experimental de ratones diabéticos 42

Figura 13. Eficacia cicatrizante de los diferentes tratamientos. 43

Figura 14. Microfotografías de piel de ratones diabéticos 44

Figura 15. Fibroblastos activos en cada grupo experimental de ratones diabéticos 45

Figura 16. Cultivo in vitro de fibroblastos 3T3-L1 ........................ 46

Figura 17. Fotografías de un ensayo de herida in vitro con fibroblastos 3T3-L1 utilizando diferentes concentraciones del látex... 47

Figura 18. Capacidad antioxidante del látex de J. neopauciflora............. 48

Figura 19. Capacidad antioxidante de quercetina ......................... 48

Figura 20. Curva patrón de ácido gálico ..................................... 49

Figura 21. Curva patrón de quercetina ................................... 50

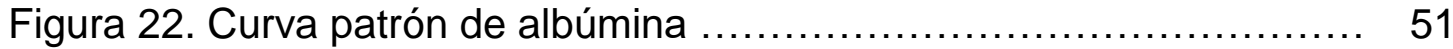




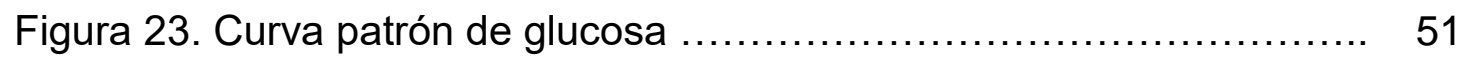

Figura 24. Determinación de carbohidratos por HPLC ..................... 52

ÍNDICE DE CUADROS

Cuadro 1. CA50 de las fracciones del látex de J. neopauciflora ............... 53 


\section{RESUMEN}

La diabetes mellitus (DM) se define como un grupo de trastornos metabólicos caracterizado por hiperglucemia crónica que a largo plazo provoca complicaciones en el organismo. Los pacientes con DM suelen presentar heridas crónicas, principalmente en los miembros inferiores que a menudo culminan en amputación, contribuyendo a su invalidez y mortalidad. Aunque existen medicamentos auxiliares en el proceso de cicatrización de pacientes con DM, éstos pueden presentar efectos adversos y, debido a que sólo presentan un blanco de actividad, es necesaria la prescripción de varios medicamentos con acciones diferentes, principalmente antiinflamatoria, antibacteriana y cicatrizante (promotores de la proliferación celular). Dado que el tratamiento adecuado de una herida requiere de un enfoque integral y completo, a menudo es inaccesible para gran parte de la población debido a su alto costo.

Jatropha neopauciflora (Euphorbiaceae) es una especie endémica de nuestro país cuyo látex es utilizado como cicatrizante. El objetivo de este trabajo fue determinar si el látex de esta especie contiene compuestos con actividad antibacteriana, antioxidante, antiinflamatoria y proliferativa que podrían contribuir de manera integral a acelerar y mejorar el proceso de cicatrización de heridas en un modelo experimental de diabetes.

Se evaluó la eficacia cicatrizante del látex por el método tensiométrico en ratones sanos. Las tres concentraciones de látex mostraron una eficacia cicatrizante del 100\%, mientras que el grupo control (recoverón) sólo alcanzó un $80 \%$. Posteriormente, se 
evaluó la actividad cicatrizante del látex a nivel histológico en ratones sanos y diabéticos. Los resultados mostraron que el látex aceleró el proceso de cicatrización, pues se observaron diferencias en cuanto a la cantidad de fibroblastos activos en la zona de la herida, además de una epidermis delgada y ordenada. Se repitió el mismo experimento, pero aumentando el número de días después de inducida la diabetes, hasta la semana 2, para realizar la incisión, sacrificándolos al día 7 de tratamiento. El tratamiento con el látex provocó un incremento en el número de fibroblastos activos, de manera similar al control positivo, mostrando una disposición tisular de la epidermis más completa. El efecto citotóxico del látex fue evaluado en dos líneas celulares: fibroblastos 3T3-L1 y CaSki. En fibroblastos la $\mathrm{CL}_{50}$ fue de $1000 \mu \mathrm{g} / \mathrm{mL}$, mientras que en CaSki fue de 1250 $\mu \mathrm{g} / \mathrm{mL}$. El látex no fue citotóxico en ninguna de las dos líneas celulares estudiadas. También se evaluó la capacidad antioxidante del látex por el método de reducción del radical DPPH, obteniendo un $\mathrm{CA}_{50}=5.4 \mu \mathrm{g} / \mathrm{mL}$.

Se cuantificaron fenoles totales mediante el método modificado de Singleton, obteniéndose una concentración de $6.9 \mathrm{mg}(\mathrm{eAG}) / \mathrm{g}$ de látex. La cantidad de flavonoides totales se realizó por el método colorimétrico de Dowd, la concentración total fue de $12.53 \mathrm{EQ} / \mathrm{g}$ de extracto. La concentración de proteínas del látex, mediante el método de Bradford, fue de $7.62 \mu \mathrm{g} / \mathrm{mL}$. La concentración de carbohidratos por el Método de Nelson-Somogyi fue de $9.26 \mu \mathrm{g} / 500 \mu \mathrm{L}$ de látex. De esta extracción, una parte se inyectó al HPLC, confirmando la presencia de fructosa.

Por último, con el látex se realizó una cromatografía de exclusión en gel; se obtuvieron 58 fracciones que fueron sometidas a HPLC. Se identificó la presencia de catequina. 
Aunado a esto, las fracciones que presentaron los mayores rendimientos fueron evaluadas en relación con su capacidad antioxidante; sólo 9 fracciones de las 24 evaluadas mostraron una $\mathrm{CA}_{50}$ menor a $50 \mu \mathrm{g} / \mathrm{mL}$

Se puede concluir que el látex de J. neopauciflora contiene varios compuestos con actividad biológica, los cuales podrían estar actuando de manera sinérgica para acelerar y propiciar una buena cicatrización, con propiedades antibacterianas, antioxidantes y antiinflamatorias, que podrían ser útiles para el tratamiento integral de heridas en pacientes con DM.

Palabras clave: Plantas medicinales, Euphorbiaceae, Jatropha spp, Jatropha neopauciflora, Látex, Cicatrización 


\begin{abstract}
Diabetes mellitus (DM) can be defined as a group of metabolic disorders characterized by chronic hyperglycemia that in the long-term causes complications in the body. Patients with DM usually have chronic wounds, mainly in the lower limbs that often culminate in amputation, contributing to their disability and mortality.
\end{abstract}

Although there are auxiliary drugs in the wound healing process of patients with DM, these can have adverse effects and, because they only present a level of activity, it is necessary to prescribe several drugs with different actions, mainly anti-inflammatory, antibacterial and healing (promoters of cell proliferation). Since proper treatment of a wound requires a comprehensive and comprehensive approach, it is often inaccessible to a large part of the population because of its high cost.

Jatropha neopauciflora (Euphorbiaceae) is an endemic species of our country whose latex is used to treat wounds, scarring, oral infections and when there are loose teeth. In this paper, we propose the idea that the latex of this species contains compounds with antibacterial, antioxidant, anti-inflammatory and proliferative activity that could contribute in an integral way to accelerate and improve the process of wound healing in an experimental model of diabetes.

First, the wound-healing efficacy of latex was evaluated by the tensiometrical method in healthy mice. The three concentrations of latex showed an efficacy of $100 \%$, whereas the control group only reached $80 \%$. Later, the wound-healing activity of latex was evaluated histologically in healthy and diabetic mice. The results showed that the latex 
accelerated the wound-healing process, as differences were observed regarding the number of active fibroblasts in the wound area, as well as a thin and orderly epidermis.

The same experiment was repeated, but mice were maintained for 14 days with diabetes, then performed the incision and were sacrificed at day 7 of treatment. Treatment with the latex induced an increase in the number of fibroblasts, like the positive control, showing a more complete tissue arrangement of the epidermis, including the presence of hair follicles. The cytotoxic effect of latex was evaluated in two cell lines: Ca Ski and fibroblast cell line 3T3-L1. The latex did not result cytotoxic in any of the two cell lines studied. The antioxidant capacity of the latex was evaluated by the DPPH radical reduction method, obtaining a $\mathrm{CA}_{50}=5.4 \mu \mathrm{g} / \mathrm{mL}$.

Total phenols were quantified using the Singleton modified method, obtaining a concentration of $6.9 \mathrm{mg}(\mathrm{eAG}) / \mathrm{g}$ of latex. The total flavonoids were measured by the Dowd's colorimetric method. The total concentration was $12.53 \mathrm{eQ} / \mathrm{g}$ extract. The protein concentration of the latex by the Bradford method was $7.62 \mu \mathrm{g} / \mathrm{mL}$. Carbohydrate concentration by the Nelson-Somogyi Method was $9.26 \mu \mathrm{g} / 500 \mathrm{~mL}$ of latex. From this extraction, one part was analyzed by HPLC, confirming the presence of fructose in the latex.

Finally, with the latex a gel exclusion chromatography was performed, obtaining 58 fractions which were also subjected to HPLC, observing catechin presence. In addition, the fractions with the highest yields were evaluated for their antioxidant capacity; only 9 fractions of the 24 evaluated showed a $C_{50}$ of less than $50 \mu \mathrm{g} / \mathrm{mL}$. 
We can conclude that the latex from Jatopha neopauciflora contains several compounds with biological activity, which could be acting synergistically to accelerate and promote a good wound-healing, with additional antibacterial, antioxidant and antiinflammatory properties, which could be useful for the integral treatment of wounds in patients with DM.

Keywords: Medicinal plants, Euphorbiaceae, Jatropha spp, Jatropha neopauciflora, Latex, Wound-healing process 


\section{INTRODUCCIÓN}

\section{Diabetes mellitus}

La Diabetes Mellitus (DM) es considerada un problema de salud pública a nivel mundial. México ocupa el primer lugar en número de defunciones por año, tanto en hombres como en mujeres; las tasas de mortalidad muestran una tendencia ascendente en ambos sexos con más de 70 mil muertes y 400,000 casos nuevos anuales (Norma Oficial Mexicana NOM-015-SSA2-2010). En México, la Secretaría de Salud informó que el tratamiento de la diabetes representa 34\% del presupuesto de servicios sociales del país. Asimismo, mencionó que los costos indirectos y directos para el tratamiento de la enfermedad son de 330 y 100 millones de dólares anuales, respectivamente (Boulton, 2004).

La DM se puede definir como un grupo de trastornos metabólicos que comparten el fenotipo de la hiperglucemia, como resultado una compleja interacción entre factores genéticos y ambientales que propician resistencia a la insulina y deficiencia en su secreción. El trastorno de la regulación metabólica que acompaña a la DM provoca alteraciones fisiopatológicas secundarias en muchos sistemas orgánicos y supone una pesada carga para el individuo que padece la enfermedad y para el sistema sanitario. La DM es causa de nefropatía en etapa terminal, de amputaciones no traumáticas de extremidades inferiores y de ceguera en adultos. También predispone a enfermedades cardiovasculares (Harrison, 2012). 
La DM se clasifica en diabetes tipo 1 y tipo 2. La diabetes tipo 1 es resultado de la ausencia de insulina y la tipo 2 es un grupo heterogéneo de trastornos que se caracteriza por grados variables de resistencia a la insulina, menor secreción de dicha hormona y mayor producción de glucosa (Harrison, 2012).

\section{Disfunción inmunológica en DM}

Se han desarrollado diversas líneas que pretenden explicar los mecanismos fisiopatológicos de esta enfermedad y sus complicaciones. Una complicación o alteración importante a consecuencia de dicha enfermedad es la inmunológica, ya que un paciente con diabetes presenta una reducción de la actividad de leucocitos polimorfonucleares (principalmente neutrófilos), la cual está directamente relacionada con hiperglucemia y acidosis. Los neutrófilos reducen su capacidad fagocítica y se presentan cambios en la adhesión, quimiotaxis y opsonización de leucocitos. Además, el sistema inmune celular tiene una respuesta retardada e ineficiente sobre agentes nocivos. También hay una alteración de los sistemas antioxidantes y hay una baja producción de interleucinas, como IL-2, que es clave en el proceso inflamatorio para una respuesta inmune efectiva (Brendan et al., 2007).

Estas deficiencias del sistema inmune, a causa de la DM, desencadenan diversos mecanismos bioquímicos asociados con procesos tales como estrés oxidante, inflamación crónica, cicatrización alterada en heridas agudas y un cierre de los tejidos más lento; además, los pacientes con DM son más sensibles a padecer heridas 
crónicas, particularmente lesiones ulcerosas en los miembros inferiores e infecciones, lo cual es causa de amputaciones (Dandona et al., 2004).

\section{Lesiones ulcerosas y amputaciones en pacientes con DM}

Las lesiones ulcerosas, conocidas como pie diabético, son la principal causa de amputaciones, generando altos costos para el Sector Salud. Alrededor del $51 \%$ de los pacientes diabéticos que se encuentran hospitalizados presentan pie diabético (Islas y Revilla 2013). El alcance de esta patología en el mundo se refleja en estas dramáticas realidades expresadas por la OMS:

1. Cada 30 segundos alguien pierde una extremidad debido a la diabetes.

2. Siete de cada 10 amputaciones de pierna se realizan en personas con diabetes.

3. En los países desarrollados, hasta un $5 \%$ de las personas con diabetes tiene problemas del pie.

4. Se calcula que el costo directo de una amputación asociada al pie diabético está entre los 30.000 y los 60.000 USD.

5. La mayoría de las amputaciones comienza con una úlcera en el pie.

6. $50 \%$ tendrá una amputación contra lateral 5 años después de la primera amputación

7. Una de cada seis personas con diabetes tendrá una úlcera a lo largo de su vida. Se puede conseguir una importante reducción de las amputaciones mediante cuidados personales basados en una buena información y, sobre todo, teniendo una buena atención médica que sea capaz de llevar un control y cuidados adecuados de las 
heridas ulcerosas, para evitar posibles infecciones (Boulton, 2004). Dado que las lesiones ulcerosas implican daño a nivel de la piel y tejidos aledaños, a continuación, se describe las características morfofuncionales de este órgano.

\section{La piel}

La piel es el órgano más grande del cuerpo; separa al organismo del medio ambiente externo y, al mismo tiempo, permite su comunicación con él mismo. Lleva a cabo muchas funciones vitales, incluyendo protección contra agresores físicos, químicos y biológicos. Además, la piel es esencial para el mantenimiento del equilibrio de fluidos corporales, actuando como barrera ante la posible pérdida de agua, el mantenimiento del equilibrio térmico y la transmisión de una gran cantidad de información externa que accede al organismo por el tacto, la presión, temperatura y receptores de dolor (Figura 1) (Kanitakis, 2002).

La piel está formada por tres capas de tejido: epidermis, dermis e hipodermis o tejido subcutáneo. La epidermis es una capa de epitelio escamoso y estratificado, alberga diferentes tipos de poblaciones celulares. Entre el 90 y 95\% está compuesta por queratinocitos y entre el 10 y $15 \%$ la conforman las células dendríticas: melanocitos, células de Langerhans y células de Merkel. Los queratinocitos son derivados del ectodermo, su morfología varía según la capa epidermal donde se encuentren, pueden ser columnares o cúbicos, poseen citoplasma basofílico y núcleos grandes; cumplen varias funciones, la más conocida es la de producir queratina, pero además sintetizan otras sustancias químicas, como: interferón alfa, prostaglandinas, factores 
estimulantes de colonias granulocíticas-monocíticas, factor activador de timocitos y el factor derivado de las células epidérmicas (Navarrete, 2003).

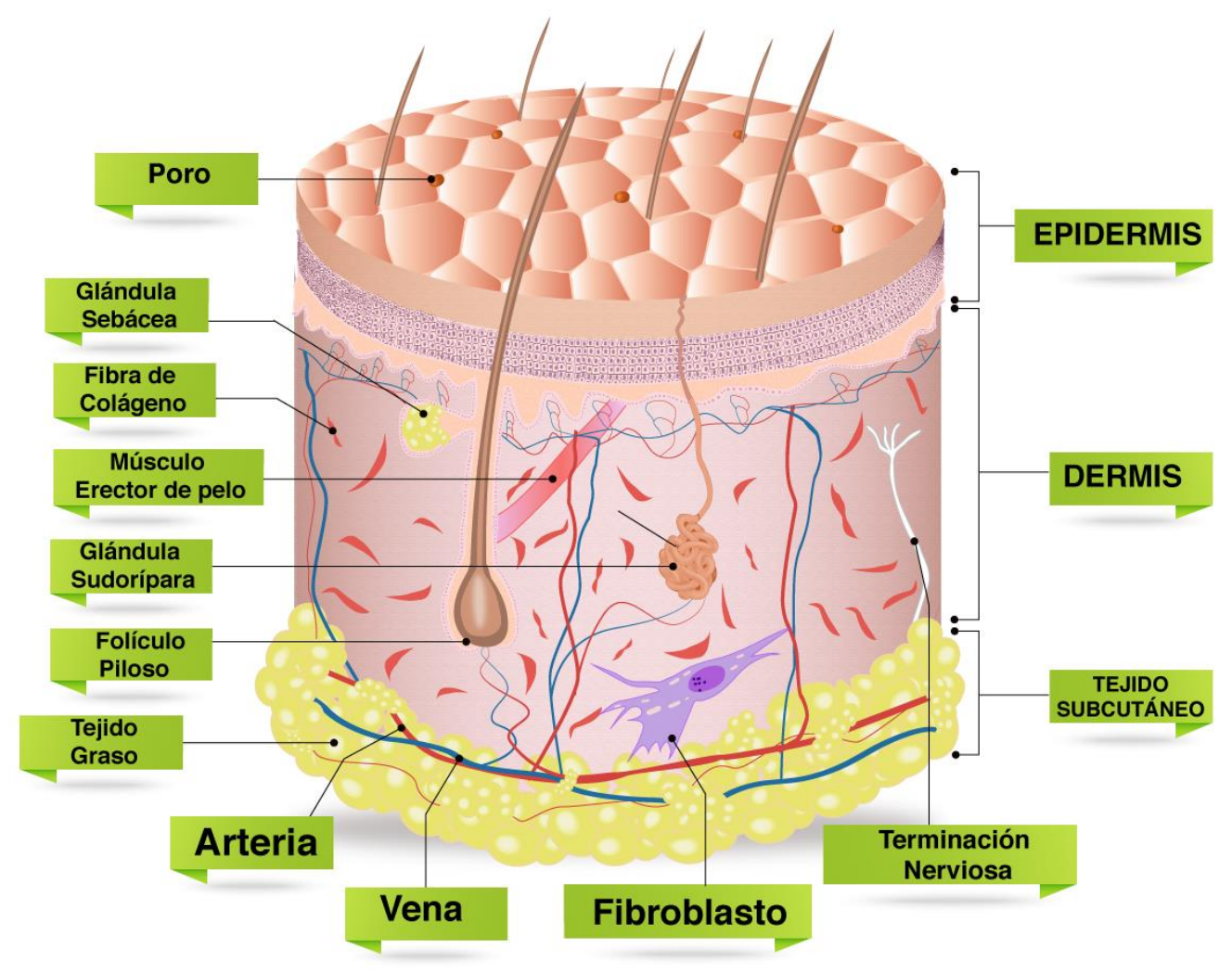

Figura 1. Organización morfológica de la piel. Imagen original (D. G. HernándezHernández P.). (Información de Merino, 2000; Navarrete, 2003).

Los melanocitos representan alrededor del $5 \%$ de las células epidérmicas; producen melanina, el principal pigmento natural de la piel, la cual tiene acción fotoprotectora de los efectos dañinos del sol, al dispersar y absorber las radiaciones (Lagunas, 2004). Las células de Langerhans son células provenientes de la médula ósea, emigradas a la piel y que forman parte del sistema inmunitario, tienen la función de captar, procesar y presentar los antígenos que llegan a la epidermis (Kanitakis, 2002). Las células de 
Merkel son células sensoriales, situadas en el estrato basal y contactan con terminaciones de neuronas sensoriales para transmitir información de tacto, es decir funcionan como mecanoreceptores. Estas células se encuentran en los dígitos de los dedos, los labios, las regiones de la cavidad oral y la vaina externa de la raíz del folículo piloso, y en ocasiones se ensamblan en estructuras especializadas conocidas como discos o domos táctiles (Navarrete, 2003).

La epidermis comúnmente está dividida en cuatro capas de acuerdo con la morfología y posición de los queratinocitos: capa basal, capa de células espinosas, capa granular y capa córnea (Figura 2).

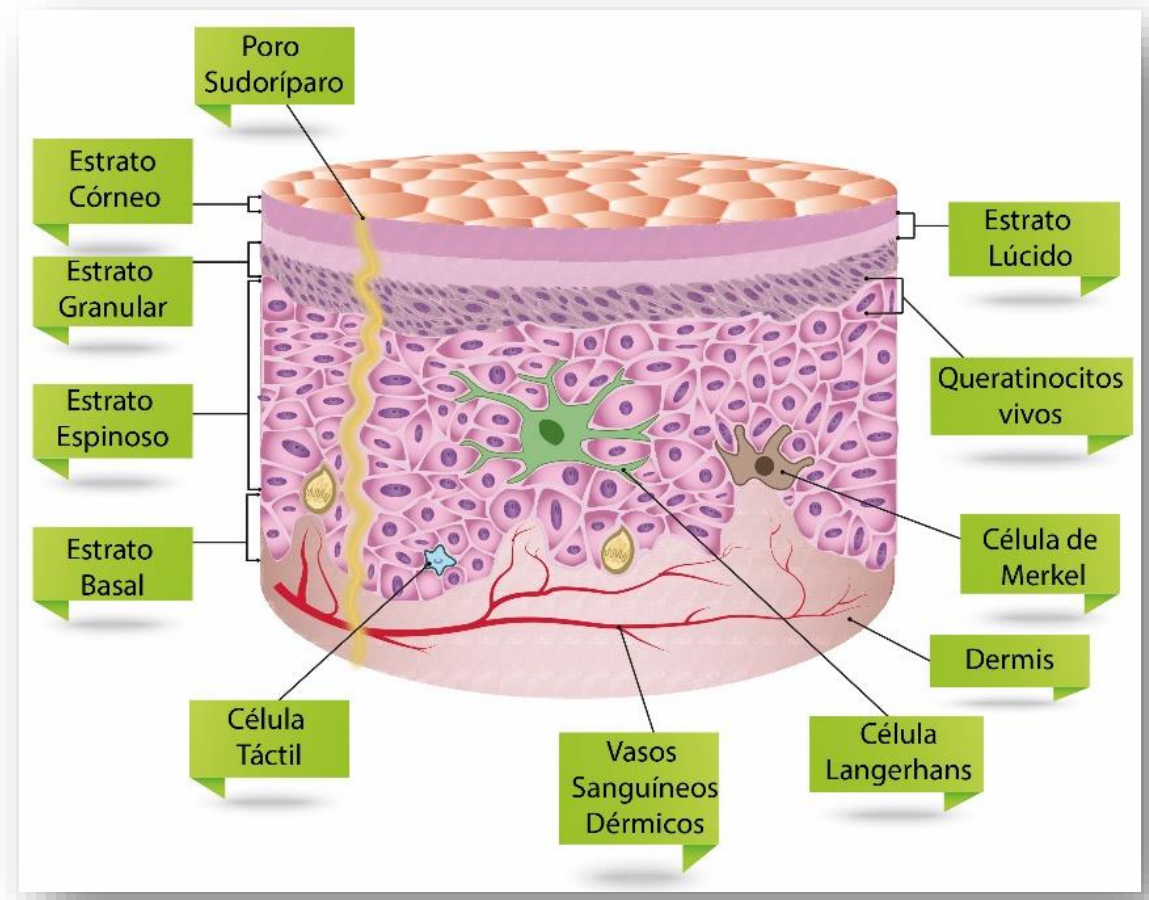

Figura 2. Capas de la epidermis. Imagen original (D. G. Hernández-Hernández P.). (Información de Merino, 2000; Navarrete, 2003). 
En aquellas zonas donde se presenta mayor grosor, como las palmas de las manos y las plantas de los pies, la epidermis presenta una capa adicional llamada capa lúcida, la cual se encuentra entre la capa córnea y la granular. La capa basal, también llamada estrato germinativo presenta células mitóticamente activas, las cuales dan lugar a las células de las capas epidérmicas exteriores. La capa espinosa se encuentra sobre la capa basal, presenta queratinocitos recién divididos con espinas proyectadas, la cuales van a diferir en forma, estructura y propiedades subcelulares, dependiendo de su localización. La capa granular es la capa más superficial de la epidermis; contiene células vivas que están comenzando un proceso de transformación gradual, cambiando células redondas nucleadas en escamas planas y ricas en queratina. La capa córnea proporciona protección mecánica a la epidermis subyacente y una barrera para impedir la pérdida de agua y la invasión por sustancias extrañas (Hidalgo, 2010).

La dermis es la estructura de soporte de la piel y le proporciona resistencia, elasticidad, fuerza y flexibilidad. Su función principal es proteger al cuerpo contra lesiones mecánicas, retiene el agua, ayuda a la regulación térmica y posee receptores de estímulos sensoriales. La dermis interactúa con la epidermis en el mantenimiento de las propiedades de ambos tejidos. Está integrada por sistema fibroso, filamentos y tejido conectivo amorfo, fibroblastos, macrófagos, mastocitos o células cebadas, linfocitos, células plasmáticas, eosinófilos y monocitos (Merino y Noriega 2000).

El principal componente de la dermis es el colágeno, el cual pertenece a una familia de proteínas fibrosas y está compuesto por tres cadenas polipeptídicas denominadas cadenas alfa (triple hélice rígida). Existen diferentes tipos de colágeno, los cuales se 
les ha asignado un número correlativo según se han ido descubriendo, en la dermis, el colágeno tipo I es el más abundante, dándole fuerza y flexibilidad a la piel (Hidalgo, 2010).

La hipodermis, llamada también panículo adiposo o tejido subcutáneo, se encuentra localizada debajo de la dermis, es una capa de sostén que está constituida principalmente por células grasas, que se conocen con el nombre de adipocitos, los cuales se disponen en lóbulos separados por tejido conectivo llamados septos 0 tabiques interlobulillares. Una de sus funciones principales es amortiguar los golpes y así proteger a estructuras y órganos vitales, además que mantiene el calor corporal, actúa como aislante y reservorio de energía en caso de ayuno. Es también el soporte de vasos sanguíneos y nervios que pasan desde los tejidos subyacentes hacia la dermis (Navarrete, 2003).

Como se mencionó anteriormente, la piel es un órgano externo que recubre todo el cuerpo, por tal motivo se encuentra expuesto a diferentes daños, como son las lesiones cutáneas o heridas, las cuales, al presentarse, desencadenan el proceso de cicatrización.

\section{Cicatrización}

Las heridas son lesiones físicas que resultan en una abertura o rotura de la piel. La curación de las heridas es un proceso biológico que inicia con el trauma y termina con la formación de cicatrices (Nalwaya et al., 2009). El proceso de cicatrización comprende tres fases: inflamatoria, proliferativa y de reparación, las cuales se 
presentan en forma secuencial con la participación de diversos tejidos y linajes celulares (Karodi et al., 2009).

En la fase inflamatoria se detiene la hemorragia por medio de las plaquetas y de la formación de fibrina. Aparecen los primeros elementos de defensa del organismo (neutrófilos, macrófagos y linfocitos) con el objetivo de evitar la contaminación de microorganismos. En la fase proliferativa, predomina el crecimiento celular (fibroblastos y colágeno) con el objetivo de que se vuelvan a formar los vasos destruidos y se rellene la zona afectada mediante el tejido de granulación. Por último, se presenta la fase de remodelación, donde se produce la contracción de la herida mediante la transformación de tejido granular en cicatricial, con lo cual, en condiciones normales, culmina el proceso de cicatrización (Figura 3) (Enoch and Leaper, 2007).

Sin embargo, en pacientes con DM este proceso de cicatrización se encuentra alterado ya que se presenta una reacción inflamatoria deteriorada, con disminución en la capacidad de liberación de factores de crecimiento y citocinas, que son sustancias de comunicación intercelulares con diversas funciones benéficas. Al estar interrumpida la migración de células de reparación, se entorpece la reparación celular con el agravante de la disminución de la calidad del estado de granulación (cicatrización desde el fondo hacia afuera) (Pickup, 2004). 


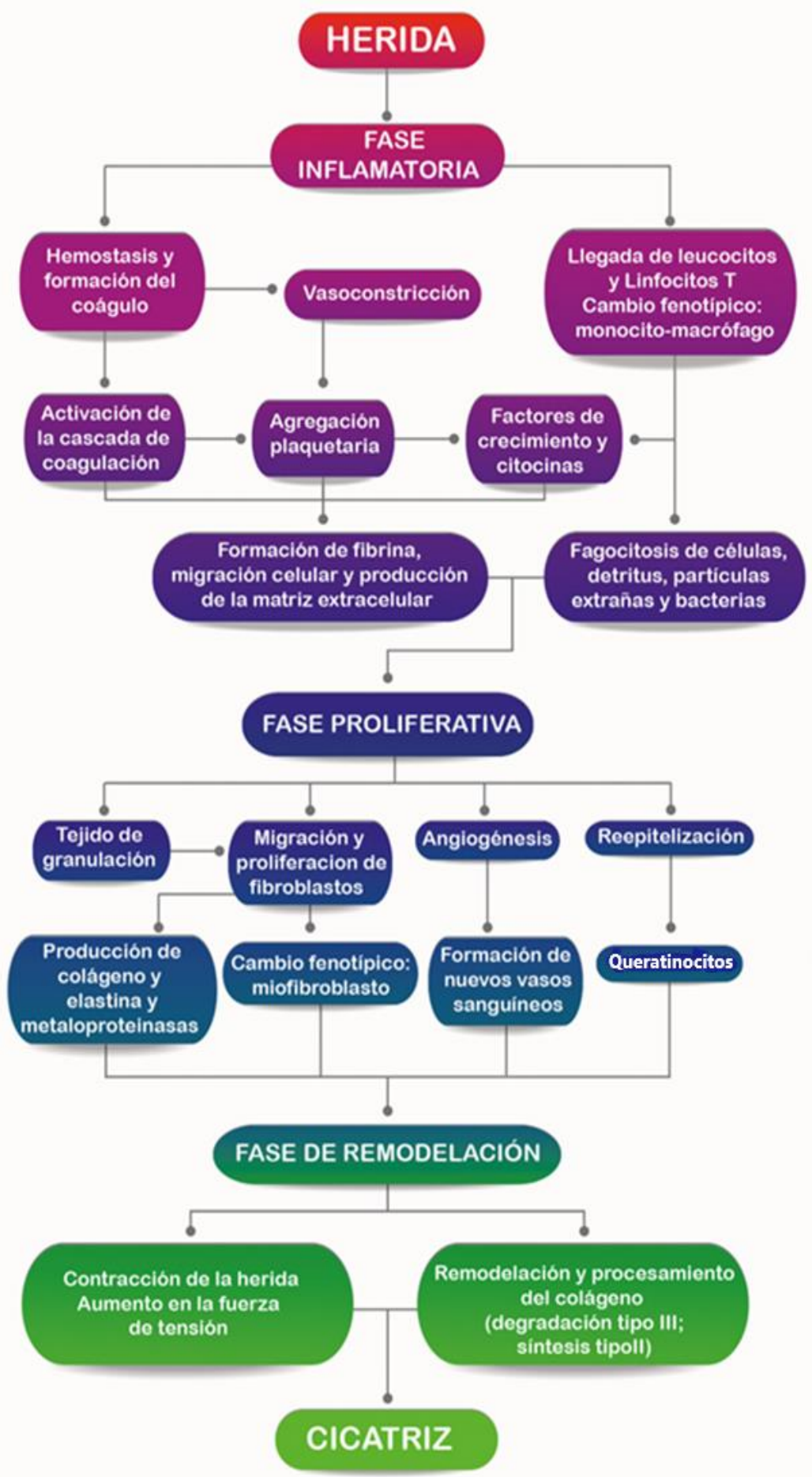

Figura 3. Fases de la cicatrización. Imagen original (M. en C. Hernández-Hernández A.B.). (información de Abbas et al., 2009, Benavides, 2008; Baum, 2005). 
El proceso también se ve afectado por la microangiopatía diabética (obstrucción de los vasos sanguíneos) en las extremidades inferiores, con lo que se reduce la capacidad de transporte y reparación de los tejidos a través de la sangre. Posteriormente, el fenómeno de epitelización (cierre de la piel de la periferia hacia el centro) se encuentra bloqueado por la falta de factores de crecimiento, entre los que están el factor de crecimiento de los queratinocitos y el factor derivado de plaquetas, que intervienen directamente en el proceso de epitelización.

Todo este conjunto de factores favorece que el cierre de las lesiones sea en forma más lenta de lo deseable, que haya mayor susceptibilidad para desarrollar infecciones, las cuales son cinco veces más frecuentes que en pacientes sanos, ocasionado a su vez por la falta de respuesta de los neutrófilos, las células de defensa altamente especializadas (Pickup, 2004). Además, en la diabetes también se produce un aumento en la producción de radicales libres de oxígeno y de nitrógeno, debido principalmente a la hiperglucemia crónica que manifiestan los pacientes con DM quienes, al no tener un control metabólico óptimo, presentan disminución de las defensas antioxidantes naturales y deterioro de diferentes tejidos y órganos (Piconi et al., 2003).

\section{Tratamiento farmacológico actual de las heridas}

Los conocimientos sobre la cicatrización han evolucionado de forma importante en las últimas décadas. Gracias a ello, actualmente es posible predecir la secuencia probable de acontecimientos que tendrán lugar a lo largo de la cicatrización y pronosticar el tiempo aproximado que tardará una herida. Sin embargo, a menudo se presentan heridas de difícil cicatrización, es decir, la cicatrización se prolonga en el tiempo o no 
se llega a alcanzar. Estas heridas complejas siguen siendo en la actualidad un problema prevalente y de especial atención en salud, que afecta a pacientes en todos los niveles asistenciales y de todas las clases sociales (Monsonís y Blanco, 2012). Actualmente existen diferentes opciones de tratamiento utilizados para la cicatrización de heridas crónicas, como los son: apósitos o gasas, parches, injertos, factores de crecimiento, colágeno, suturas, ozonoterapia y cremas de aplicación tópica (Castillo, 2004). Sin embargo, no toda la población tiene acceso a este tipo de tratamientos, ya sea por no contar con algún servicio médico o porque el costo de los tratamientos es muy elevado. Además, es importante mencionar que algunos fármacos sólo cuentan con un blanco de acción en particular, teniendo que comprar varios medicamentos para un tratamiento integral, sin mencionar que también pueden provocar algún efecto secundario nocivo para la salud.

Por ejemplo, la beclapermina es un estimulante de la cicatrización de heridas y úlceras cutáneas. Está constituida por dos cadenas polipeptídicas idénticas de 109 aminoácidos, unidas entre sí por un puente disulfuro. Es la forma recombinante del factor de crecimiento de plaquetas. Se utiliza en el tratamiento de las úlceras diabéticas neuropáticas crónicas. Su actividad biológica radica en la proliferación de las células involucradas en la reparación de heridas. No obstante, no se recomienda utilizar esta crema en pacientes que padecen o padecieron algún tipo de cáncer, pues se han observado casos de pacientes que presentan cáncer después de haber utilizado esta crema, además que tiene un costo demasiado elevado al cual no puede acceder la población en general (Papanas y Maltezos 2008). 
El recoverón NC, es una crema que también se utiliza para la cicatrización cutánea; está compuesta por ácido acexámico que participa en la acción proteínica de la colágena, regulando la producción de fibroblastos y la disposición de las fibras de colágeno de manera ordenada y neomicina, que es un antibiótico de amplio espectro (Armstrong Laboratorios de México). Sin embargo, al igual que el medicamento anterior, no toda la población tiene acceso a este tipo de medicamentos, lo que hace necesaria la búsqueda de nuevas alternativas terapéuticas para la cicatrización de heridas que estén accesibles a toda la población y, al mismo tiempo, que sean eficaces sin efectos adversos. Una opción la encontramos dentro de la medicina tradicional, en la cual, el uso de plantas medicinales con propiedades cicatrizantes se encuentra ampliamente difundido entre la población.

\section{México, medicina tradicional, biodiversidad vegetal y endemismo}

El estudio y reconocimiento de la medicina tradicional en el mundo occidental ha cobrado notable interés en los últimos tiempos. En el caso de América Latina y en especial de México, la medicina tradicional es un fenómeno vigente de la cultura nacional que podría definirse como un legado de recursos y prácticas curativas (Lozoya y Zolla, 1984).

Las plantas medicinales son el recurso terapéutico por excelencia de la medicina tradicional mexicana. Se ha reportado que entre el 70 y $80 \%$ de la población recurre a las plantas para curar diversos padecimientos, que van desde un simple resfriado hasta enfermedades de tipo gastrointestinal, dermatitis, antiinflamatorios, antioxidantes, cicatrizantes, etc. Sin embrago, de las más de 6000 especies usadas con fines terapéuticos en el país, sólo el 10\% han sido estudiadas a nivel 
farmacológico, microbiológico y fitoquímico; es decir, únicamente el 10\% tiene una validación experimental de su uso popular (Aguilar et al., 1994).

Es importante mencionar que la existencia de esta medicina tradicional mexicana se debe sin duda alguna a la gran diversidad biológica de nuestro país. México es reconocido como un país Megadiverso en el cual están representados casi todos los tipos de vegetación del planeta. Se ha calculado que nuestro país contiene $10 \%$ de la flora del mundo (Aguilar et al., 1994). Se estima hasta la fecha una riqueza florística de 22411 especies (sin incluir casi un millar adicional de especies introducidas). Estas cifras ubican a México en el tercer lugar de la clasificación mundial por su número de plantas vasculares. Además, México tiene uno de los mayores índices de especies endémicas. Se calcula que $54.2 \%$ de las plantas vasculares de México son especies endémicas (Magaña y Villaseñor, 2002).

\section{Plantas medicinales utilizadas como cicatrizantes}

Las plantas han sido desde la antigüedad un recurso al alcance del ser humano para alimentación y curación de enfermedades y, en la actualidad, cientos de plantas son utilizadas en la medicina tradicional. Por su parte, la ciencia analiza y evalúa sus efectos terapéuticos para precisar, comparar y clasificar sus propiedades farmacológicas, principalmente con el fin de agrupar a las plantas con efectos similares, conocer los principios activos responsables de la actividad, aislarlos, caracterizarlos químicamente, procurar su síntesis y proponer sus modificaciones estructurales. Todo en busca de una mejor actividad para poder emplearlos en el tratamiento de diversas enfermedades. Gran parte de los principios activos vegetales 
se encuentran dentro de los llamados productos naturales o metabolitos secundarios (Ávalos y Pérez-Urria, 2009).

Actualmente se conocen diversas plantas que muestran actividad cicatrizante. Con los extractos de dichas plantas se han realizado pruebas in vitro y con modelos animales, en los que se ha observado que aceleran el proceso de cicatrización. Algunas plantas evitan la infección en la herida, otras actúan regulando el proceso inflamatorio y en la migración y proliferación celular de fibroblastos o queratinocitos, entre otros.

Dentro de la medicina tradicional, un gran número de plantas medicinales se utilizan para la cicatrización de heridas, varias especies ya son muy conocidas y estudiadas por presentar estas propiedades medicinales, tal es el caso de Aloe vera (Liliaceae) (Jettanacheawchankit et al., 2009), Ginkgo biloba (Ginkgoaceae) (Bairy et al., 2006), Punica granatum (Lythraceae) (Nayak et al., 2013), entre otras.

\section{Familia Euphorbiaceae}

Una familia que ha sido utilizada dentro de la medicina tradicional por presentar diversas propiedades biológicas, como actividad antimicrobiana, antiinflamatoria, antiulcerosa, antidiarreica, inmunomoduladora y principalmente como cicatrizante, es la familia Euphorbiaceae. Esta familia es una de las más diversas entre las angiospermas. La constituyen cinco subfamilias, 49 tribus, 317 géneros y cerca de 8100 especies, distribuidas principalmente en las zonas tropicales y subtropicales del mundo. En México se cuentan con 50 géneros y 826 especies; de éstas, 55.52 \% son endémicas de nuestro país. Estos números ubican a Euphorbiaceae como la sexta familia en importancia nacional, atendiendo al número de especies y la cuarta en porcentaje de endemismos (Rzedowskii, 1991). 
Dentro de esta familia, el género Croton es el más representativo en cuanto a especies productoras de látex y también es el género más estudiado. Tal es el caso de $C$. lechleri Müll. que a nivel popular se usa fundamentalmente como cicatrizante, antidiarreico, en el tratamiento de úlceras gastrointestinales, cólicos uterinos, retención de orina y como anticancerígeno entre otras (Pieters et al., 1993). Una de las actividades más conocidas es la cicatrizante, ya que el látex estimula la contracción de la herida, favorece la formación de la cicatriz y regenera rápidamente la piel, ayudando a la formación de colágeno; estas actividades son atribuidas a diferentes metabolitos secundarios, como a la taspina que es un alcaloide que promueve las fases tempranas de la curación de una herida, estimulando la quimiotaxis de fibroblastos (Vaisberg et al., 1989). Otros compuestos también juegan un papel importante, como el lignano 3'4-O-dimetilcedrusina y los polifenoles, debido a su acción secuestradora de radicales libres, y las proantocianidinas que estimulan la contracción de la herida y su cicatrización (Pieters et al., 1993).

\section{El género Jatropha}

Otro género perteneciente a esta familia es Jatropha, que cuenta con más de 70 especies. A nivel biológico este género se utiliza ampliamente en el control de plagas por sus propiedades como insecticida y fungicida, además también se ha reportado su uso medicinal de varias especies, en especial en el tratamiento de infecciones de la piel, como cicatrizante, enfermedades de transmisión sexual, ictericia, fiebre, entre otras (Aiyelaagbe et al., 2007). Tal es el caso de J. curcas, J. gaumeri, J. mahafalensis, J. podagrica, entre otras, cuyas partes vegetativas (hojas, raíces, semillas, parte aérea 
y látex) han mostrado actividad antioxidante, anticoagulante, antibacterial, antiinflamatoria, antitumoral, entre otras. En particular, el látex es utilizado para promover la curación de heridas, úlceras y como astringente en cortes y contusiones (Thomas et al., 2008). Además, en algunas especies del género se han identificado diferentes moléculas, como alcaloides, péptidos cíclicos, saponinas, diterpenos, triterpenos lignanos, cumarinas, y proteínas, probablemente responsables de alguna actividad biológica (Can-Aké et al., 2004).

\section{Jatropha neopauciflora Pax}

Dentro de este género se encuentra $J$. neopauciflora, una especie endémica de México, originaria del Valle de Tehuacán-Cuicatlán, Puebla (Apéndice 1). Su floración es durante el periodo de sequía, en el que la planta pierde sus hojas y sólo se observan sus flores de color rojo. Es un arbusto de porte robusto que alcanza alturas hasta de 2 metros (Figura 4) (Arias et al., 2001). Su látex es utilizado en San Rafael Coxcatlán en el tratamiento de heridas, cicatrización, infecciones bucales y cuando existen piezas dentales flojas (para amacizar) (Canales et al., 2006 y 2005; Arias et al., 2001).
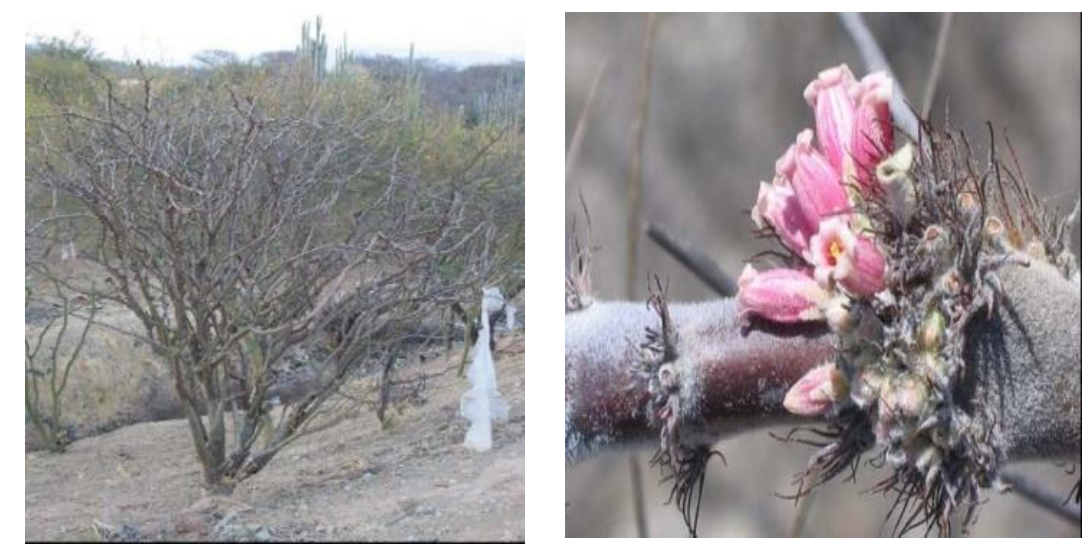

Figura 4. Jatropha neopauciflora Pax. Imagen original (Dr. Rodríguez-Monroy MA.) 
Sobre esta especie se han realizado escasos estudios fitoquímicos, como los realizados por García y Delgado (2006 a, b), quienes obtuvieron sesquiterpenos de la corteza. También se ha reportado actividad antibacteriana y antifúngica sobre hongos filamentosos, tanto de extractos como del aceite esencial, observando efecto bacteriostático tanto en bacterias Gram positivas como Gram negativas, así como actividad antioxidante. Además, estudios recientes realizados en nuestro laboratorio permitieron la identificación de diferentes compuestos presentes en esta especie (Hernández et al., 2017).

\section{JUSTIFICACIÓN}

La presente investigación pretende, por un lado, dar validez científica al uso tradicional de J. neopauciflora ya que dentro de la medicina tradicional en San Rafael, Coxcatlán, Puebla, es una de las especies más utilizadas para la curación de heridas, además de que es una especie endémica de nuestro país; por otro lado, también se busca proponer una nueva alternativa de tratamiento para la curación de heridas cutáneas en pacientes diabéticos pues, ya que los medicamento utilizados en la actualidad están diseñados para el tratamiento en particular de una de las fases o componentes del proceso de cicatrización, lo que hace necesaria la adquisición de varios medicamentos para un tratamiento integral, haciéndolos inaccesibles para la mayoría de la población debido a su alto costo. Por tal motivo, el látex de J. neopauciflora es una alternativa, pues al presentar diversas propiedades biológicas puede actuar de una manera integral promoviendo el proceso de cicatrización 


\section{PREGUNTA DE INVESTIGACIÓN}

¿El látex de J. neopauciflora promoverá el proceso de cicatrización en un modelo animal de diabetes?

\section{HIPÓTESIS:}

Si el látex de Jatropha neopauciflora es utilizado en la medicina tradicional para sanar heridas, entonces contiene compuestos que promuevan la cicatrización en animales sanos y diabéticos.

\section{OBJETIVO GENERAL:}

Determinar el efecto del látex de J. neopauciflora en un modelo de cicatrización en ratones sanos y diabéticos

\section{OBJETIVOS PARTICULARES:}

Del látex de J. nepauciflora:

1. Determinar el efecto cicatrizante en ratones sanos y diabéticos.

2. Evaluar la proliferación y la migración celular en fibroblastos 3T3-L1.

3. Determinar la citotoxicidad en dos líneas celulares.

4. Determinar la capacidad antioxidante in vitro.

5. Determinar los principales componentes químicos. 


\section{MATERIAL Y MÉTODOS}

\section{Evaluación tensiométrica de la eficacia cicatrizante del látex de Jatropha neopauciflora en ratones sanos}

Primero se realizó la evaluación de la eficacia cicatrizante del látex en ratones sanos mediante el método tensiométrico (Apéndice 2). Se utilizaron ratones macho (Mus musculus) de la cepa CD1 de 6 semanas de edad, los cuales se obtuvieron del Bioterio de la FES-Iztacala UNAM y se mantuvieron en un ambiente libre de patógenos según las normas nacionales e institucionales.

Los ratones fueron distribuidos en 6 grupos experimentales de 6 animales cada uno: Grupo 1 sin tratamiento, Grupo 2-4 con administración de Látex (50, 75 y 100\%, respectivamente, Grupo 5 Control positivo (recoverón NC), Grupo 6 Control negativo (gel a base de carbopol en el que se disolvió el látex).

Previo al inicio del estudio (24 horas antes) se depiló el dorso de los ratones; luego los ratones se anestesiaron con isoflurano al 5\% (Hawk et al., 1999). Posteriormente se realizó un corte de $1 \mathrm{~cm}$ de largo en la piel depilada, involucrando las 3 capas de la piel (epidermis, dermis e hipodermis) e inmediatamente después se iniciaron los tratamientos por vía tópica cada 12 horas durante 10 días. Al final del experimento, a los ratones se les realizó eutanasia utilizando una cámara de $\mathrm{CO}_{2}$ y se midió la fuerza necesaria para la nueva apertura de la herida, utilizando un dinamómetro digital. Esto con la finalidad de determinar la efectividad de los tratamientos en el proceso de cicatrización. 


\section{Evaluación morfológica de la eficacia cicatrizante del látex de Jatropha neopauciflora en ratones sanos.}

Una vez que se observó la eficacia del látex a nivel macroscópico, se realizó la evaluación a nivel microscópico mediante histología (Apéndice 3). Se utilizaron ratones machos (Mus musculus) de la cepa CD1 con las mismas características para el método tensiométrico y se formaron los mismos grupos experimentales $(n=6$ para cada grupo experimental). Se llevó a cabo la misma metodología utilizada para el método tensiométrico, realizando la incisión en la parte dorsal de cada ratón y aplicando todos los tratamientos cada 12 horas por 10 días para, finalmente, ser sometidos a eutanasia utilizando una cámara de $\mathrm{CO}_{2}$ con la finalidad de obtener las muestras de piel del área de la herida, las cuales fueron procesadas mediante técnica histológica convencional y teñidas con Hematoxilina-Eosina (H\&E) y Tricrómica de Masson, obteniendo 5 cortes por cada ejemplar.

\section{Inducción de diabetes en ratones}

Después de determinar la eficacia cicatrizante en ratones sanos, se procedió a evaluar la misma actividad en ratones con diabetes experimental inducida con estreptozotocina (STZ). En este caso, ratones con las mismas características del experimento anterior y ayuno de 4 horas recibieron intraperitonealmente una dosis única de $130 \mathrm{mg} / \mathrm{kg}$ de STZ disuelta en un buffer de citrato $(100 \mathrm{mM})$ a un $\mathrm{pH}$ de 4.5 (Apéndice 4). Los ratones en ayuno de 4 horas se pesaron diariamente y la glucemia fue medida de muestras sanguíneas obtenidas de la vena caudal, utilizando el método de la deshidrogenasa 
(Accu Chek, Active, Roche Diagnostic). Los ratones que presentaron glucemias superiores a $200 \mathrm{mg} / \mathrm{dL}$ fueron considerados diabéticos y fueron seleccionados para continuar con el estudio (Ventura et al., 2011).

\section{Evaluación morfológica de la eficacia cicatrizante del látex en ratones con diabetes.}

Los ratones con diabetes se dividieron en 3 grupos experimentales con 6 organismos cada uno: Grupo 1 Sin tratamiento; Grupo 2 tratado con Látex al 50\%; Grupo 3 Control positivo (recoverón NC). En cada grupo se siguió el mismo protocolo antes mencionado para la obtención de los cortes de piel y realización de las tinciones H\&E y Tricrómica de Masson para su posterior análisis (Apéndice 3).

\section{Evaluación de la proliferación y la migración celular en fibroblastos 3T3-L1}

Se realizó una prueba de viabilidad celular con fibroblastos 3T3-L1 utilizando el MTT como indicador de viabilidad celular, con varias concentraciones de látex (1:1, 1:10, 1:100, 1:1000 y 1:10000 ppm) (Apéndice 5). Se sembraron fibroblastos en cajas de cultivo de 6 pozos hasta formar una monocapa y así realizar en cada pozo "una herida" utilizando una punta amarilla esterilizada y flameada. Los tratamientos fueron los siguientes: control positivo (fitohemaglutinina), látex a diferentes concentraciones $(1: 1000,1: 10000,1: 100000$ y 1:1000000 ppm) y finalmente el grupo testigo. Cada tratamiento se realizó por triplicado. Una vez que se observó el cierre de la herida con el control positivo, todos los pozos fueron fijados y teñidos con cristal violeta para su análisis. 
Evaluación de la citotoxicidad del látex de J. neopauciflora en fibrolastos 3T3-L1 y macrófagos P-388

Para evaluar la citotoxicidad del látex, se utilizó la línea celular de fibroblastos 3T3-L1, obtenidas de embriones de ratón (Mus musculus) y la línea de macrófagos P-388. Se utilizó el método de viabilidad celular usando cristal violeta, sembrando las células en placas de cultivo de 96 pozos, las cuales fueron tratadas con diferentes concentraciones de látex de J.neopauciflora $(10-0.004 \mathrm{mg} / \mathrm{mL})$. Los ensayos se realizaron por triplicado.

Evaluación de la capacidad antioxidante in vitro del látex de Jatropha neopauciflora

Se llevó a cabo mediante el método de reducción del radical 2,2-Difenil-1-Picrilhidracil $(\mathrm{DPPH} \bullet$ ), método modificado de Murillo (2006) (Apéndice 6). La Concentración Antioxidante Media $\left(\mathrm{CA}_{50}\right)$ del látex se determinó utilizando las siguientes concentraciones: $1,2,4,6,8,10,15,20,25,30,35,40,45,50,60,70,80,90$, y 100 ppm. Como control positivo se usó quercetina. Como blanco se utilizaron pozos con $200 \mu \mathrm{L}$ de $\mathrm{MeOH}$ grado HPLC. 


\section{CARACTERIZACIÓN QUÍMICA DEL LÁTEX DE J. neopauciflora}

\section{Determinación de fenoles totales en el látex de J. neopauciflora por el método modificado de Singleton y Rosi (1999).}

Se midió por espectrofotometría con base en una reacción colorimétrica de óxidoreducción, utilizando el reactivo de Follin-Ciocalteu como agente oxidante (Apéndice 7). Se preparó una curva de calibración con ácido gálico $(0.2 \mathrm{mg} / \mathrm{mL})$. Se tomaron alícuotas seriadas de ácido gálico $(0.00625,0.012,0.025,0.05,0.1$ y $0.2 \mathrm{mg} / \mathrm{mL})$, a cada una se le agregó el volumen correspondiente de agua destilada para obtener las concentraciones mencionadas a un volumen de $1 \mathrm{~mL}$. Se tomó $1 \mathrm{~mL}$ de cada una de las concentraciones (ácido gálico y látex) y se transfirió a un tubo de ensayo con $6 \mathrm{~mL}$ de agua destilada; a continuación, se adicionaron $500 \mu \mathrm{L}$ de reactivo Folin-Ciocalteu. Después de cinco minutos se añadió $1.5 \mathrm{~mL}$ de una solución de $\mathrm{Na}_{2} \mathrm{CO}_{3}(200 \mathrm{~g} / \mathrm{L})$ y agua hasta completar un volumen de $10 \mathrm{~mL}$. Después de dos horas de reacción a temperatura ambiente, se determinó la absorbancia a 760 nm. Cada concentración se determinó por triplicado. Los resultados se expresaron como equivalentes de ácido gálico por gramo de látex (EAG/g).

Determinación de flavonoides totales en el látex de J. neopauciflora por el método de Dowd.

Se determinó usando una curva patrón de quercetina (0-100 mg/L) (Apéndice 8). Para el análisis de flavonoides totales del látex se prepararon $3 \mathrm{~mL}$ de cloruro de aluminio $\left(\mathrm{AlCl}_{3}\right)$ al 2\% en metanol, se mezcló con $6 \mathrm{mg}$ de látex en solución a probar $(0.2$ 
$\mathrm{mg} / \mathrm{mL}$ ). La prueba se hizo por triplicado. La preparación del blanco consistió en $3 \mathrm{~mL}$ del extracto en solución con $3 \mathrm{~mL}$ de metanol $\sin \mathrm{AlCl}_{3}$. Después de 10 minutos de reacción a temperatura ambiente se determinó la absorbancia a $415 \mathrm{~nm}$. Los resultados se expresaron como equivalentes de quercetina por gramo de látex (EQ/g).

\section{Cuantificación de carbohidratos en el látex de J. neopauciflora por la técnica de} Nelson-Somogyi.

Primero se realizó la extracción de carbohidratos utilizando 100 mg del látex en $2 \mathrm{~mL}$ de etanol frío, enfriando en baño de hielo durante 15 minutos para precipitar proteínas. Centrifugar, decantar el sobrenadante y evaporar en vacío a sequedad, posteriormente reconstituir en $5 \mathrm{~mL}$ de agua destilada.

Una vez extraídos los carbohidratos se cuantificaron por el método de Nelson-Somogyi (González y Peñalosa, 2000) (Apéndice 9), utilizando $1 \mathrm{~mL}$ de la muestra problema, la cual se procesó de acuerdo con la curva patrón, como lo describe la técnica, el patrón fue glucosa $(200 \mu \mathrm{g} / \mathrm{mL})$.

\section{Determinación de carbohidratos por cromatografía líquida de alta resolución (HPLC).}

Los estándares con los que se realizó la comparación fueron: glucosa, fructosa y sacarosa, la fase móvil que se utilizó fue $\mathrm{H}_{2} \mathrm{O}$ y la preparación de la muestra consistió en $0.01 \mathrm{~g}$ de látex en $5 \mathrm{~mL}$ de agua destilada. Se centrifugó a 14000 rpm por 5 minutos y se inyectaron $30 \mu \mathrm{L}$ en el HPLC, con una columna para carbohidratos de $30 \mathrm{~cm} \times 7.8$ 
cm, con un detector de refracción de la luz. Una vez que se corrió la muestra, se comparó y cuantificó la concentración de cada azúcar presente en la muestra.

\section{Cuantificación de proteínas en el látex de $J$. neopauciflora por el método de} Bradford.

De la muestra de látex se tomó $1 \mathrm{~mL}$ al cual se le agregó $2 \mathrm{~mL}$ de metanol-cloroformoagua, proporción: 12:5:3, respectivamente. Se mantuvo a $-25^{\circ} \mathrm{C}$ hasta utilizarse. Posteriormente se centrifugó a 1000-5000 rpm y se colectó el sobrenadante. Se extrajo el residuo agitándolo 5 minutos con otros $2 \mathrm{~mL}$ de mezcla de metanol-cloroformo-agua y se centrifugó y se juntó este segundo sobrenadante con el primero, repitiendo 2 veces más. A los sobrenadantes colectados se le agregó $1 \mathrm{~mL}$ de cloroformo y $1.5 \mathrm{~mL}$ de agua, centrifugando para separar las fases y retirar la fase clorofórmica. Se secó al vacío a $35^{\circ} \mathrm{C}$. Posteriormente se realizó la cuantificación por el método de Bradford, se utilizó como patrón BSA $100 \mu \mathrm{g} / \mathrm{mL}$ y se leyó en el espectrofotómetro a 595 nm (González y Peñalosa, 2000) (Apéndice 10).

\section{Fraccionamiento biodirigido del látex de J. neopauciflora.}

La fase estacionaria fue Sephadex LH-21. Para esta columna se utilizaron $5 \mathrm{~mL}$ de látex, la fase móvil consistió inicialmente en metanol, posteriormente se hicieron mezclas con agua, diferentes proporciones hasta llegar a metanol agua 1:1 y finalmente se utilizó sólo agua destilada. 


\section{ANÁLISIS ESTADÍSTICO}

Los resultados se expresan con la media del error estándar de los datos. Para evaluar estadísticamente las diferencias entre los tratamientos, se realizó un análisis de varianza unifactorial (ANOVA) con una prueba de comparación múltiple (TukeyKramer) $(\mathrm{P}<0.05)$, utilizando el software GraphPad Prism 6.

\section{RESULTADOS.}

\section{EFECTO CICATRIZANTE DEL LÁTEX DE J. neopauciflora.}

\section{Eficacia cicatrizante del látex por el método tensiométrico en ratones sanos}

En la Figura 5 se muestran las imágenes del proceso de cicatrización de las heridas (día 1 y día 10) de cada tratamiento. En los ratones tratados con el látex se observó un cierre de la herida similar al producido por el recoverón. La evaluación de la eficacia cicatrizante del látex de J. neopauciflora por el método tensiométrico de Vaisberg, (Figura 6) mostró que para las tres concentraciones utilizadas (50\%, $75 \%$ y $100 \%$ ) se necesitó de mayor fuerza para abrir la herida que la requerida con el recoverón. También se puede observar que entre las tres concentraciones no hay diferencias significativas, por lo tanto, las tres concentraciones tienen la misma eficacia cicatrizante, sin diferencias significativas con el grupo control (piel sana sin herida). Los grupos con herida sin tratamiento y tratados con gel (vehículo) presentaron valores similares de fuerza, sin diferencias significativas, es decir, que el gel con el cual se disuelve el látex no interviene en el proceso de cicatrización (Figura 6). 


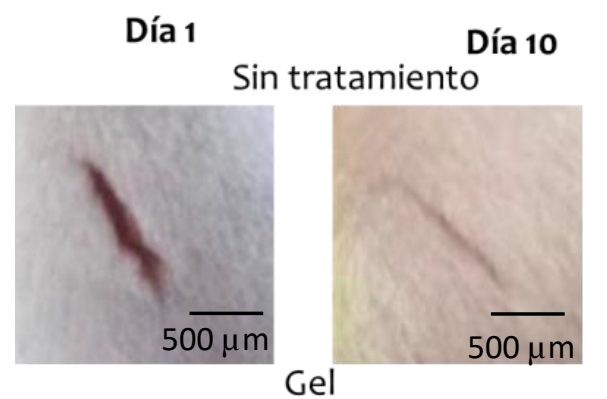

Día 1 Látex 50\% Día 10
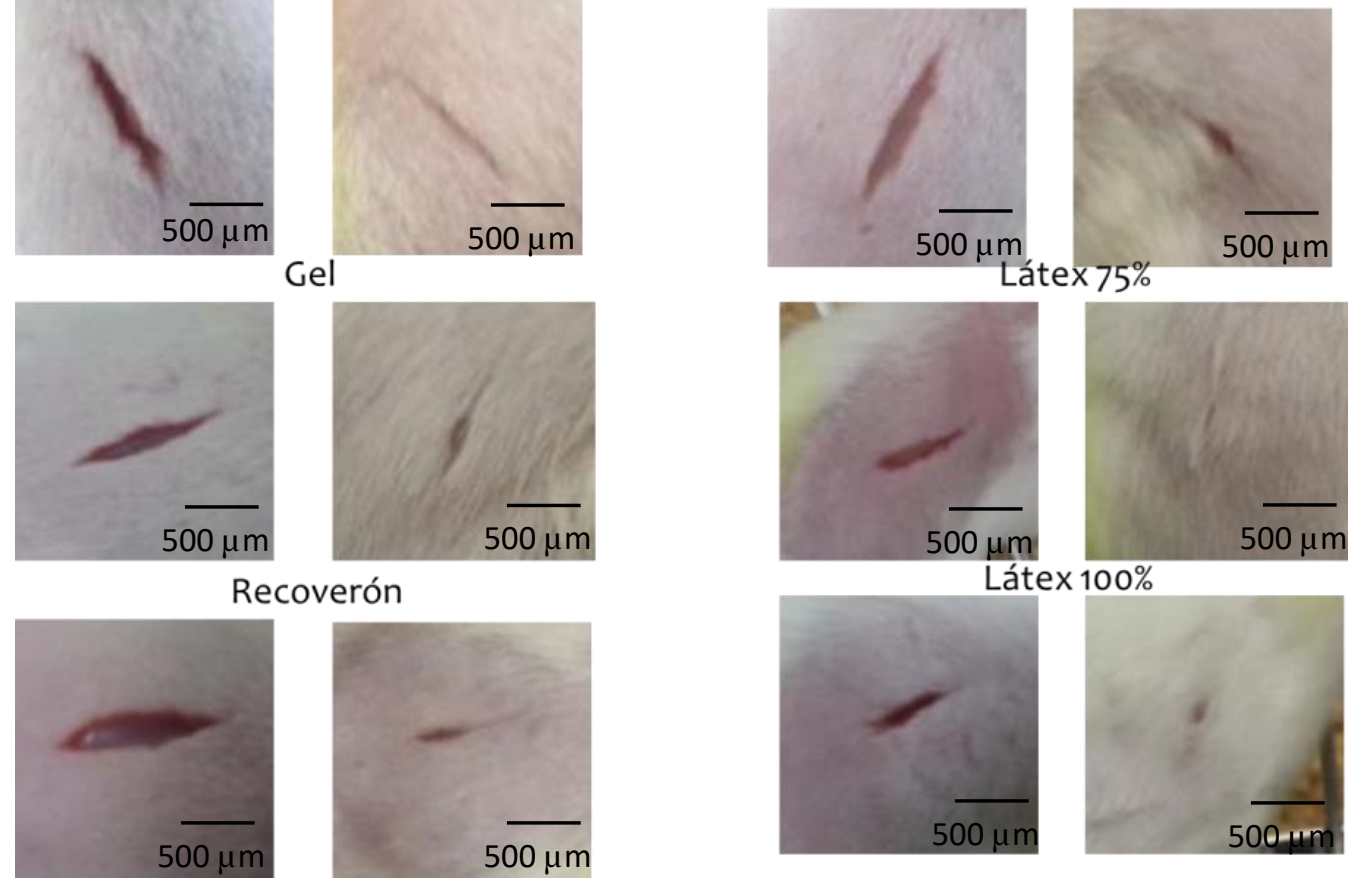

Figura 5. Eficacia cicatrizante de los diferentes tratamientos. Se aprecia macroscópicamente la eficacia cicatrizante de las tres concentraciones del látex de J. neopauciflora (50, 75 y $100 \%$ ) en ratones sanos.

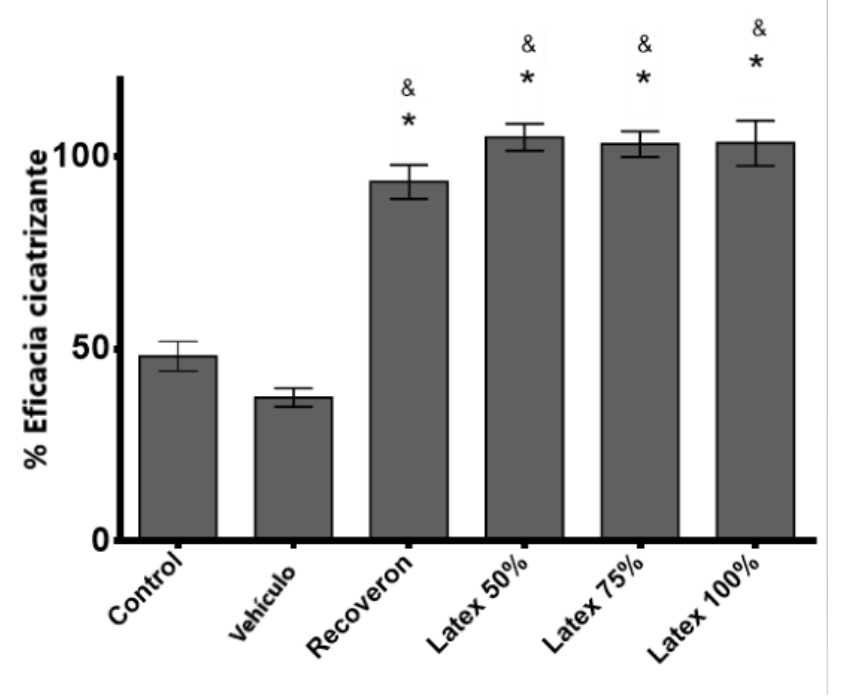

Figura 6. Eficacia cicatrizante del látex de J. neopauciflora por el método tensiométrico. Los datos representan la media t. E.E.M. $(n=6)$ para cada tratamiento. *Diferencia significativa comparada con el grupo control $(\mathrm{P}<0.05)$. \&Diferencia significativa comparada con el grupo vehículo $(P<0.05)$. 


\section{Eficacia cicatrizante del látex en ratones sanos: estudio morfológico}

Se realizó la Tinción de Hematoxilina-Eosina y la Tinción Tricrómica de Masson en todos los grupos experimentales de ratones sanos. La Hematoxilina y Eosina son colorantes básicos y ácidos, respectivamente, por lo cual tiñen estructuras de la misma naturaleza química, como núcleos celulares y estructuras tisulares.

En la Figura 7 se presentan las microfotografías de cortes de piel de las heridas en ratones sanos, utilizando el programa AxioVision 4.8. Los cortes se obtuvieron 10 días después de la lesión; se presentan dos aumentos de cada tratamiento una visión general de la herida (x100 y x400), esto con la finalidad de poder identificar los fibroblastos.

Los grupos sin tratamiento y gel muestran la presencia de la matriz extracelular. Las tres concentraciones del látex (50, 75 y 100\%), presentan epidermis completa, la matriz extracelular provisional ha desaparecido y hay presencia de fibroblastos activos. 

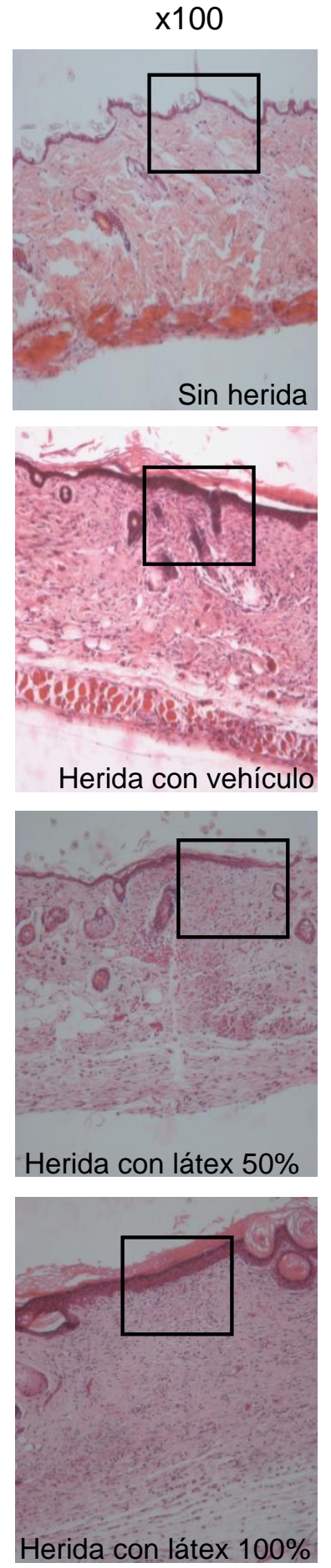

$x 400$
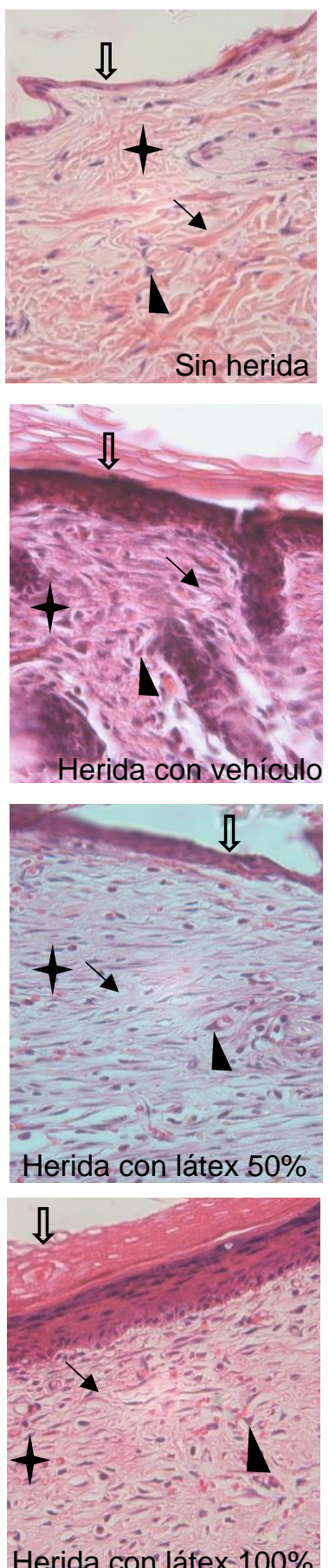
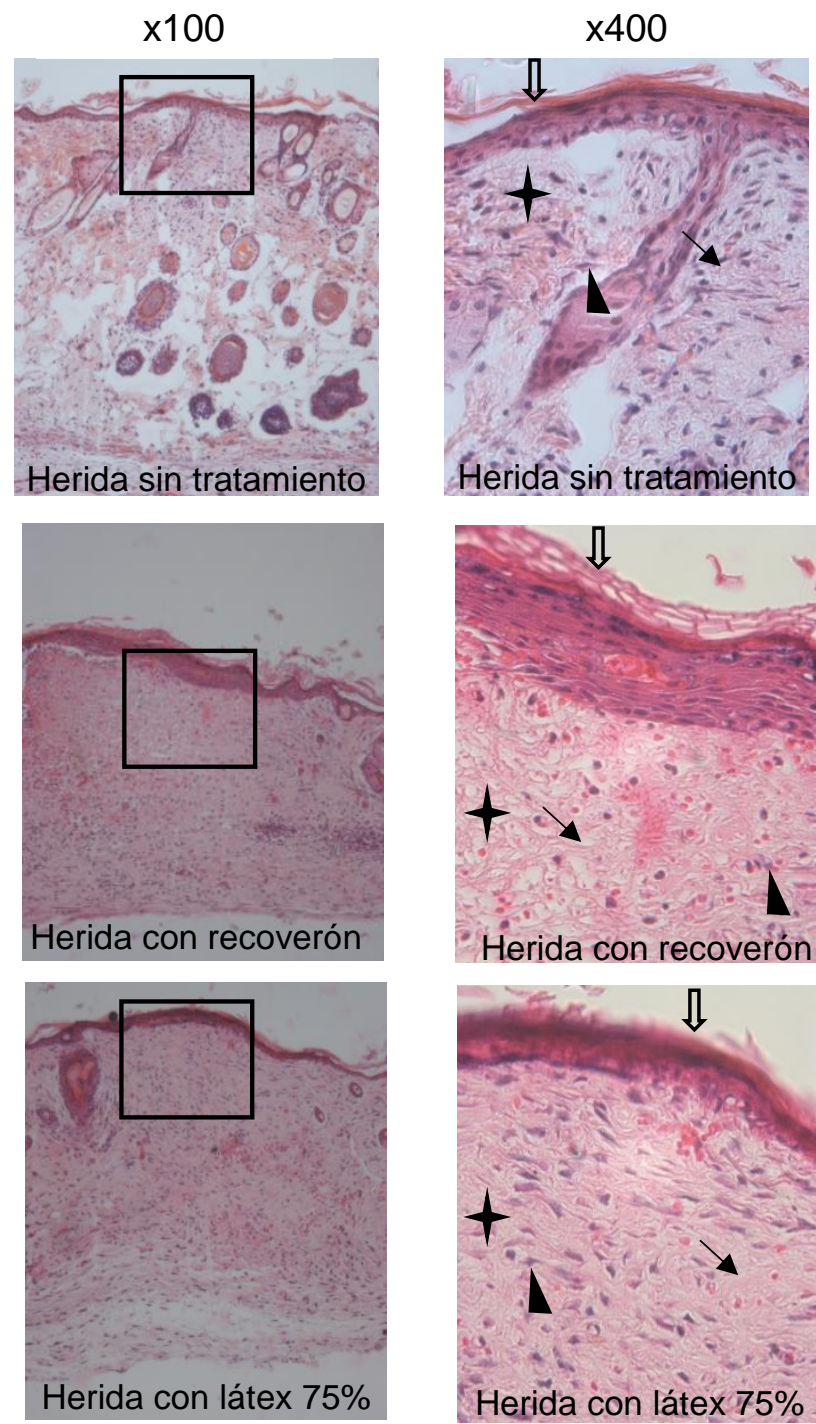

Herida con recoverón

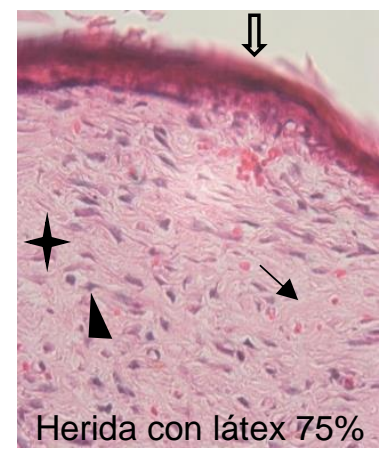

Figura 7. Microfotografías de piel de ratones sanos: Sin herida, Herida sin tratamiento, Herida con vehículo (gel), Herida con recoverón, herida tratada con Látex 50, 75 y $100 \%$, respectivamente. Se observan cambios importantes en epidermis, densidad de fibroblastos y fibras de colágeno. Tinción H\&E, aumento original y zona enmarcada se amplió a $\times 400$; epidermis $(\rrbracket)$, dermis $(\downarrow)$, fibras de colágeno $(\downarrow)$, fibroblasto $(\mathbf{\Lambda})$. 
Dado que los fibroblastos activos son muy importantes en el proceso de cicatrización, pues en la etapa de proliferación celular estas células migran y proliferan en la zona de la herida para sintetizar el colágeno necesario para regenerar la herida y posteriormente sufrir un cambio fenotípico a miofibroblastos para contraer la herida y concluir el proceso de cicatrización, éstos fueron cuantificados (Figura 8). El grupo experimental de piel sana no expuesto a lesión presentó el promedio más bajo de fibroblastos activos $(9.75 \pm 0.95)$, mientras que los grupos sin tratamiento y gel mostraron los promedios más altos de fibroblastos $(58.75 \pm 1.25,55.75 \pm 4.5$, respectivamente); además, entre estos dos grupos no hubo diferencias significativas $(P<0.05)$, es decir, el vehículo no interviene en el proceso de cicatrización ya que la cantidad de fibroblastos es similar al grupo de piel con herida sin tratamiento.

El grupo experimental con recoverón (control positivo), mostró un número muy bajo de fibroblastos $(15 \pm 0.81)$, similar al grupo sin herida $(9.75 \pm 0.95)$, sin diferencias significativas entre ellos $(P<0.05)$. Los grupos tratados con el látex $(50,75$ y $100 \%)$, presentaron un número parecido de fibroblastos $(41 \pm 2.16,41 \pm 5.71$ y $38 \pm 4.39$, respectivamente) y el número de fibroblastos fue menor en relación con los grupos sin tratamiento y gel, aunque el número fue mayor comparado con la piel sana y recoverón. 


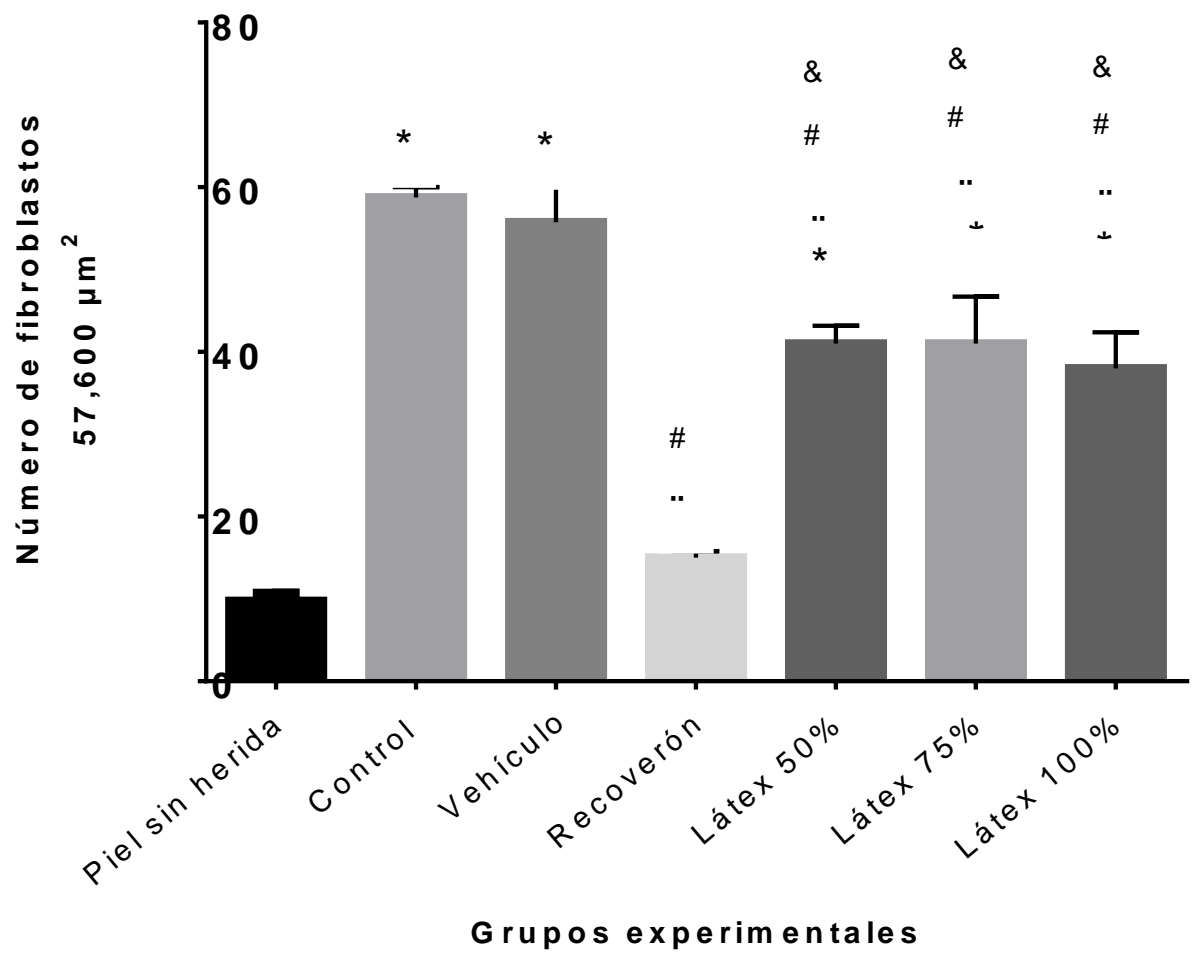

Figura 8. Fibroblastos activos en cada grupo experimental de ratones sanos. Los datos se representan como medias \pm E.E.M $(n=6)$. ${ }^{*}$ Diferencia significativa comparada con el grupo de piel sin herida $(P<0.05)$. "Diferencia significativa comparada con el grupo control $(P<0.05)$. \#Diferencia significativa comparada con el grupo vehículo $(P<0.05)$. \&Diferencia significativa comparada con el grupo recoverón $(P<0.05)$.

Para identificar las fibras de colágeno se utilizó la tinción Tricrómica de Masson, la cual tiñe las fibras de color azul. En la Figura 9 se muestran las microfotografías de cada uno de los tratamientos en ratones sanos (x400). Se observó el colágeno presente en cada tratamiento; en el grupo de piel sana hay mayor densidad de colágeno y las fibras están engrosadas en comparación con el grupo sin tratamiento, que presentan espacios vacíos y fibras de colágeno adelgazadas, similar a lo observado con recoverón. En las tres concentraciones de látex se observó mayor densidad de fibras de colágeno sin espacios entre éstas. 

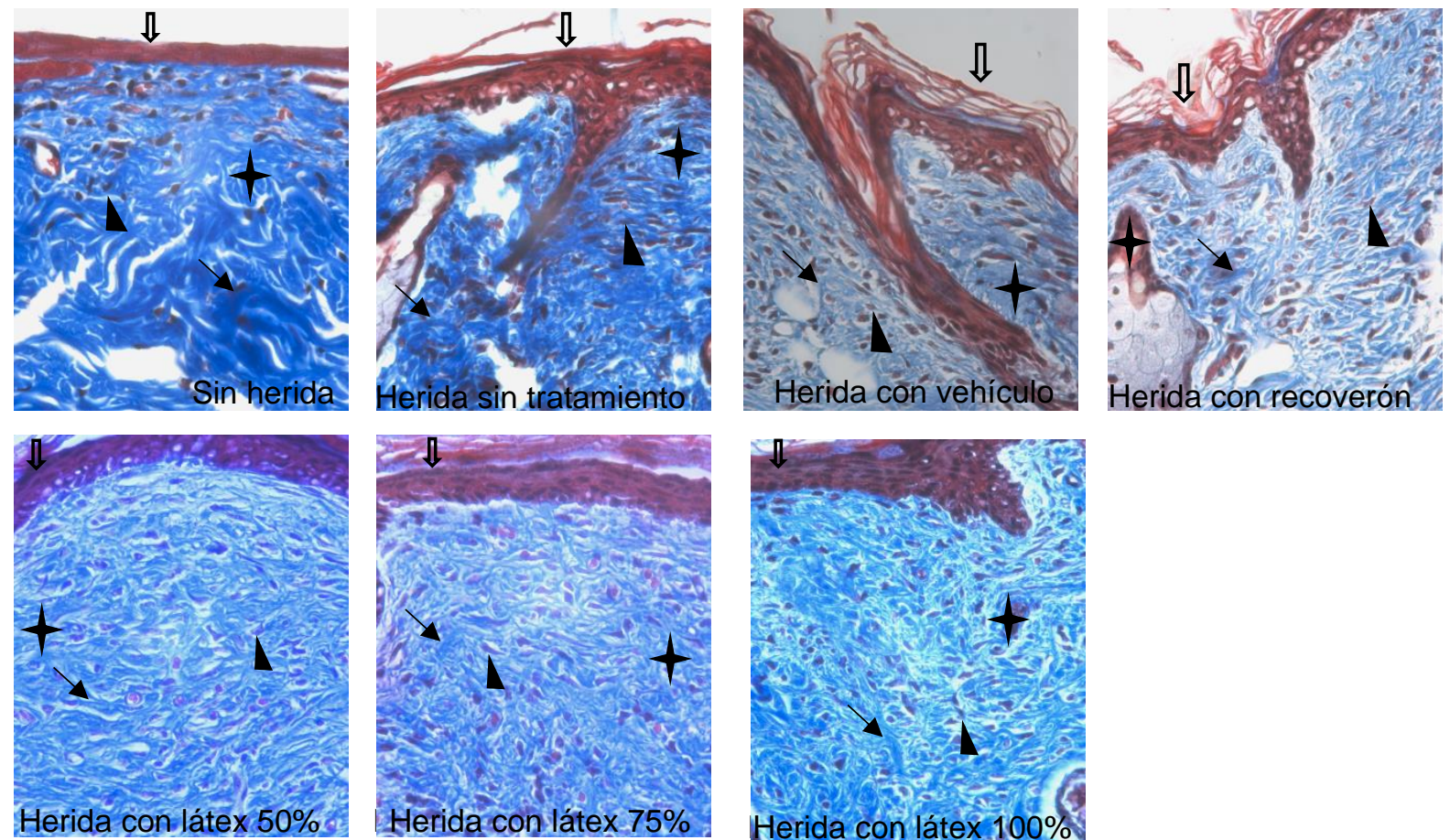

Figura 9. Microfotografías de piel de ratones sanos: Sin herida, Herida sin tratamiento, Herida con vehículo (gel), Herida con recoverón, Herida tratada con Látex 50, 75 y $100 \%$, respectivamente. Se observan cambios importantes en epidermis, densidad de fibroblastos y fibras de colágeno. Tinción tricrómica de Masson, aumento original x400 epidermis $(\mathbb{\Downarrow})$, dermis $(\boldsymbol{t})$, fibras de colágeno $(\searrow)$, fibroblasto $(\mathbf{\Lambda})$.

Eficacia cicatrizante del látex en ratones con diabetes inducida con STZ: estudio morfológico

Para los grupos de ratones diabéticos también se realizó la Tinción de HematoxilinaEosina. Los cortes se obtuvieron 10 días después de haber realizado la lesión. En la Figura 10 se muestran las imágenes de la herida de cada grupo experimental, donde se observa un cierre de herida en los tres grupos experimentales, sin embrago, en el grupo del látex se observa una costra bien formada y además es el único grupo con crecimiento de pelo. 
Sin tratamiento
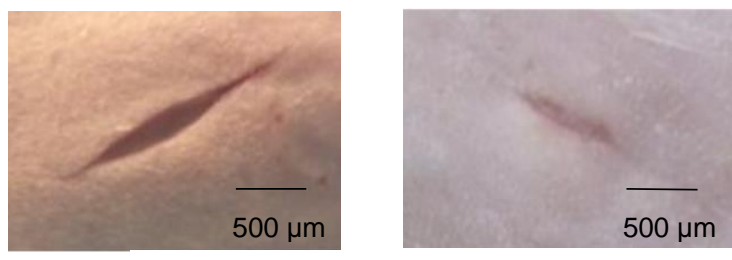

Recoverón
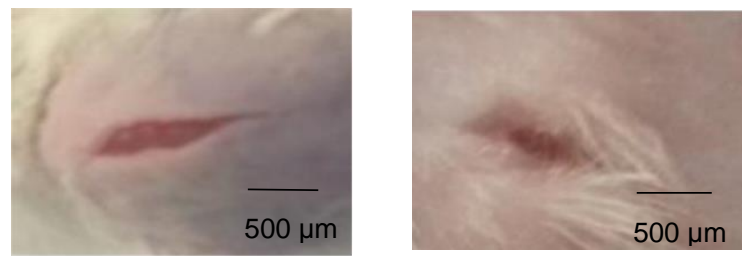

Látex 50\%
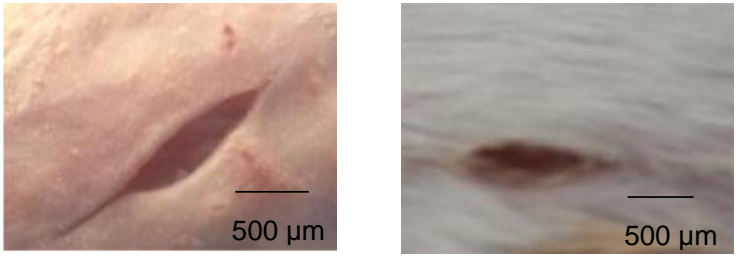

Figura 10. Eficacia cicatrizante de los diferentes tratamientos. Se aprecia macroscópicamente la eficacia cicatrizante del látex de J. neopauciflora $(50 \%)$ en ratones diabéticos.

En la Figura 11 se presentan las microfotografías de los grupos trabajados utilizando el programa AxioVision 4.8. Se presentan dos aumentos de cada tratamiento, una visión general de la herida $(x 40)$ y un mayor aumento $(x 400)$ para poder apreciar el arreglo celular presente en cada lesión. En los cortes podemos observar que la piel ya no presentó la misma firmeza en comparación con los grupos de ratones sin diabetes, pues se observaron pliegues en todo lo largo de la epidermis. En el grupo de piel sin tratamiento se observó que las fibras de colágeno están más adelgazadas en comparación con los grupos de recoverón y látex, además de un número mayor de fibroblastos. 

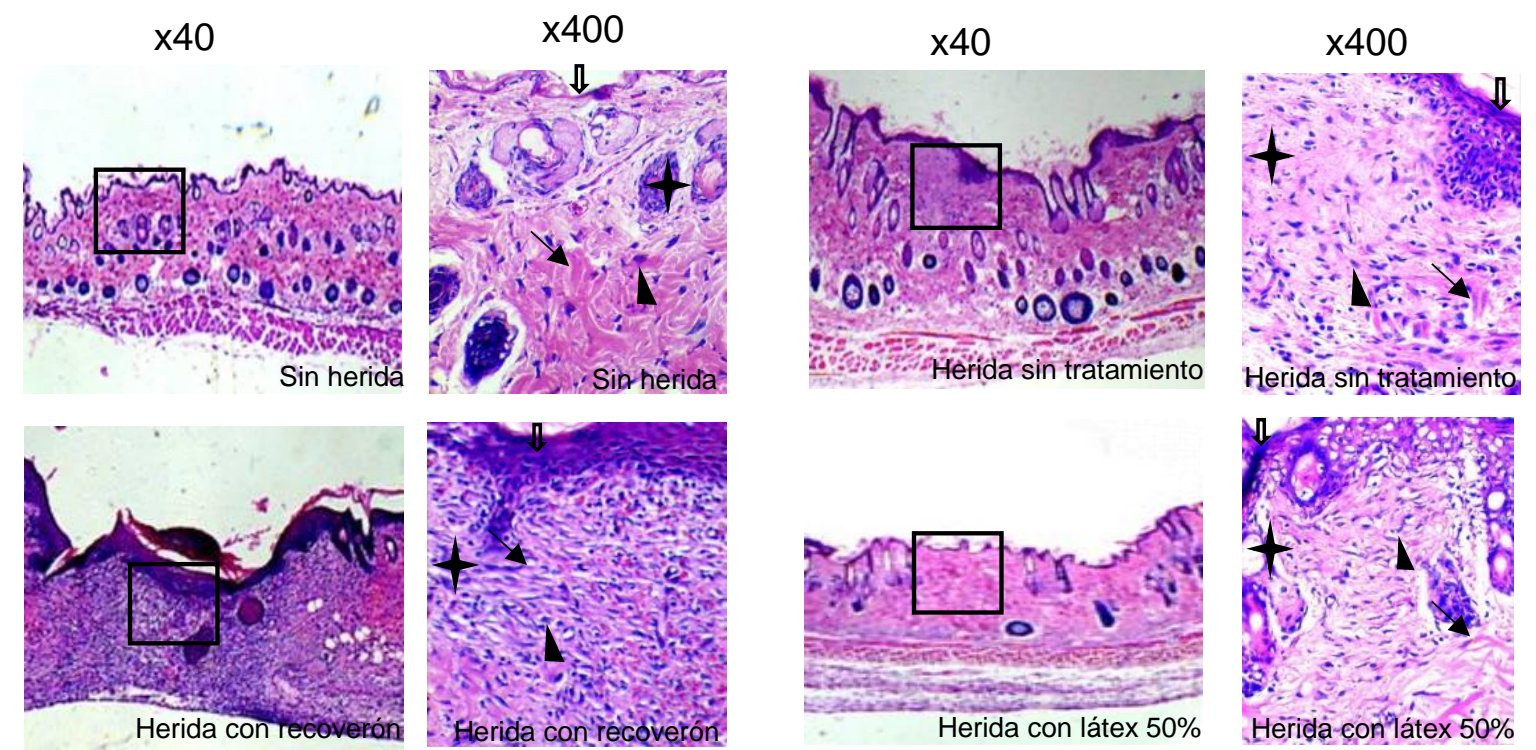

Figura 11: Microfotografías de piel de ratones diabéticos:Sin herida, Herida sin tratamiento, Herida con recoverón, Herida tratado con látex $50 \%$. Se observan cambios importantes en epidermis, densidad de fibroblastos y fibras de colágeno. Tinción H\&E,

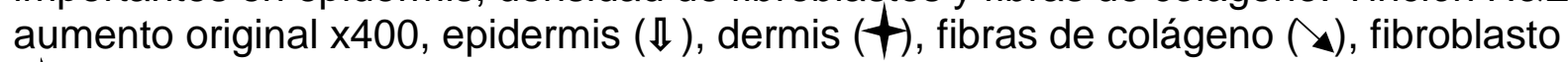
$(\mathbf{\Lambda})$.

Después de observar las diferencias entre cada grupo experimental, se realizó un conteo de fibroblastos en la zona de la lesión. En la Figura 12 se muestran los resultados de este conteo, el grupo de piel sin herida presentó el numero más bajo de fibroblastos (10.33 \pm 0.57$)$ al igual que el grupo sin tratamiento $(20 \pm 3)$ ya que no hay diferencias significativas entre estos dos grupos $(P<0.05)$. El grupo de recoverón y látex presentaron un número mayor de fibroblastos $(38 \pm 8.66,41.66 \pm 7.76) \mathrm{y}$, de igual manera, entre estos dos grupos no hubo diferencias significativas. 


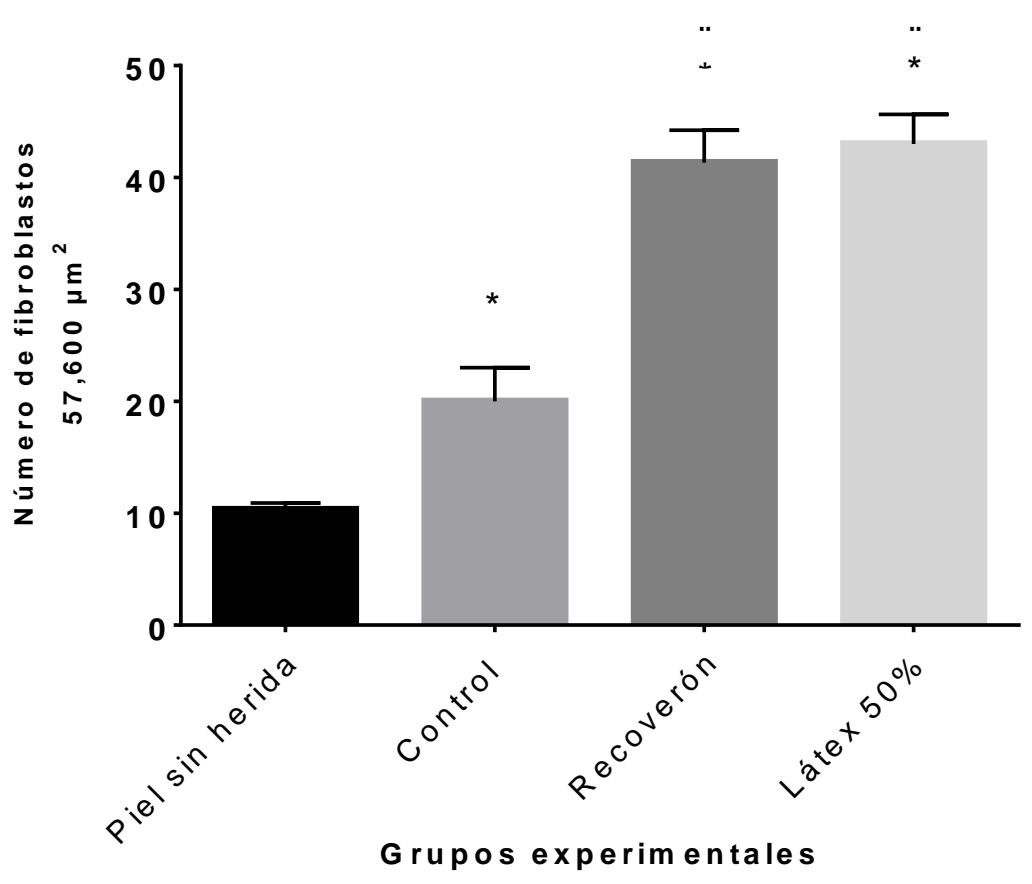

Figura 12. Fibroblastos activos en cada grupo experimental de ratones diabéticos. Los datos se representan como medias \pm E.E.M $(n=6)$. ${ }^{*}$ Diferencia significativa comparada con el grupo de piel sin herida $(P<0.05)$. "Diferencia significativa comparada con el grupo control $(\mathrm{P}<0.05)$.

Para confirmar que el látex si tiene efecto cicatrizante en un modelo de diabetes, se realizó un segundo experimento, donde los ratones permanecieron por más tiempo diabéticos (15 días) antes de realizar la incisión, posteriormente se sacrificaron en el día 7 de sus tratamientos.

A continuación, se muestran las imágenes de cada grupo experimental del día 1 que fue cuando se realizó la herida y el día 7 que fue cuando se sacrificaron (Figura 13). Se aprecia que en el grupo sin tratamiento no hubo formación de cicatriz, mientras que en los grupos experimentales recoverón y látex $50 \%$ si se observa un cierre de la herida y la formación de cicatriz, además que en el grupo del látex $50 \%$ creció el pelo en la zona circundante de la herida. 
Día 1

\section{Día 7}

Sin tratamiento
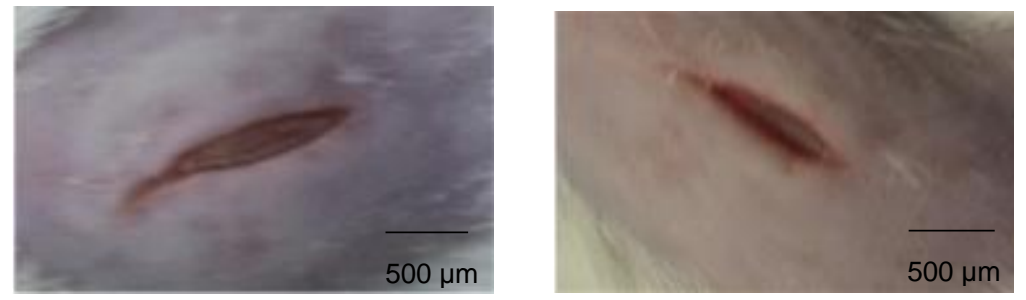

Recoverón
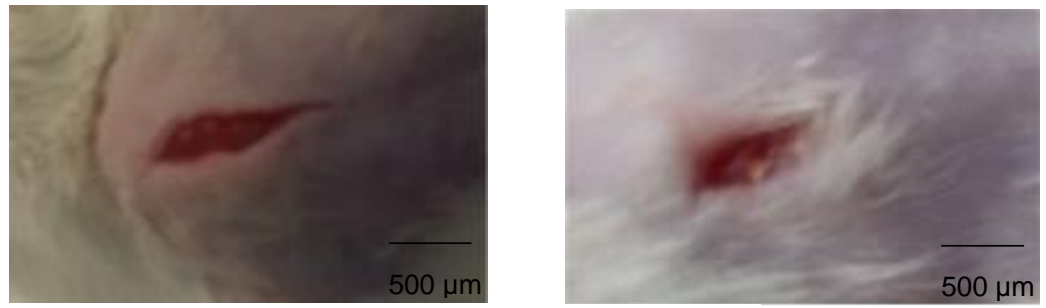

Látex 50\%
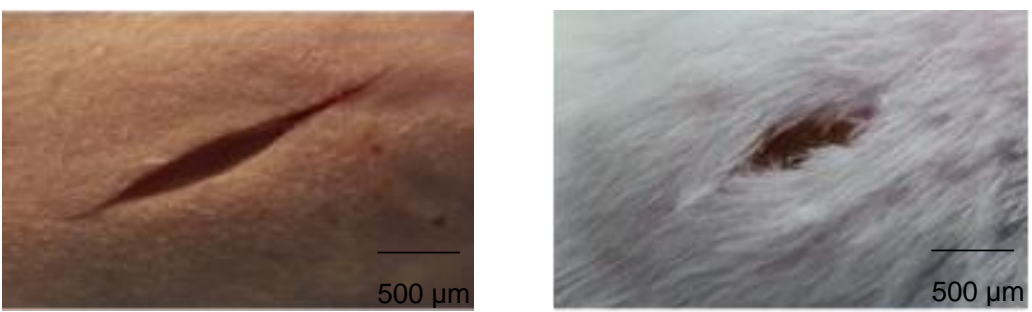

Figura 13. Eficacia cicatrizante de los diferentes tratamientos. Se aprecia macroscópicamente la eficacia cicatrizante del látex de J. neopauciflora (50\%) en ratones diabéticos.

Al igual que en los experimentos anteriores, se presentan los resultados histológicos obtenidos (Figura 14). En el grupo de piel sin herida se observó una epidermis muy delgada además de presentar varios huecos en la dermis, ocasionados por la falta de colágeno en esta área. El grupo experimental sin tratamiento presentó una gran cantidad de células diferentes a los fibroblastos, además la epidermis se observó engrosada en comparación con la piel sin herida y también se pueden apreciar huecos en la dermis por falta de colágeno. Por otro lado, el grupo de recoverón presentó una 
epidermis más delgada en comparación con el grupo sin tratamiento y se puede observar sólo un tipo celular presente que son los fibroblastos y aunque en menor presencia, también se observan faltantes de fibras de colágeno en la dermis. Por último, en el grupo del látex 50\%, también se observó la presencia de varias células, sin embargo, los fibroblastos son las células mayoritarias, además no se observaron los huecos en la dermis por falta de colágeno como en los grupos descritos anteriormente y aunque la epidermis se observó más engrosada en comparación con el grupo de piel sin herida, ésta se ve ordenada e íntegra.
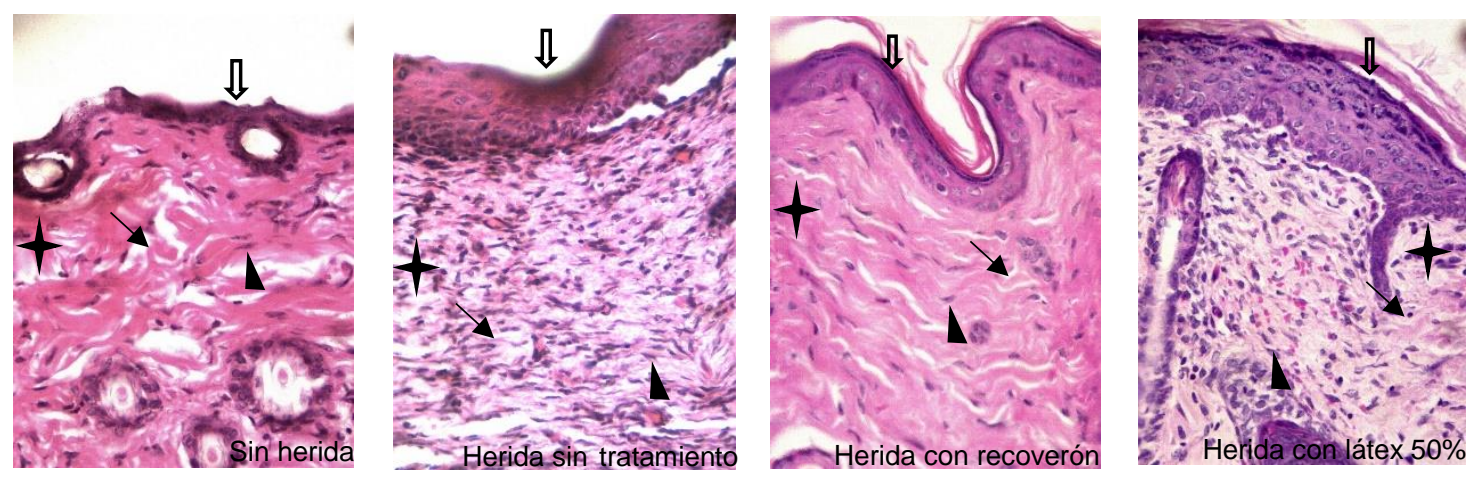

Figura 14. Microfotografías de piel de ratones diabéticos: Sin herida, Herida sin tratamiento, Herida con recoverón, Herida con látex 50\%. Se observan cambios importantes en epidermis, densidad de fibroblastos y fibras de colágeno. Tinción H\&E, aumento original $\times 400$, epidermis $(\Downarrow)$, dermis $(t)$, fibras de colágeno ( $\downarrow$ ), fibroblasto (A).

Al realizar el conteo de fibroblastos activos (Figura 15), el grupo experimental de piel sin herida presentó el valor más bajo (12 \pm 1.4$)$, aunque entre este grupo y el grupo control $(13.75 \pm 4.11)$ no se presentaron diferencias significativas $(P<0.05)$. Sin embargo, el grupo de recoverón y látex $50 \%$ mostraron un mayor número de fibroblastos activos ( $26.5 \pm 3.87$ y $26.5 \pm 3.41$ respectivamente) . 


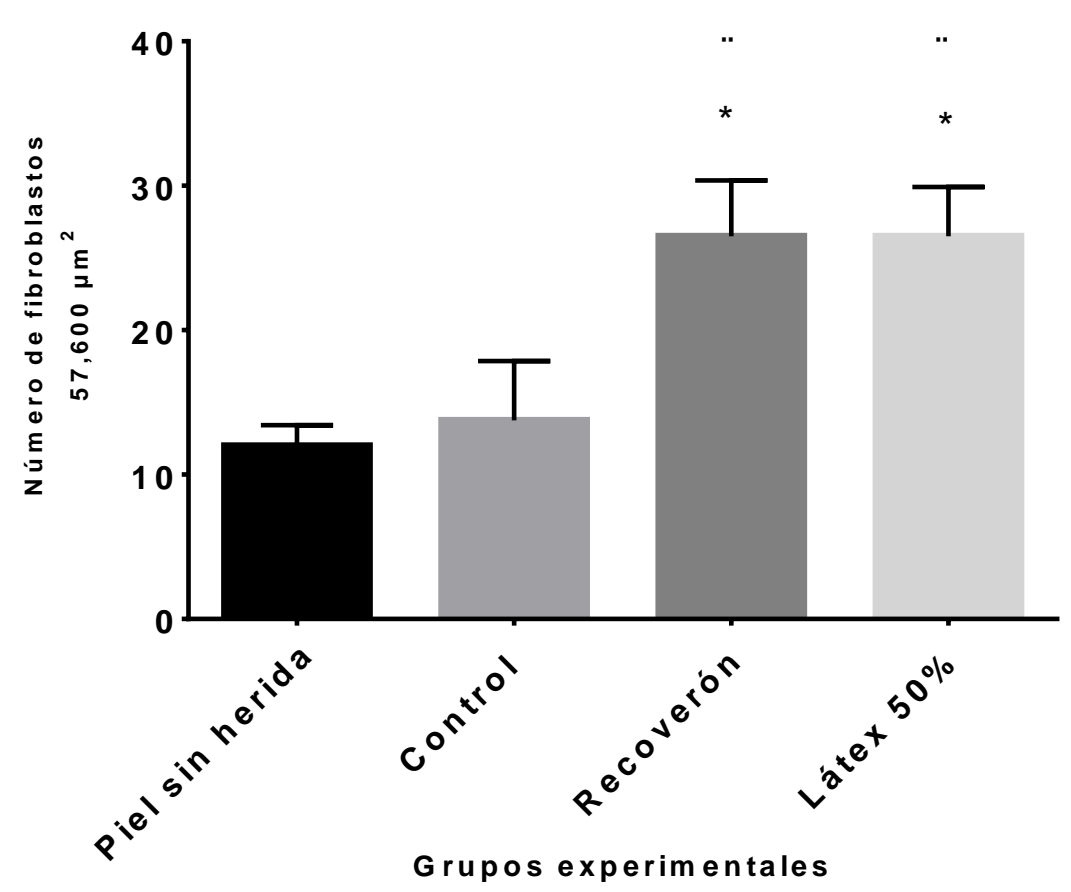

Figura 15. Fibroblastos activos en cada grupo experimental de ratones diabéticos. Los datos se representan como medias \pm E.E.M. $(n=6)$. ${ }^{*}$ Diferencia significativa comparada con el grupo de piel sin herida $(P<0.05)$. "Diferencia significativa comparada con el grupo control $(\mathrm{P}<0.05)$.

\section{Evaluación de la proliferación y migración de fibroblastos.}

Este ensayo se realizó para observar si el látex interviene en la proliferación o migración celular cuando existe una lesión o herida. Primero se realizó una prueba de viabilidad con MTT con varias concentraciones del látex para encontrar la concentración ideal para este ensayo. La concentración inicial (stock) 1:1 látex y DMEM, respectivamente, posteriormente se hicieron diferentes diluciones a partir de esta concentración. 
Posteriormente, los fibroblastos fueron sembrados en cajas de cultivo de 6 pozos y una vez formada la monocapa se realizaron las heridas. Las concentraciones utilizadas de látex fueron: 1:100, 1:1000 y 1:10000. En la siguiente imagen (Figura 16) se observa la monocapa de fibroblastos (A) y la apariencia de cada pozo con la herida ya realizada (B). Al aplicar todos los tratamientos, y después de 24 horas, se observó que la concentración más baja (1:10000) (Figura C) fue la que no produjo daño a los fibroblastos y se observó migración y proliferación celular ya que la herida sí cerró, sin embargo en las concentraciones más altas de látex no se observó sobrevivencia celular
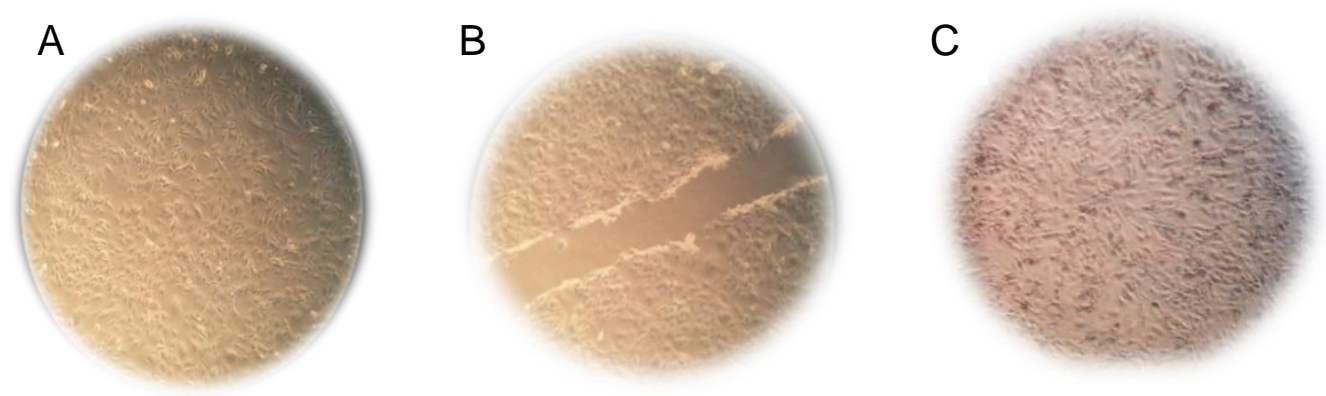

Figura 16. Cultivo in vitro de fibroblastos 3T3-L1: A) Monocapa de fibroblastos; B) Herida C) Cierre de la herida con el látex de J. neopauciflora. Todas las imágenes a $10 x$.

Una vez obtenidos estos resultados, se repitió el ensayo utilizando concentraciones diferentes de látex $(1: 1000,1: 10000.1: 100000$ y 1:1000000), un control positivo estimulante de la proliferación celular (fitohemaglutinina) y un grupo testigo. El tiempo del ensayo sólo fue de 6 horas que fue el tiempo en que el grupo control cerró la herida. A continuación se presentan las microfotografías de cada grupo experimental (Figura 
17), donde se observó que en el grupo control se cerró la herida, mientras que las concentraciones más altas de látex mostraron actividad proliferativa.

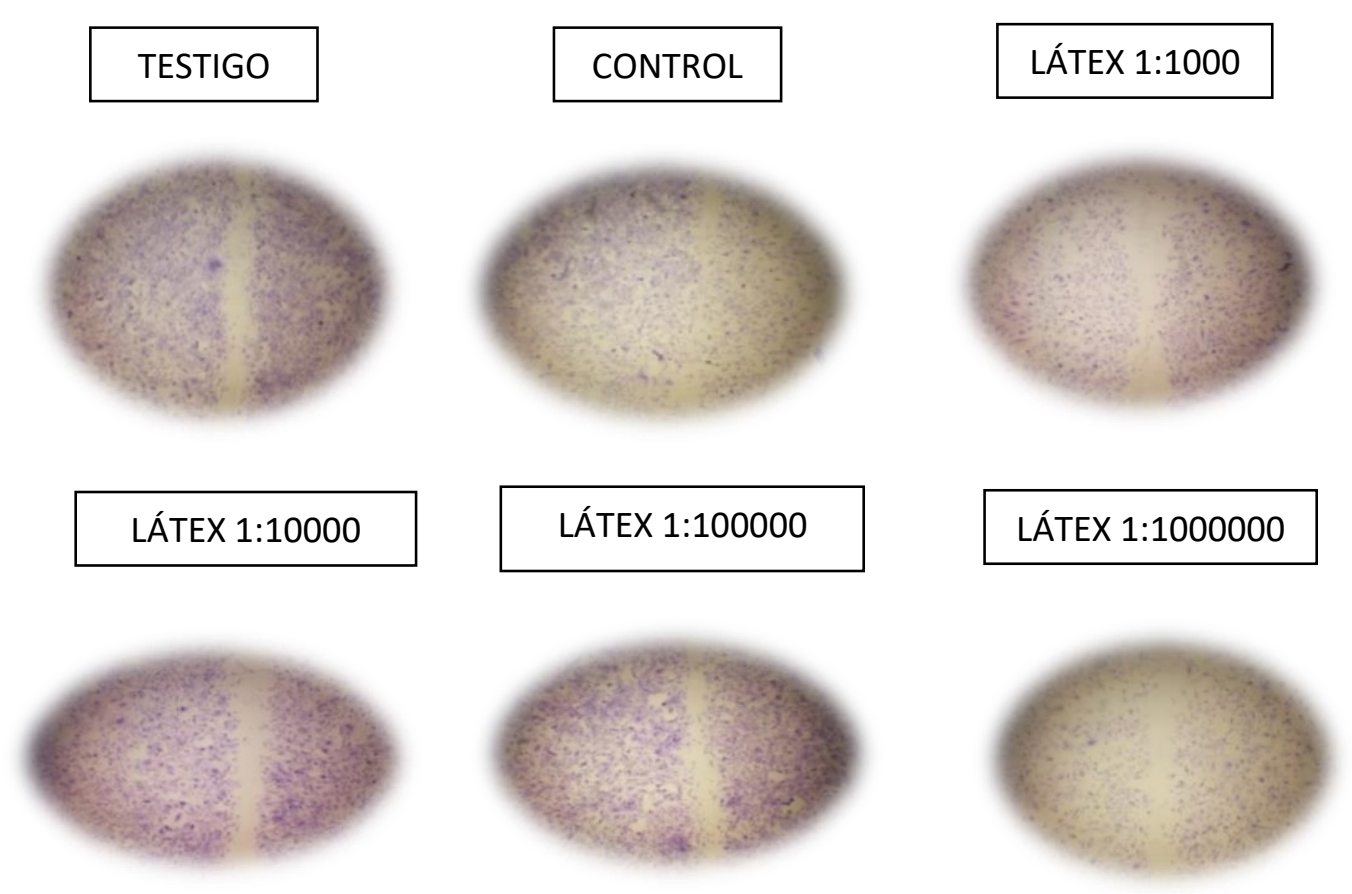

Figura 17. Fotografías de un ensayo de herida in vitro con fibroblastos 3T3-L1 utilizando diferentes concentraciones del látex. Todas las imágenes a 10x.

\section{Evaluación de la capacidad antioxidante}

Se evaluó la capacidad antioxidante del látex de J. neopauciflora mediante el método de reducción del DPPH (Figura 18). Observando que el látex tiene una $\mathrm{CA}_{50}=5.4$ $\mu \mathrm{g} / \mathrm{mL}$. Como control positivo se utilizó quercetina (Figura 19), la cual es un antioxidante conocido, mostrando una $\mathrm{CA}_{50}=4.3 \mu \mathrm{g} / \mathrm{mL}$. Con estos resultados podemos observar que el látex presenta una buena afinidad para reducir el DPPH. 


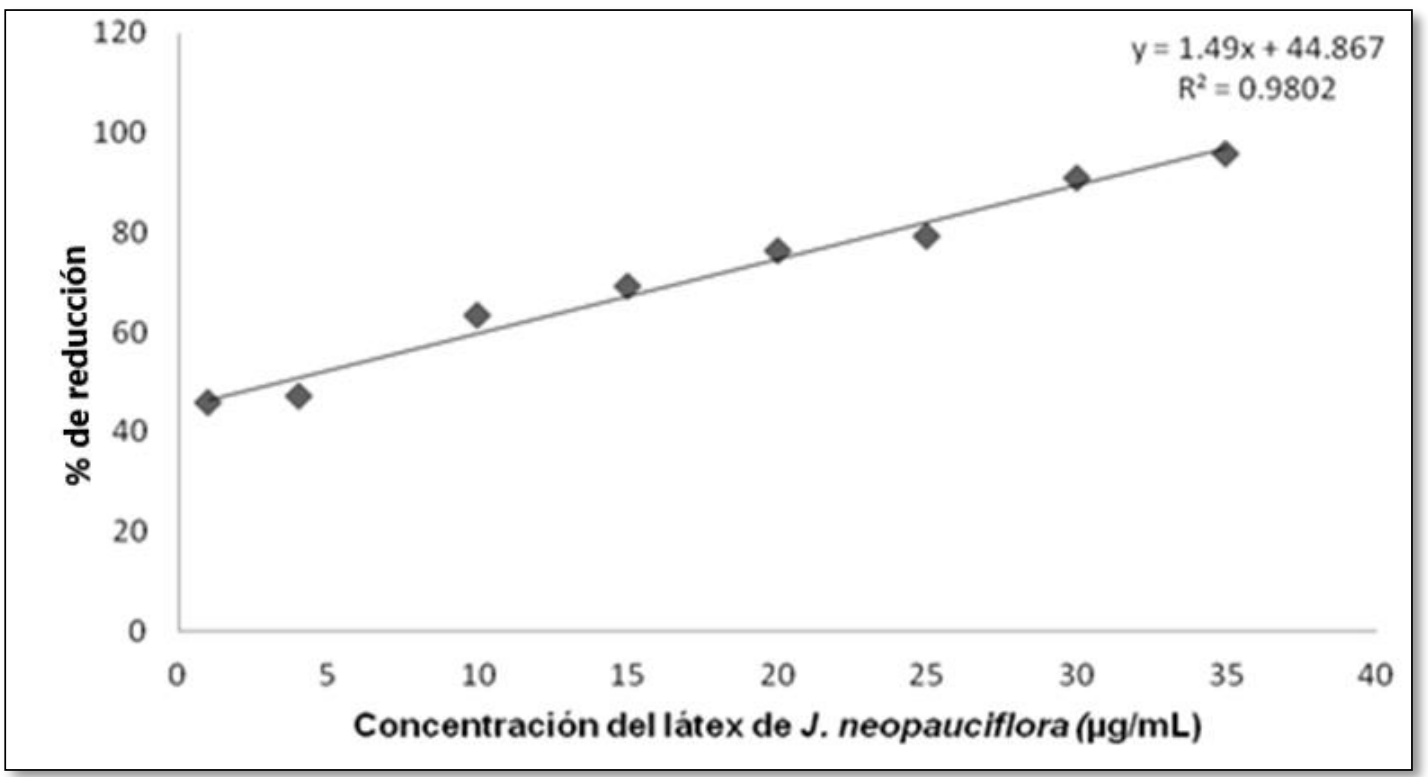

Figura 18. Capacidad antioxidante del látex de J. nepauciflora

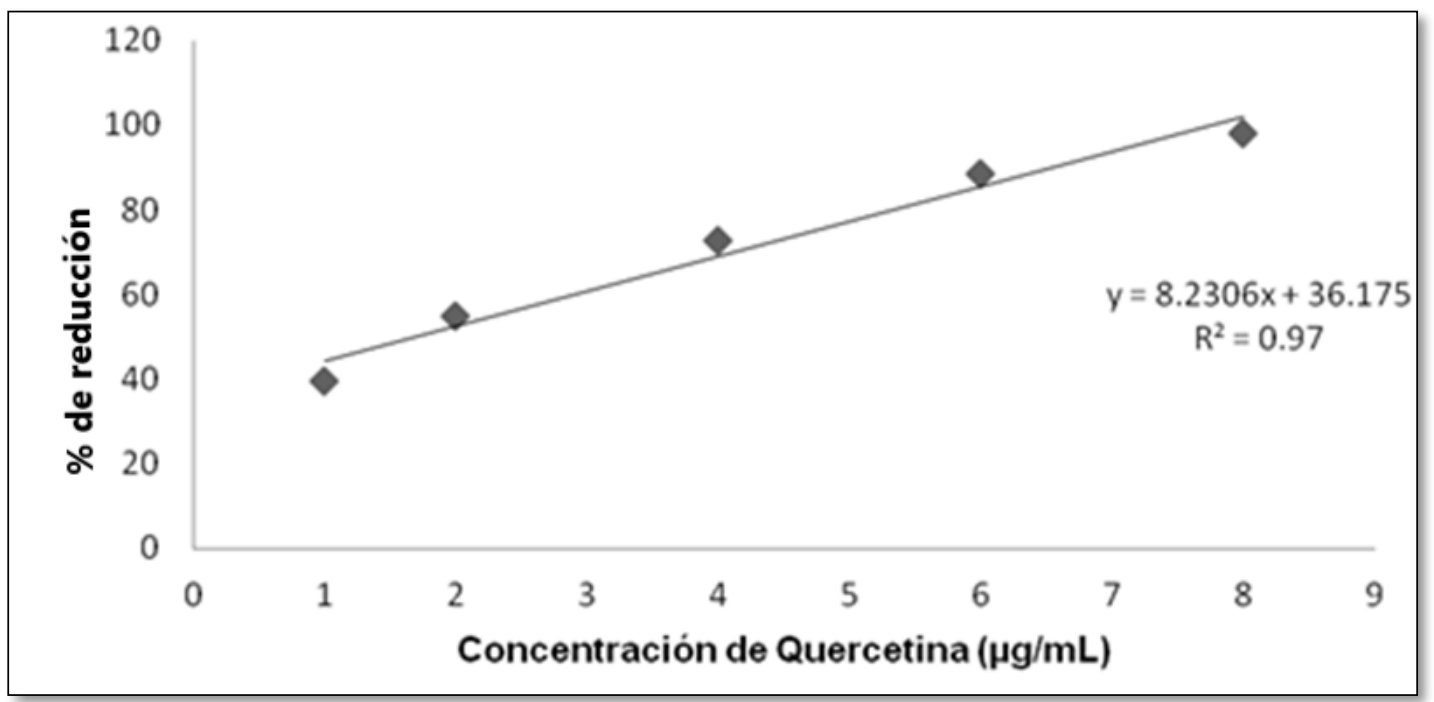

Figura 19. Capacidad antioxidante de Quercetina

Además, de acuerdo con el índice de actividad antioxidante (AAI) utilizando el método de DDPH (Scherer y Teixeira, 2009), el cual nos dice que si el valor de este índice es 
$<0.5 \mu \mathrm{g} / \mathrm{mL}$, hay una pobre actividad antioxidante, sí el valor es de $0.5-1.0 \mu \mathrm{g} / \mathrm{mL}$ es de actividad moderada, si el valor es de 1.0 a 2.0 la actividad antioxidante es fuerte y si el valor es mayor de 2 la actividad antioxidante se considera muy fuerte; el valor del índice del látex de J. neopauciflora fue de 5.55, por tal motivo su actividad antioxidante es muy fuerte.

\section{CARACTERIZACIÓN QUÍMICA DEL LÁTEX DE J. neopauciflora}

\section{Fenoles Totales}

Para determinar el contenido de fenoles se utilizó el Método modificado de Singleton, realizando una curva patrón con un Fenol utilizado frecuentemente dentro de la investigación (ácido gálico) (Figura 20). El resultado obtenido fue una concentración de $6.9 \mathrm{mg}$ eAG/g de látex.

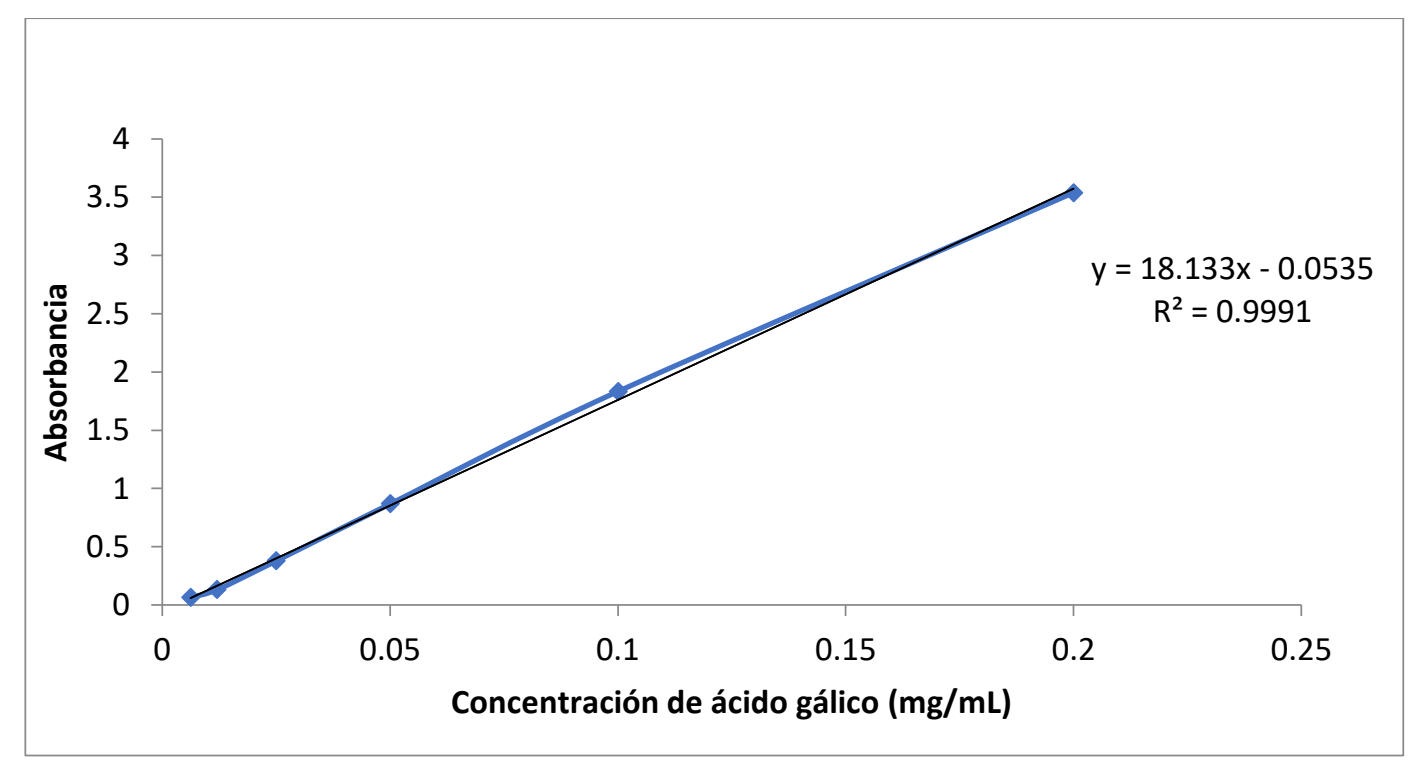

Figura 20. Curva patrón de ácido gálico. 


\section{Flavonoides Totales}

Para obtener el contenido total de Flavonoides Totales, se realizó por el Método de Ramamoorthy (2007), utilizando Quercetina para la curva patrón (Figura 21). La concentración total fue de $12.53 \mu \mathrm{g} \mathrm{eQ} / \mathrm{g}$ de látex lo que equivale a un $1.2 \%$ del total de flavonoides presentes en un gramo de látex.

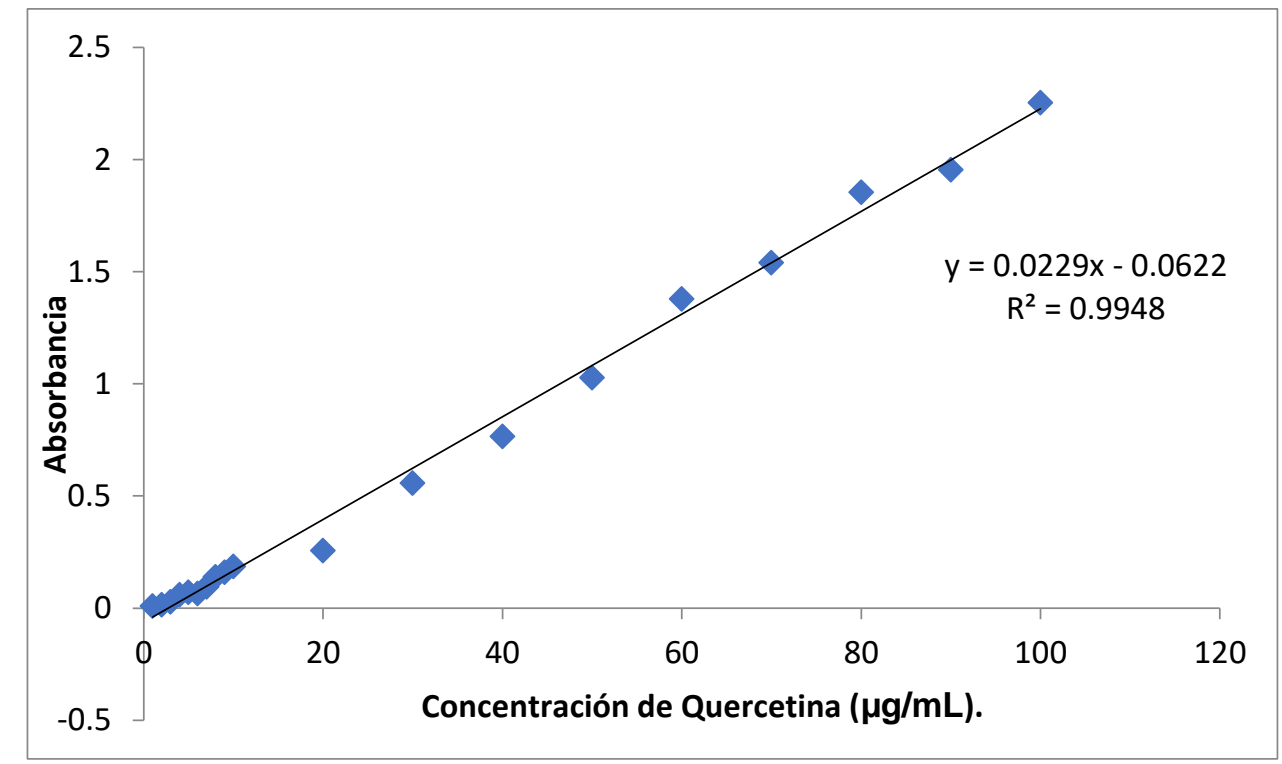

Figura 21. Curva patrón de quercetina

\section{Proteínas}

La cuantificación de proteínas se llevó a cabo mediante el Método de Bradford, realizando una curva patrón con albumina (Figura 22), obteniendo una concentración de $7.62 \mu \mathrm{g}$ de proteína en $1 \mathrm{~mL}$ de látex. 


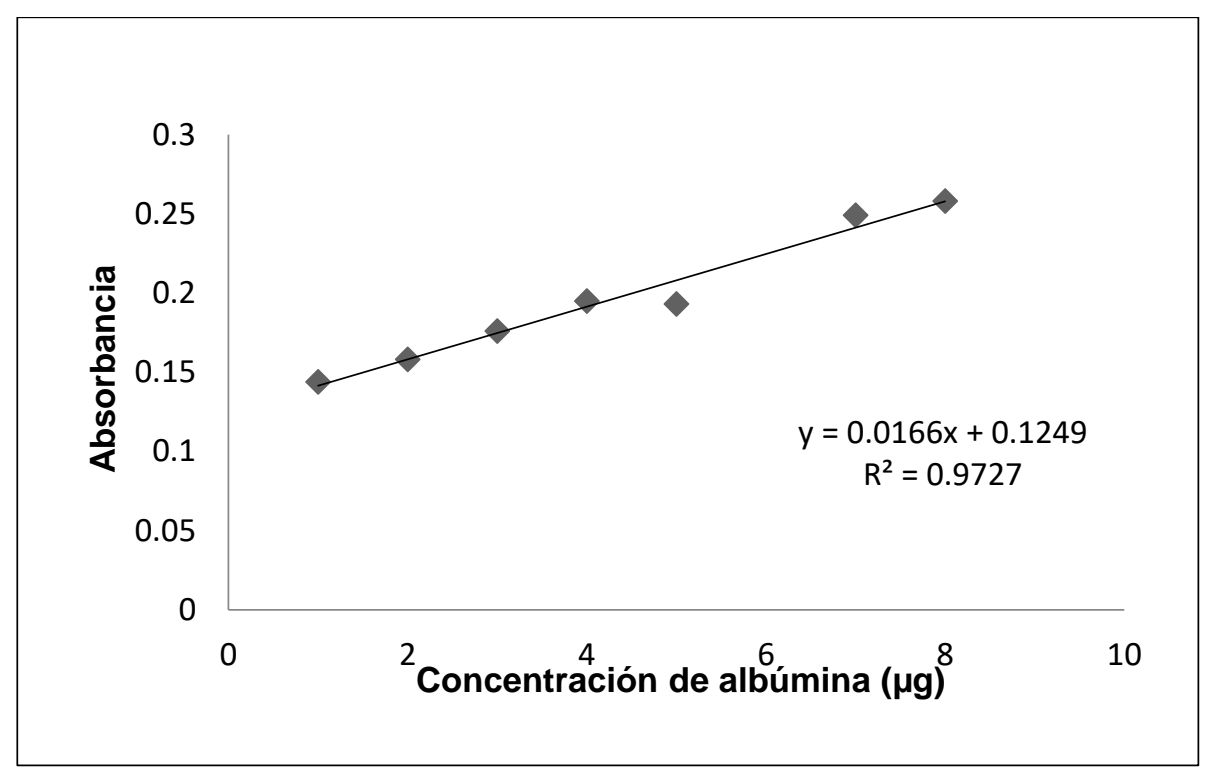

Figura 22. Curva patrón de Albumina.

\section{Carbohidratos}

Para la cuantificación de carbohidratos se utilizó el Método de Nelson-Somogy, realizando una curva patrón con glucosa (Figura 23), obteniendo una concentración de $9.26 \mu \mathrm{g}$ de carbohidratos en $500 \mu \mathrm{L}$ de látex.

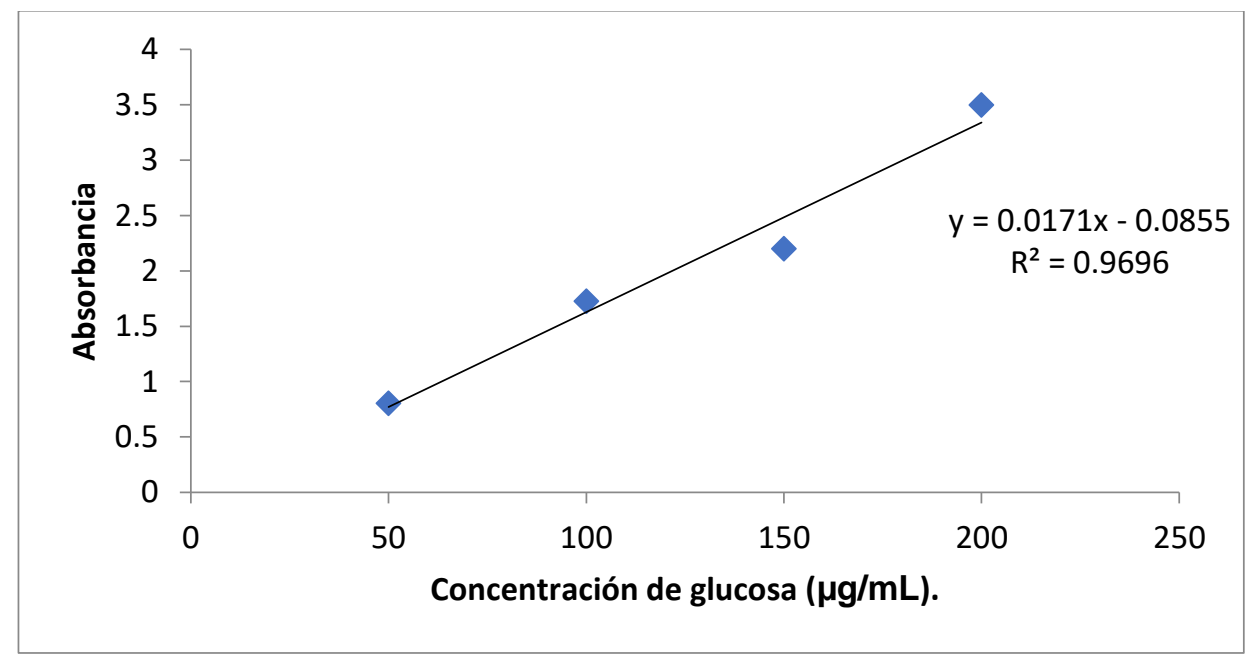

Figura 23. Curva patrón de glucosa. 
Determinación de Carbohidratos por cromatografía líquida de alta resolución (HPLC).

Una vez que se realizó la extracción de carbohidratos, se sometieron a una Cromatografía Líquida de Alta Resolución (Figura 24), donde se comparó con los diferentes estándares, dando como resultado la presencia de fructosa $(79.025 \%$ de carbohidratos) en el látex de J. neopauciflora.

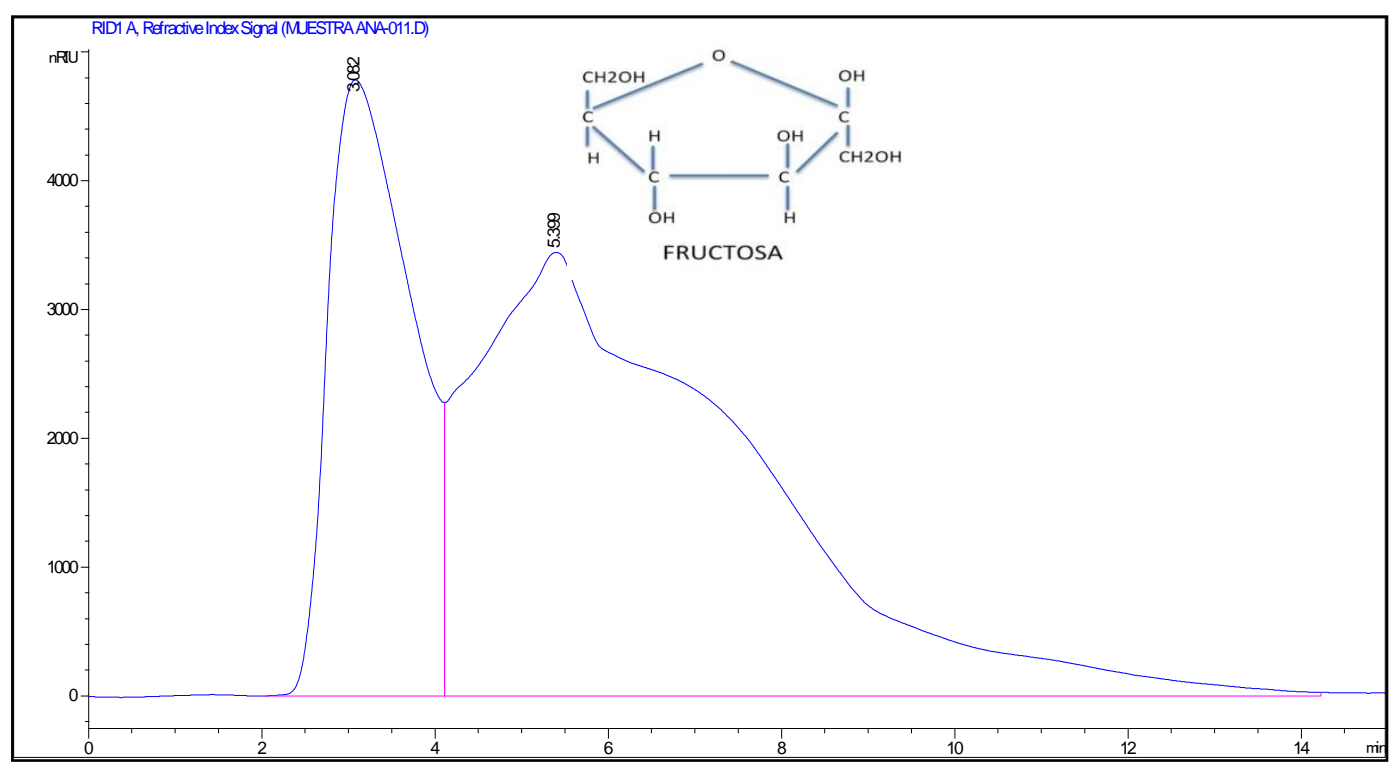

Figura 24. Determinación de Carbohidratos por HPLC

\section{$>$ Cromatografía de exclusión en gel.}

Se realizó una columna de exclusión en gel para separar los compuestos del látex dependiendo su tamaño. Se obtuvieron 58 fracciones, las cuales fueron analizadas, sometiéndolas a una Cromatografía Líquida de Alta Resolución donde se identificó catequina en varias fracciones. 
Por otro lado, las fracciones con los mayores rendimientos fueron sometidas para medir su capacidad antioxidante mediante el método de reducción del DPPH. En el cuadro 1 se muestran los resultados, en total se midieron 24 fracciones con 6 concentraciones diferentes $(5,10,15,20,30$ y 50 ppm), de las cuales sólo 9 fracciones mostraron una $\mathrm{CA}_{50}$ menor a $50 \mathrm{ppm}$ (resultados en color rojo).

Cuadro 1. CA 50 de las fracciones del látex de J. neopauciflora

\begin{tabular}{cccc}
\hline FRACCIÓN & $\mathbf{C A}_{\mathbf{5 0}}(\mathbf{p p m})$ & FRACCIÓN & CA $_{50}(\mathbf{p p m})$ \\
\hline 2 & $>50$ & 14 & 45 \\
3 & $>50$ & 15 & $>50$ \\
4 & $>50$ & 16 & $>50$ \\
5 & $>50$ & 17 & $>50$ \\
6 & $>50$ & 19 & 35 \\
7 & $>50$ & 20 & $>50$ \\
8 & $>50$ & 21 & $>50$ \\
9 & 10 & 23 & $>50$ \\
10 & 14 & 24 & $>50$ \\
11 & 26 & 25 & $>50$ \\
12 & 22 & 26 & $>50$ \\
13 & 30 & 35 & $>50$ \\
\hline
\end{tabular}




\section{DISCUSIÓN}

La cicatrización de las heridas constituye una respuesta básica de los seres vivos y, en general, produce restablecimiento satisfactorio de la integridad de los tejidos. Aunque existe una gran variedad de medicamentos utilizados como cicatrizantes, algunos se han asociado con efectos adversos. Por ejemplo, se ha observado que el gel de becaplermina podría aumentar la susceptibilidad al desarrollo de cáncer después de su uso prolongado. Por otro lado, a menudo sucede que, en varias patologías sistémicas, el proceso de cicatrización se ve alterado y la capacidad del medicamento para regenerar el tejido se ve disminuida. Tal es el caso de la diabetes, en la cual el proceso de cicatrización se encuentra alterado en alguna de las fases mencionadas, provocando una cicatrización lenta, débil y superficial, resultando en una herida recurrente, e incluso la amputación de extremidades.

En esta investigación se evaluó el efecto cicatrizante del látex de J. neopauciflora. En primer lugar, se midió la eficacia cicatrizante de dicho látex mediante el método tensiométrico, para determinar la fuerza (gramos) necesaria para abrir nuevamente la herida. Las tres concentraciones utilizadas de látex (50, 75 y 100\%) actuaron de manera similar, presentando un porcentaje de eficacia del 100\%. Sin embargo, sí hubo diferencias en cuanto a la estética de la herida, pues la cicatriz con látex $100 \%$ presentó apariencia gruesa, parecida a una cicatriz queloide, mientras que la cicatriz con látex $50 \%$ es delgada y bien definida.

Estos resultados concuerdan primeramente con la investigación etnobotánica realizada por Canales (2006), donde reporta que esta especie es utilizada dentro de la 
medicina tradicional para sanar heridas. Por otra parte, Salas y colaboradores (1994), quienes evaluaron la actividad cicatrizante del látex de Jatropha curcas mediante el método tensiométrico en un modelo murino in vivo, utilizando concentraciones de 10 , 50 y $100 \%$, observaron después de 48 horas que con una dosis única $(50 \mu \mathrm{L})$, las tres concentraciones presentaron actividad cicatrizante, particularmente la concentración del $100 \%$, ya que presentó actividad cicatrizante del $92.8 \%$, y utilizando dosis múltiples, la concentración del 50\% fue la que obtuvo la mejor actividad cicatrizante. Por otra parte, Villegas y colaboradores (1997) evaluaron la actividad cicatrizante de varias plantas utilizadas en la medicina tradicional de Perú, utilizando el método tensiométrico. Entre las especies que estudiaron se encuentra J. curcas, cuyo látex presentó actividad cicatrizante significativa. Vaisberg (1989) reporta que en el látex de Croton lechleri y C. draconoides, ambas de la familia Euphorbiaceae, se ha identificado al alcaloide taspina como principio cicatrizante; en una investigación sobre el mecanismo de acción en un cultivo celular mostró que la sal de hidrocloruro del alcaloide no es tóxica. Además, también se observó que no tiene ningún efecto sobre la proliferación celular, pero si aumenta la migración de fibroblastos, este efecto da como resultado acelerar el proceso de cicatrización de la herida.

Risco y colaboradores (2005) también estudiaron las bases químicas y farmacológicas del látex de $C$. lechleri, observando la presencia de varias moléculas con propiedades biológicas, incluyendo el alcaloide taspina, el cual presentó propiedades cicatrizantes y antiinflamatorias, promoviendo la migración de fibroblastos durante las primeras 60 horas después de la lesión. 
Además del análisis de la progresión del cierre de la herida a nivel macroscópico, se revisó también la estructura y organización celular del proceso de cicatrización a nivel microscópico mediante un análisis morfológico de la herida, tanto in vivo como in vitro. En el estudio in vivo se utilizó la tinción Hematoxilina-Eosina para identificar y cuantificar los fibroblastos presentes en cada grupo experimental. Los fibroblastos tienen como función principal la formación de fibras de colágeno y elastina y tienen la capacidad de sintetizar y fagocitar el colágeno y los componentes de la matriz extracelular en la fase de remodelación (Acosta 2006). Son estimulados por PDGF, factor de crecimiento nervioso (NGF), TGF- $\beta$, factor de crecimiento del tejido conectivo (CTGF), fibronectina y cisteína 61 (Cyr61), que actúa regulando la adhesión celular, migración, proliferación, diferenciación y apoptosis, ayudando así a la reparación de tejidos (Monaco y Lawrence, 2003).

En relación con el conteo de fibroblastos de cada uno de los grupos experimentales, la piel sana presentó el menor número de fibroblastos activos, lo que representa la condición normal de la piel sin lesión y no existe estimulación alguna para la migración y proliferación de fibroblastos. Los ratones con herida sin tratamiento y tratados con el vehículo (gel) presentaron el mayor número de fibroblastos activos. La etapa proliferativa se caracteriza por presentar mayor número de estas células, de tal manera que es probable que estos dos grupos experimentales se encontraran en dicha fase, donde los fibroblastos sintetizan colágeno y sufren un cambio fenotípico a miofibroblastos, adquiriendo filamentos de actina en su citoplasma para adquirir la habilidad de contraerse para el cierre de la herida (Benavides, 2008). 
Es evidente con estos resultados, que el gel no interviene en el proceso de cicatrización ya que la cantidad de fibroblastos es similar a la del grupo sin tratamiento; entre ambos grupos no hubo diferencias significativas. El grupo tratado con recoverón, un cicatrizante comercial, y el grupo de piel sana presentaron un número similar de fibroblastos. El recoverón contiene neomicina, un antibiótico del grupo de los aminoglucósidos que actúa inhibiendo la síntesis de proteínas por bloqueo de la subunidad 30s del ribosoma, actuando de varias maneras diferentes: inhibiendo el inicio de la síntesis de proteínas, separando los polisomas en monosomas no funcionales o induciendo la incorporación de aminoácidos incorrectos (Flórez et al., 2008). También contiene acexamato de sodio, que estimula la proliferación de fibroblastos y la síntesis de colágeno, regulando el tejido conectivo. Por lo tanto, este cicatrizante comercial por un lado evita la infección de la herida y por otro, acelera el proceso de cicatrización, resultando en un menor número de fibroblastos activos.

Las tres concentraciones del látex (50, 75 y 100\%) mostraron un menor número de fibroblastos en comparación con los grupos sin tratamiento y gel. Se puede deducir que el látex acelera el proceso de cicatrización, probablemente en menor medida que el recoverón, con la diferencia que este medicamento contiene dos principios activos, mientras que el látex es un conjunto de varias moléculas, presentes en concentraciones bajas, que podrían estar actuando sinérgicamente.

En relación con el estudio morfológico mediante la tinción tricrómica de Masson, dado que este colorante tiñe estructuras acidófilas, como las fibras de colágeno, se observaron diferencias de densidad y grosor en las fibras de colágeno de cada grupo experimental. En este caso, los fibroblastos son los encargados de sintetizar colágeno 
por lo que las diferencias en el número de fibroblastos podrían reflejarse en el contenido de colágeno, Además, este método tiñe colágeno tipo I y éste se sintetiza en la fase de remodelación del proceso de cicatrización; por tal motivo, las muestras de piel con mayor densidad de colágeno podrían estar en esta etapa.

Como se mencionó, la diabetes juega un papel importante en el proceso de cicatrización, siendo la hiperglucemia el principal detonador etiopatogénico proximal en el inicio y progresión de los desórdenes bioquímicos, moleculares y celulares que dan lugar a las complicaciones sistémicas. En un proceso normal de cicatrización cada fase lleva un orden y las células involucradas cumplen su función en dicho proceso. Después sufren eliminación apoptótica, sin embargo, en la diabetes este proceso está alterado, ya que la eliminación de células inflamatorias se detiene, lo que provoca un anormal estancamiento de la fase inflamatoria. Por tal motivo, existe una sobreexpresión de citocinas proinflamatorias, como TNF- $\alpha$ e interleucina 1- $\beta$ (Berlanga et al., 2010).

Esta red de citocinas proinflamatorias, proteasas locales, así como especies reactivas de oxígeno y de nitrógeno, propician un ambiente citotóxico y degenerativo en la zona de la herida, perjudicando así las siguientes fases de la cicatrización: granulación y reepitelización.

Así mismo, la acumulación anormal de productos glicados a causa de la diabetes interfiere con la replicación del ADN, el anclaje, la migración y la proliferación celular, afecta además la liberación, el reclutamiento y la diferenciación de las células madre derivadas de médula ósea, lo que limita la disponibilidad de estas células para reparar el tejido (Berlanga et al., 2010). 
La complejidad del proceso de cicatrización en la diabetes y sus consecuencias incapacitantes remarca la necesidad de la búsqueda de nuevas alternativas terapéuticas que ayuden a reducir la tasa de amputaciones de miembros inferiores en la diabetes debido a una mala cicatrización. Por esta razón, el látex de J. neopauciflora fue evaluado también en un modelo murino de diabetes.

Las microfotografías muestran cómo la piel de los ratones diabéticos perdió la elasticidad, ya que presenta pliegues a todo lo largo de la epidermis, mientras que la dermis está adelgazada, en comparación con los grupos de ratones normales.

El conteo de fibroblastos activos en la zona de la herida en el grupo testigo (ratones sin incisión), tienen el promedio más bajo de fibroblastos activos, al igual que el grupo de ratones con incisión sin tratamiento, sin diferencias significativas entre estos dos grupos. En la piel sin herida la cantidad de fibroblastos es poca ya que no existe razón para que los fibroblastos migren y proliferen; por otra parte, el grupo de ratones diabéticos con incisión sin tratamiento, también presentaron escasos fibroblastos en la zona de la herida. Esto probablemente se deba a que el proceso de cicatrización está retardado ya que, como se mencionó, la diabetes provoca que las células no migren y proliferen adecuadamente (Pickup, 2004).

Los grupos de recoverón y látex presentaron mayor cantidad de fibroblastos, siendo muy similares y sin diferencias significativas. Dado que el acexamato de sodio, un componente del recoverón, promueve la migración y proliferación celular, este grupo presentó mayor número de este tipo celular, mientras que el látex podría tener un efecto similar al del control positivo. Se puede observar que, en el grupo de ratones diabéticos con herida sin tratamiento, las fibras de colágeno están muy delgadas, 
mientras que en los grupos de recoverón y látex, las fibras de colágeno presentan una mayor densidad. Esto se puede deber al mayor número de células presentes en la zona de la lesión, pues como sabemos, la función principal de los fibroblastos es la secreción de colágeno.

Es importante mencionar que este es el primer trabajo donde se evalúa la actividad cicatrizante del látex de J. neopauciflora tanto en ratones sanos como diabéticos, se han reportado varios trabajos sobre otras especies del género Jatropha que presentan actividad cicatrizante, sin embargo, son pocos los estudios a nivel histológico, tal es el caso de J. gossypiifolia, donde el extracto crudo fue probado como cicatrizante utilizando ratas Wistar, dando como resultado la proliferación de fibroblastos, así como una mejor reepitelización y actividad antiinflamatoria (Da Silva et al., 2006). Dentro de la familia Euphorbiaceae, Euphobia hirta L. es una especie que ha sido estudiada por sus propiedades cicatrizantes en un modelo de diabetes experimental inducida por aloxan en ratas Wistar, se probaron varias dosis administradas de manera tópica, observando a nivel histológico, que con la dosis de $400 \mathrm{mg} / \mathrm{kg}$ la piel se veía mejorada, la epidermis estaba bien formada, así como la restauración de fibrosis extensa y del colágeno dentro de la dermis (Haque, 2017).

Los radicales libres son protagonistas de numerosas enfermedades que provocan reacciones en cadena. Son átomos o grupos de átomos que tienen un electrón desapareado, por lo que son muy reactivos, ya que tienden a captar un electrón de otros átomos con el fin de alcanzar su estabilidad electroquímica. Una vez que el radical libre ha conseguido sustraer el electrón (reducción) que necesita, la molécula 
estable que lo pierde (oxidación) se convierte a su vez en un radical libre por quedar con un electrón desapareado, iniciándose así una reacción en cadena.

Debido a que estas especies reactivas no poseen receptores específicos, tienen una capacidad de agresión indiscriminada sobre células y tejidos vivientes (Maldonado et al., 2010). Como producto de nuestro metabolismo generamos distintos tipos de radicales libres, tales como: Especies Reactivas de Oxígeno (ERO) como el anión superóxido, el anión peróxido, el radical perhidroxilo, el radical hidroxilo y Especies Reactivas de Nitrógeno (ERN): óxido nítrico y radical peroxinitrito, entre otros, cuya principal fuente son las mitocondrias, los lisosomas, los peroxisomas, así como la membrana nuclear, citoplasmática y del retículo endoplásmico.

Así, cuando existe un proceso infeccioso el sistema inmunitario responde mediante diversas reacciones de defensa, generando radicales libres, los cuales inhiben el crecimiento de los microorganismos (Céspedes y Sánchez 2000). En condiciones fisiológicas normales, el organismo neutraliza las ERO a través de varios mecanismos antioxidantes que involucran la producción de enzimas antioxidantes como la superóxido dismutasa, catalasa, glutatión peroxidasa y otras, para prevenir el daño oxidante. Cuando la capacidad de control de las sustancias oxidantes es superada, se establece una situación conocida como estrés oxidante, dañando macromoléculas (lípidos, proteínas, hidratos de carbono y ácidos nucleicos) y alterando los procesos celulares (funcionalidad de las membranas, producción de enzimas, respiración celular, inducción génica, etc.) (Finkel y Holbrook, 2000).

En la diabetes mellitus se presentan varias complicaciones como daño renal, neuronal, ceguera, infecciones crónicas que terminan en amputaciones de extremidades 
inferiores, entre otras, lo cual se deben principalmente a que se produce un desequilibrio bioquímico propiciado por la producción excesiva de radicales libres, lo que provoca daño oxidativo a las biomoléculas que no puede ser contrarrestado por los sistemas antioxidantes de defensa (Ramos et al., 2006).

En este sentido, se realizó un ensayo para medir la capacidad antioxidante $\left(\mathrm{CA}_{50}\right)$ del látex de J. neopauciflora mediante el método de reducción del DPPH, el cual consiste en que el radical 2,2-difenil-1-picril hidrazilo tiene un electrón desapareado y es de color azul-violeta, decolorándose a amarillo pálido por la reacción de la presencia de una sustancia oxidante (donador de un átomo de Hidrógeno), siendo medida espectrofotométricamente a $517 \mathrm{~nm}$ (Ramos et al., 2008).

El látex de J. neopauciflora, presentó una actividad antioxidante muy fuerte ( $\mathrm{AAl}=5.55$ $\mu \mathrm{g} / \mathrm{mL}$ ) y una $\mathrm{CA}_{50}=5.4 \mu \mathrm{g} / \mathrm{mL}$ (Fig. 18), al comparar este resultado con la quercetina que presentó una $\mathrm{CA}_{50}=4.3 \mu \mathrm{g} / \mathrm{mL}$ (Fig. 19), podemos decir que el látex tiene un capacidad antioxidante significativa, ya que la quercetina es un flavonoide con diferentes propiedades, siendo una de las más importantes la actividad antioxidante, ya que retira oxígeno reactivo especialmente en forma de aniones superóxidos, radicales hidróxidos, peróxidos lipídicos o hidroperóxidos.

De esta manera, la quercetina bloquea el accionar de estas sustancias sobre las células. Los efectos citoprotectores de la quercetina se presentan en diferentes células como fibroblastos de la piel humana, queratinocitos y células endoteliales (Havsteen, 1983). Por tal motivo, el látex tiene capacidad antioxidante significativa ya que el valor de la $\mathrm{CA}_{50}$ es muy similar al de la quercetina y estos datos concuerdan con los resultados obtenidos con el índice de actividad antioxidante (AAI) donde el látex se 
considera un antioxidante muy fuerte, aunque todavía no se sabe el mecanismo de acción del látex, probablemente actúa de manera similar a la quercetina, que promueve una cicatrización rápida y correcta.

Estos datos son similares a los obtenidos por Hernández (2013), en los que el látex de J. neopauciflora presentó una $\mathrm{CA}_{50}=5.4$, similar a la obtenida en este ensayo. El látex de J. curcas presentó una $C A_{50}=6.8 \mu \mathrm{g} / \mathrm{mL}$ (Oskoueian et al., 2011), siendo un resultado parecido al de J. neopauciflora. Por otro lado, Can-Ake y colaboradores (2004) trabajaron con hojas y raíces de J. gaumeri; las hojas mostraron capacidad antioxidante.

Un grupo de metabolitos secundarios que se han asociado con varias propiedades biológicas importantes, entre ellas su capacidad de neutralizar radicales libres para retardar o prevenir la oxidación, es decir, con actividad antioxidante, son los polifenoles. Los polifenoles son un grupo de compuestos presentes en la naturaleza que poseen anillos aromáticos con sustituyentes hidroxilos. Estos compuestos son en su mayoría potentes antioxidantes por su estructura química (donador de $\mathrm{H}^{+} \mathrm{O}$ electrones), necesarios para el funcionamiento de las células vegetales (Leighton et al., 1997). Los flavonoides son derivados fenólicos compuestos por dos anillos de benceno combinados por mediación del oxígeno contenido en el anillo pirano (Figura 25), estos compuestos han sido reportados por presentar actividad antioxidante, la cual va a depender de la estructura individual de cada flavonoide y del número de oxidrilos sustituyentes, así como el peso molecular (Velioglu et al., 1998). 
Mediante el método modificado de Singleton se llevó a cabo la cuantificación de fenoles totales del látex de J. neopauciflora utilizando ácido gálico para la curva patrón y como reactivo Folin-Ciocalteu (Fig. 20). Este método se basa en la capacidad de los fenoles para reaccionar con agentes oxidantes. El reactivo de Folin-Ciocalteu contiene molibdato y tungstato sódico, que reaccionan con cualquier tipo de fenol, formando complejos fosfomolíbdico-fosfotúngstico. La transferencia de electrones a pH básico reduce los complejos fosfomolíbdico-fosfotúngstico en óxidos, cromógenos de color azul intenso, de tungsteno $\left(\mathrm{W}_{8} \mathrm{O}_{23}\right)$ y molibdeno $\left(\mathrm{Mo}_{8} \mathrm{O}_{23}\right)$, siendo proporcional este color al número de grupos hidroxilo de la molécula (Gutiérrez et al., 2008).

Los resultados mostraron que el látex contiene fenoles en su composición química, con una concentración de $6.9 \mathrm{mg}$ eAG/g de fenoles presentes en el látex. Al comprobar la presencia de fenoles, el siguiente paso fue determinar la cantidad de flavonoides totales por el Método colorimétrico de Dowd, utilizando quercetina para realizar la curva patrón y como reactivo $\mathrm{AlCl}_{3}$ que va a interactuar con los grupos hidroxilo de los flavonoides. La concentración total fue de $12.53 \mu \mathrm{g} \mathrm{eQ} / \mathrm{g}$ de látex, lo que equivale a un $1.2 \%$ del total de flavonoides presentes en un gramo de látex.

Con estos resultados se demuestra la capacidad antioxidante del látex de $\mathrm{J}$. neopauciflora, puesto que los flavonoides tienen ya una comprobada actividad antioxidante, por lo que pueden proteger las células contra el daño oxidativo y por lo tanto limitar el riesgo de varias enfermedades degenerativas asociadas al estrés oxidativo causado por los radicales libres. Retiran oxígeno reactivo especialmente en forma de aniones superóxidos, radicales hidroxilos, peróxidos lipídicos o 
hidroperóxidos, bloqueando la acción de dichas sustancias sobre las células. Estos efectos citoprotectores se han observado en fibroblastos de la piel humana, queratinocitos y células endoteliales (Merck, 2000). Además de la actividad antioxidante, también se ha reportado que presentan una gran diversidad de efectos terapéuticos, tales como actividades cardiotónica, antiinflamatoria, antimicrobiana, hepatoprotectora, antineoplásica, etc.

Es muy importante que los flavonoides presenten actividad antimicrobiana y antiinflamatoria, ya que durante el proceso de cicatrización se puede presentar alguna infección, esto provocaría que algunas células del sistema inmune como macrófagos secreten ERO para eliminar a estos patógenos, pero también dañarían las células del huésped, además que se podría desencadenar una inflamación crónica y retardar el proceso de cicatrización, pero si se le suma su actividad antiinflamatoria, ya que evitan la liberación de prostaglandinas e histaminas y evitan la migración celular, entonces los flavonoides presentes en el látex tendrían mayor relevancia, ya que podrían evitar la aparición de infecciones en la herida, neutralizando los radicales libres, tanto del estrés oxidativo generado por el metabolismo como del sistema inmune, evitando que se presente una inflamación crónica, ayudando así a una buena cicatrización (Berlanga et al., 2010).

Se han identificado flavonoides en diferentes especies del género Jatropha, los que probablemente son responsables de actividades biológicas reportados en cada especie. Por ejemplo: nobiletina (raíz J. curcas), tomentin (parte aérea J. curcas), 
vitexina, isovitexina, y apigenina (hojas J. gossypiifolia), luteolina (hojas J. unicostata) y catequina (tallos J. macrantha y gossypiifolia) (Sabandar et al., 2013).

También se han aislado péptidos cíclicos con actividad biológica del látex de varias especies del género Jatropha. Por ejemplo, de J. curcas se aisló curcaciclina A, que tiene actividad inmunomoduladora inhibiendo la vía clásica del complemento y la proliferación de células $\mathrm{T}$; curcaciclina $\mathrm{B}$, con actividad antimalaria, y rotamasa de ciclofilina. De J. multifida se aisló labaditina, con actividad antibacteriana contra bacterias Gram-positivas y actividad inmunomoduladora. De J. pohliana se aislaron pohlininas $A, B$ y $C$, para J. mahafalensis se aisló mahafaciclina $A$, entre otras (Sabandar et al., 2013).

En relación con la cuantificación de proteínas del látex de J. neopauciflora mediante el método de Bradford (Fig. 22), el cual se basa en la cuantificación de la unión del colorante Azul Brillante de Coomassie a una proteína desconocida y la comparación de esta unión con la de diferentes cantidades de una proteína standard, como la albumina, leyendo a $595 \mathrm{~nm}$. La concentración de proteína en el látex fue de 7.62 $\mu \mathrm{g} / \mathrm{mL}$ de látex.

Aunque la cuantificación de proteínas se utiliza mucho en la industria alimentaria, como se mencionó anteriormente, el género Jatropha presenta péptidos cíclicos con actividades biológicas, entonces muy probablemente el látex de $J$. neopauciflora posea moléculas similares las cuales sean responsables de alguna actividad. 
Por otro lado, es importante mencionar que el azúcar granulado (sacarosa) y la miel han sido usadas desde hace mucho tiempo para la cicatrización de heridas. Por tal motivo, dentro de este perfil químico realizado al látex, también se cuantificaron los carbohidratos con el Método de Nelson-Somogyi (Fig. 23), el cual se basa en la capacidad de un azúcar, en este caso glucosa, para reducir agentes oxidantes como el $\mathrm{Cu}^{2+}$. $\mathrm{El} \mathrm{Cu}^{2+}$ se reduce a $\mathrm{Cu}^{+}$, y en presencia de arsenomolibdatoamónico forma un complejo de color azul, a partir del cual podemos conocer mediante espectrofotometría la cantidad de cobre reducido, y por lo tanto, de azúcar reductor. Obteniendo una concentración de $9.26 \mu \mathrm{g}$ de carbohidratos en $500 \mu \mathrm{L}$ de látex.

De la extracción de carbohidratos, una parte se utilizó para someterla a una Cromatografía Líquida de Alta Resolución (Fig. 24), donde al hacer una comparación con algunos estándares, podemos confirmar la presencia de fructosa $(79.025 \%)$ en el látex de $J$. neopauciflora.

Haddad y colaboradores (2000), explican que cuando existe una herida, se necesita una concentración mínima de agua en el ambiente de un microorganismo para que éste se reproduzca; el azúcar crea un medio con bajo contenido de agua (alta osmolaridad), dado que el plasma y la linfa migran fuera del tejido hacia la solución e inhiben el crecimiento bacteriano por disminución en la concentración de agua. Además el azúcar atrae macrófagos que fagocitan detritus y aceleran el desprendimiento de tejido desvitalizado, necrótico o gangrenoso; provee una fuente de energía local y forma una capa protectora en la herida. 
Por otro lado, la miel de abeja que contiene varios azúcares, entre ellos fructosa, favorece la cicatrización, actuando sobre la división celular, la síntesis y maduración del colágeno, la contracción y la epitelización de la herida. Además, actúa como antibacteriano ya que la miel contiene la enzima glucosa oxidasa, la cual produce peróxido de hidrógeno cuando está en contacto con la herida (Aljadi et al., 2004).

Por todo lo anterior, es muy probable que la fructosa presente en el látex de $\mathrm{J}$. neopauciflora intervenga en el proceso de cicatrización, teniendo un comportamiento similar a la sacarosa, ya que existen estudios que confirman la importancia de la sacarosa para la cicatrización de heridas, como el caso de Vizcaíno y colaboradores (2013), quienes probaron la actividad cicatrizante de dicha azúcar en un modelo con ratas, observando el mismo fenómeno mencionado anteriormente; hay una mayor osmolaridad que el plasma e hipertonía en la superficie de la herida, lo que produce por osmosis la reducción rápida del edema local y el paso de elementos plasmáticos y linfa a través de la lesión y el depósito de fibrina. Además, concluyen que se obtiene un alto grado de epitelización total con la sacarosa en comparación con medicamentos tópicos convencionales (facdermín y nitrofurazona), induciendo maduración más rápida de la dermis, por lo que se puede asociar con un mayor grado de calidad de la cicatrización.

En cuanto a la cromatografía de exclusión en gel, que permite separar moléculas de acuerdo con su tamaño molecular, del látex se obtuvieron 58 fracciones, identificando la catequina dentro de su composición química. Como se mencionó anteriormente, los flavonoides presentan diversas propiedades biológicas, las cuales contribuyen a tener 
una mejor cicatrización. Por otro lado, a las fracciones que presentaron los mayores rendimientos se les midió su capacidad antioxidante. Sólo 7 fracciones mostraron una CA50 menor de $50 \mu \mathrm{g} / \mathrm{mL}$. Esto es importante ya que el látex completo mostró mejor capacidad antioxidante $\left(\mathrm{CA}_{50}=5.4 \mu \mathrm{g} / \mathrm{mL}\right)$, esto probablemente debido a que los compuestos presentes en el látex actúan sinérgicamente.

Con todo lo anterior, se puede decir que el látex de J. neopauciflora interviene en el proceso de cicatrización debido a que contiene moléculas que evitan la infección de la herida, neutralizan radicales libres y regulan el sistema inmune, evitando el desarrollo de inflamación crónica en la herida, contribuyendo así, de manera integral, a acelerar y mejorar el proceso de cicatrización. 


\section{CONCLUSIONES}

El látex de Jatropha neopauciflora:

- Presentó $100 \%$ de eficacia cicatrizante con el método tensiométrico en ratones sanos.

- Aumentó el número de fibroblastos activos en las heridas de ratones sanos de manera similar al recoverón, mientras que disminuyó el número de fibroblastos en ratones diabéticos de igual forma que el recoverón mostrando una epidermis más delgada y mejor definida.

- Promovió la proliferación de fibroblastos a concentraciones bajas (1:1000 a 1:100000)

- Presentó capacidad antioxidante similar a la quercetina por el método de reducción del $\mathrm{DPPH}$, mientras que las fracciones muestran menor capacidad antioxidante, probablemente debido a sinergismo entre sus componentes.

- Contiene fenoles $(6.9 \mathrm{mg}(\mathrm{eag}) / \mathrm{mL})$, flavonoides $(12.53 \mu \mathrm{G}(\mathrm{eq}) / \mathrm{g})$, proteínas (7.62 $\mu \mathrm{g} / \mathrm{mL})$ y azúcares $(9.26 \mu \mathrm{g} / 500 \mu \mathrm{L}$ de látex) de los cuales $79 \%$ son fructosa, así como catequina, los cuales podrían estar implicados en la actividad farmacológica.

- No resultó citotóxico en células Ca Ski ni en fibroblastos 3T3-L1.

Esta investigación valida científicamente el uso tradicional del látex de Jatropha neopauciflora como cicatrizante en un modelo experimental de diabetes, el cual promueve la proliferación de fibroblastos, provee de mayor resistencia a la piel, tiene 
actividad antioxidante y no es citotóxico, por lo que podría ser usado como una alternativa terapéutica para el tratamiento integral de heridas en pacientes con DM.

\section{PERSPECTIVAS}

Realizar el ensayo de eficacia cicatrizante por el método tensiómetrico con ratones diabéticos.

Analizar la participación de otros tipos celulares o citocinas dentro del proceso de cicatrización.

Evaluar la actividad antioxidante del látex en la zona de la herida

Caracterizar los compuestos detectados, como por ejemplo aislar los péptidos cíclicos en el látex, así como comprobar e identificar la presencia de alcaloides.

Promover el uso sustentable de esta especie dentro de la comunidad donde se encuentra.

Generar un producto fitofarmacéutico que ayude a la cicatrización en pacientes diabéticos. 


\section{Apéndice 1. Zona de colecta.}

Las dos especies estudiadas se colectaron en el poblado de San Rafael, Municipio de Coxcatlán, que se localiza al sureste de Tehuacán, en el Valle de Tehuacán-Cuicatlán, entre $18^{\circ} 12^{\prime}$ y $18^{\circ} 14^{\prime}$ de latitud norte, así como $97^{\circ} 07^{\prime}$ y $97^{\circ} 09^{\prime}$ de longitud oeste, con un rango de altitud de 957 a 1400 m.s.n.m.

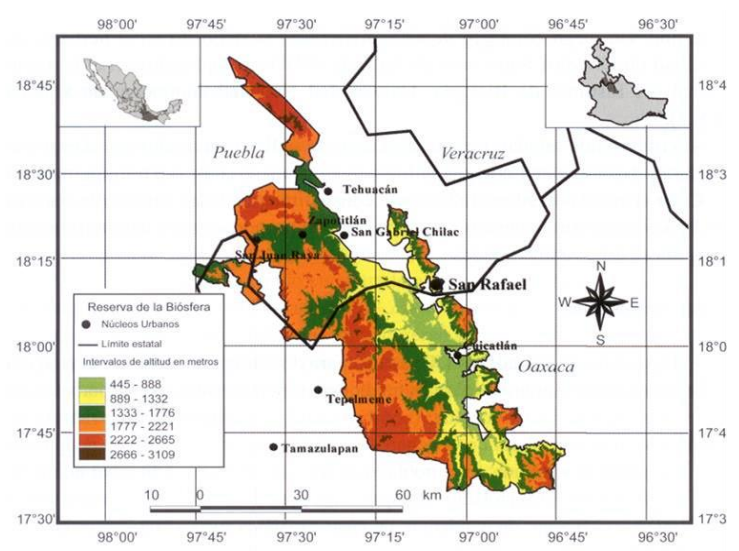

Ubicación geográfica del poblado de San Rafael

Clima

El clima es de tipo Bs (h') w" (w), de acuerdo con la clasificación de Koeppen, modificado por García (1981), el cual corresponde a un tipo seco o árido con lluvias en verano y temperatura media anual de $22{ }^{\circ} \mathrm{C}$, variando entre $25^{\circ} \mathrm{C}$ en abril y mayo, y $18^{\circ} \mathrm{C}$ en enero.

Hidrografía

El sureste de Puebla se encuentra irrigado por el Río Salado. La parte sur del Valle de Tehuacán-Cuicatlán es drenado por el Río Grande o Tomellín, que fluye al norte desde 
Oaxaca; uniéndose cerca de Quitepec los dos forman el Río de Santo Domingo, el cual corta la Sierra Madre de Oaxaca en dirección este y eventualmente se vuelve el Río Papaloapan. El Río Tehuacán encuentra su camino al oeste del Cerro Colorado, para entrar en el Valle de México cerca de San Diego, Chalma. Este pequeño río, el cual se convierte en el Río Salado, se une por un número de cortas ramificaciones, alcanzando la Sierra Madre de Oaxaca en el noreste (Salcedo-Sánchez, 1997).

\section{Edafología}

El origen del suelo data del periodo Cuaternario, era Cenozoica. Los suelos en las regiones están pobremente desarrollados y pueden ser divididos en dos grandes tipos: regosoles, predominantemente calcáreos y regosoles éutricos y xerosoles, predominantemente xerosoles háplicos.

\section{Vegetación}

La vegetación predominante es un bosque tropical caducifolio, donde Escontria chiotilla (F. A. C. Weber) Rose y Pachycereus weberi (J. Coulter) Backeberg son particularmente abundantes (Valiente-Banuet et al., 2000). Fernández (1999), reconoció por nivel topográfico los siguientes tipos de vegetación en San Rafael: Cordonal de Pachycereus weberi (J. Coulter) Backeberg, que se caracteriza por el predominio de cactáceas columnares (cardones).

Chiotillal de Escontria chiotilla, en el nivel próximo al cauce del río, sobre niveles de terreno de 0.7 a $1.5 \mathrm{~m}$ por encima del nivel basal de esta región, con una alta densidad arbustiva. 
Cuajiotal con especies dominantes como Bursera morelensis Ramírez, Mimosa polyantha (Brandegee), Fouquieria formosa (Kunth), así como arbustos y hierbas como Sanvitalia fructicosa (Helms). Fouquieria con especies dominantes como Fouquieria formosa, Bursera aptera (Ramírez), Mimosa polyantha, Ceiba parvifolia (Rose), Manihotoides pasiflora (Brandegee), Senna wisliseni (DC), Mimosa luisiana (Brandegee) y Sanvitalia fructicosa. Localizada en el nivel más alto, de 3.5 a $5 \mathrm{~m}$ por encima del nivel basal. La densidad de plantas en los estratos arbustivos y herbáceos es muy baja, dominado en su totalidad por Sanvitalia fructicosa. En un estudio etnobotánico realizado en San Rafael (Rosas, 2003), se determinó un total de 374 especies pertenecientes a 249 géneros y 87 familias botánicas, de las cuales 368 especies fueron registradas con uno o más usos (18\% son usadas como plantas medicinales). Las familias con un mayor número de especies fueron Asteraceae, Cactaceae, Solanaceae, Araceae y Euphorbiaceae, que corresponden a las familias más representativas del Valle de Tehuacán-Cuicatlán.

La población.

La comunidad es relativamente joven. Se fundó a principios del siglo XX y cuenta con 298 habitantes (151 mujeres y 147 hombres) (Secretaría de Salud, 2001). La mayor parte de la población actual es nativa de San Rafael y la actividad económica más importante es la agricultura, cuyo principal ingreso proviene del cultivo de la caña de azúcar. También se dedican a la cría de ganado caprino, la recolección de frutos, semillas, leña y madera para diversos fines (Rosas, 2003). 


\section{Apéndice 2. Método Tensiométrico (Vaisberg et al., 1989).}

Las diferentes concentraciones del látex (50, 75 y 100\%), así como el control positivo (Recoveron) y control negativo (gel), se aplicaron de forma tópica. Se utilizaron ratones macho (Mus musculus) de la cepa CD1. Los tratamientos fueron aplicados cada 12 horas, durante 10 días. Posteriormente los ratones fueron sacrificados utilizando una cámara de $\mathrm{CO}_{2}$ y se midió la fuerza con la que se abre la herida utilizando dinamómetros digitales de diferentes escalas para evaluar la eficacia cicatrizante.

Para logar la medición se utilizaron ganchos de metal, los cuales fueron insertados en la piel periférica a la herida, de los cuales se sujetó el dinamómetro que se tensó hasta observar la apertura de la herida y en ese momento se tomó la lecturamen gramos del dinamómetro.

Con los datos obtenidos se calculó el porcentaje de eficacia cicatrizante mediante la siguiente fórmula:

Eficacia de cicatrización (\%) = [(GC/GS)/GS $]$ x 100

Donde: $\mathrm{GC}=$ gramos en que abre la piel cicatrizada GS= gramos para abrir la piel sana

De los datos obtenidos se calculó la media y desviación estándar de cada grupo experimental. Para determinar la significancia entre los tratamientos aplicados, los datos fueron analizados con el software GraphPad Prism 6. 


\section{Apéndice 3. Técnica histológica}

Una vez que se obtienen las muestras de piel, se colocan en formol al 4\% durante 24 horas y se lleva acabo el siguiente proceso:

$>$ Deshidratación

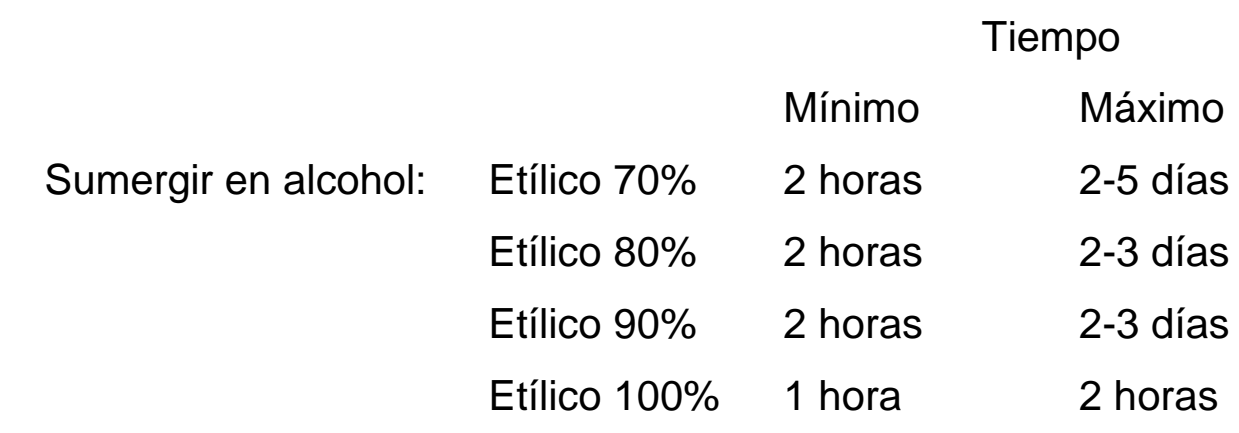

> Impregnación en solvente (aclaración)

Sumergir en butanol por 2 horas, posteriormente quitar el exceso de este alcohol antes de pasar las muestras de tejido a la parafina.

$>$ Infiltración

Colocar las muestras en:

Parafina I (impura) por 24 horas

Parafina II (pura) por 24 horas

$>$ Formación de bloques de parafina

Una vez que las muestras permanecieron 24 horas en parafina II, son puestos en moldes cuadrados para formar los cubos de parafina. Estos moldes son llenados con parafina de inclusión, la cual fue previamente fundida utilizando un horno a una temperatura de $50^{\circ} \mathrm{C}$, cuando los moldes están llenos, con una pinza se toma 
cuidadosamente el tejido y se introduce dentro de este y se dejan a temperatura ambiente para que se solidifiquen.

> Microtomía

Se coloca el bloque en el congelador durante 20 minutos aproximadamente antes de ser cortado. Posteriormente se coloca en el micrótomo y se obtienen los cortes de un grosor de 5 micras.

\section{Tinción con Hematoxilina - Eosina}

La hematoxilina es un colorante natural que se extrae del corazón o duramen del árbol Hematoxylon campechianum. El extracto natural que se obtiene debe de ser oxidado para dar Hemateína. En esta transformación oxidativa, el hematoxilón pierde dos átomos de hidrógeno y uno de sus elementos se vuelve quinona. Sin mordiente la hemateína es casi inútil, los mordientes son sustancias cuya estructura fisicoquímica facilita la fijación del colorante sobre los tejidos, las sales bi o trivalentes o hidróxidos de metales se utilizan en esta tinción. Por lo tanto, la hematoxilina actúa como colorante básico, lo cual se asocia y colorea estructuras aniónicas como núcleos, $\mathrm{RNa}$ ribosomal y matriz extracelular, cualquier componente de los tejidos que reaccionen con un colorante básico se dice que es basófilo. Por otra parte, la eosina se utiliza como colorante de fondo o de contraste en unión con los colorantes de núcleos, es considerado un colorante ácido y colorea estructuras catiónicas del citoplasma y matriz extracelular y los componentes de los tejidos que reaccionen con un colorante ácido se llaman acidófilos (Lynch 1988).

Lo primero que se lleva a cabo es desparafinar las muestras en el horno durante 3 horas aproximadamente. Posteriormente se procede a hacer el tren de tinción: 
Xilol I: 5 minutos

Xilol II: 10 minutos

Alcohol 100\%: 10 lavados

Alcohol 90\%: 10 lavados

Alcohol 80\%: 10 lavados

Alcohol 70\%: 10 lavados

Agua corriente: 10 lavados

Hematoxilina: 5 minutos

Agua corriente: 10 lavados

Alcohol ácido: 1 lavado

Agua corriente: 10 lavados

Carbonato de litio: Sumergir los cortes hasta que vire el color

Agua corriente: 1 lavado

Alcohol 100\% 10 lavados

Eosina: 7 minutos

Alcohol 70\%: 10 lavados

Alcohol 80\%: 10 lavados

Alcohol 90\%: 10 lavados

Alcohol 100\%: 10 lavados

Xilol I: 10 lavados

Xilol II: Dejar ahí las muestras hasta que sean montadas

Tinción Tricrómica de Masson

Esta tinción permite visualizar claramente las fibras de colágeno tipo I, que son proteínas fibrilares que forman fibras gruesas o haces. Este método tricrómico fue inventado por Mallory en 1900 y modificado por Masson en 1912, utiliza azul de anilina y ácido fosfotúngstico. La metodología que seguir es la siguiente:

Xilol I: 5 minutos

Xilol II: 3 minutos

Alcohol 100\%: 3 minutos

Alcohol $90 \% 3$ minutos

Alcohol 80\%: 2 minutos

Alcohol 70\%: 1 minuto

Agua destilada: 3 minutos

Bouin $56-60^{\circ} \mathrm{C}$ : 1 hora

Agua corriente hasta que desaparezca el color amarillo

Agua destilada

Hematoxilina de Weigert: 10 minutos 
Agua: 10 minutos

Escarlata- Biebrich- fucshina ácida: 2 minutos

$\mathrm{H}_{2} \mathrm{O}$ destilada

Sol de ácidos fossfomolib-fosssfotungsteno: 15 minutos

Azul de anilina: 5 minutos

$\mathrm{H}_{2} \mathrm{O}$ destilada

Ácido acético glacial 1\%: 5 minutos

Alcohol 96\%: 3 minutos.

Alcohol 100\%: 5 minutos

Xilol I: 3 minutos

Xilol II: 5 minutos 


\section{Apéndice 4. Inducción de diabetes con estreptozotocina (STZ)}

La estreptozotocina (STZ) (1-metil-1-nitrosouera-2-desoxiglucosa), es un antibiótico derivado del hongo Streptomyces acromógenes, el cual posee propiedades antitumorales y es utilizado para inducir diabetes experimental.

La diabetes inducida por STZ produce alteraciones en las concentraciones de glucosa e insulina sanguínea. Dos horas después del tratamiento, la hiperglucemia se acompaña con un descenso en los niveles de insulina. Finalmente hay una hiperglucemia franca con niveles bajos de insulina. Estos cambios son reflejo del daño en la función de las células- $\beta$ del páncreas (West et al., 1996).

La STZ es relativamente selectiva para la célula- $\beta$ pancreática ya que se une al transportador de glucosa 2 (GLUT 2), presente en su membrana; este reconoce el residuo de glucosa de la molécula de STZ, facilitando su entrada (Delaney et al., 1995, Elsner et al., 2000), de tal forma que la reducción en la expresión de GLUT 2 previene la acción diabetogénica de STZ (Schnedl et al., 1994).

El blanco de acción de la STZ es el ADN de la célula- $\beta$ del páncreas, se lleva a cabo por dos mecanismos: primero por ser un agente alquilante muy potente, propiedad que le confiere el residuo 1-metil-1 nitrosourea, que alquila y fragmenta al ADN, especialmente en la posición $\mathrm{O}^{6}$ de la guanina (Elsner et al., 2000); el segundo mecanismo esta mediado por la producción de óxido nítrico (NO), que contribuye a la destrucción de los islotes pancreáticos, exacerbando el daño al ADN. 
La STZ también genera especies reactivas de oxígeno (ERO), las cuales lesionan al ADN y provocan otros cambios deletéreos en las células. La formación del anión superóxido $\left(\mathrm{O}_{2}\right)$, precursor de ERO en la mitocondria, es inducida por la STZ, debido a que al inhibir el ciclo de Krebs decrece el consumo de oxígeno en la mitocondria, limitando la producción de ATP y causando la caída de este nucleótido en las células$\beta$ (Welsh y Sandler, 1994).

Para la inducción de diabetes con STZ se utilizaron ratones de la especie Mus musculus, cepa CD-1, los cuales sobresalen entre los ratones de uso más común en la investigación como un stock exogámico (los ratones endogámicos son referidos como cepas, mientras que los exogámicos son referidos como stocks).

La STZ fue disuelta en un buffer de citratos $(0.1 \mathrm{M}, \mathrm{pH}$ de 4.5$)$, preparada justo antes de su administración. Los ratones recibieron una dosis única de 130 mg de STZ/kg de peso por vía intraperitoneal con 4 horas de ayuno previo.

Todos los ratones fueron pesados para así obtener el peso total y hacer el stock de STZ, una vez conocido dicho peso se hicieron los cálculos necesarios para tener la concentración de $130 \mathrm{mg}$ de STZ/kg de peso. Se trabajó con una solución de $13 \mathrm{mg}$ de STZ/mL y se administraron $0.1 \mathrm{~mL}$ por cada 10 gramos de peso. La STZ debe de ser utilizada en un lapso no mayor a 15 minutos después de ser disuelta en el buffer de citratos.

Una vez que se administró la STZ, diariamente a los ratones se les midió los niveles de glucosa en sangre obtenida de la vena caudal, utilizando tiras reactivas Accu Chek 
y glucómetro Active con 4 horas de ayuno previo; también fueron pesados para llevar un registro de pérdida de peso. El desarrollo de la diabetes fue confirmado cuando los ratones presentaron niveles de glucosa en sangre mayores a $250 \mathrm{mg} / \mathrm{dL}$ (Ventura et al., 2012). 


\section{Apéndice 5. Proliferación y migración celular.}

Para llevar a cabo este ensayo, lo primero que se realizó fue el descongelamiento de los fibroblastos, pasándolos a tubos falcón con medio DMEM para centrifugar, recuperando el paquete celular y re suspendiéndolo en medio para finalmente pasar las células a botellas de cultivo, las cuales se incubaron a $37^{\circ} \mathrm{C}$ y $5 \% \mathrm{CO}_{2}$.

Una vez que los fibroblastos se activaron, se realizó una prueba de viabilidad celular con MTT, donde se probaron varias concentraciones del látex (1:1, 1:10, 1:100, 1:1000 y 1:10000 ppm). Las células se sembraron en cajas de cultivo de 96 pozos, después de 24 horas, se aplicaron los tratamientos antes mencionados y nuevamente se incubaron a $37^{\circ} \mathrm{C}$ y $5 \% \mathrm{CO}_{2}$ por 24 horas. Posteriormente se retiró el medio y se agregaron $200 \mu \mathrm{L}$ de MTT a cada pozo y se dejó reposar por 3 horas. Transcurrido el tiempo, se retira el MTT y se adiciona el isopropanol con $\mathrm{HCl} 0.04 \mathrm{M}, 200 \mu \mathrm{L}$ en cada pozo, se agitó por 15 minutos ligeramente para finalmente leer en lector de Elisa a 570 $\mathrm{nm}$.

Posteriormente se realizaron varias resiembras para aumentar el número de estas células y poder pasarlas a cajas de cultivo de 6 pozos para formar la monocapa de fibroblastos.

Una vez formada la monocapa, en cada pozo con medio se realizaron las "heridas" utilizando una punta amarilla de micropipieta esterilizada y flameada, inmediatamente después se retiró el medio y se administró nuevo medio disuelto con los diferentes tratamientos (2 $\mathrm{mL}$ por pozo). 
Los tratamientos fueron los siguientes: control positivo (fitohemaglutinina), látex a diferentes concentraciones $(1: 1000,1: 10000,1: 100000$ y $1: 1000000 \mathrm{ppm})$ y finalmente el grupo testigo. Cada tratamiento se realizó por triplicado.

Una vez que se aplicaron los tratamientos, las cajas fueron incubadas a $37^{\circ} \mathrm{C}$ y $5 \%$ $\mathrm{CO}_{2}$, cada tres horas fueron monitoreadas y cuando se observó que el control positivo tenía efecto sobre la herida, se fijaron todas las cajas utilizando formol al $4 \%$ y posteriormente se tiñeron con cristal violeta al $0.1 \%$ para su análisis posterior. 


\section{Apéndice 6. Método de reducción del radical 2,2-difenil-1-picrilhidracil (DPPH•) (Murillo, 2006)}

El 2,2-difenil-1-picrilhidracil (DPPH•) es un radical libre, con un electrón desapareado que le da una coloración violeta y que no se dimeriza. Cuando el DPPH• está en contacto con una sustancia que le puede donar un átomo de hidrógeno, éste se reduce, produciendo un cambio de color de violeta a amarillo, coloración dada por el grupo picril. Con base en lo anterior, la Capacidad Antioxidante Media ( $\left.\mathrm{CA}_{50}\right)$ se evalúa midiendo el grado de decoloración de una solución metanólica de DPPH•, por la adición del compuesto activo a diferentes concentraciones (1-100 ppm). A partir de la medición obtenida por medio de espectrometría UV-VIS, se determina la concentración a la cual el radical es reducido al $50 \%$.

\section{Solución DPPH}

Se prepara en un matraz aforado, colocando $0.00197 \mathrm{~g}(0.002 \mathrm{~g})$ y $50 \mathrm{ml}$ de $\mathrm{MeOH}$ grado HPLC.

\section{Stock del extracto}

Se prepara una solución con $5 \mathrm{mg}$ del látex y se disuelven en $5 \mathrm{~mL}$ de $\mathrm{MeOH}$ grado HPLC

Las concentraciones a evaluar son 1, 2, 3, 4, 5, 6, 7, 8, 9, 10, 15, 20, 30, 40, 50, 60, $70,80,90,100,150,200,250,300,400,500,600,700,800,900$ y 1000 ppm, las cuales se preparan en frascos de $1 \mathrm{~mL}$. 
Para la concentración de 1, 2, 3 y 4 ppm hacer:

Del stock ( $5 \mathrm{mg}$ en $5 \mathrm{~mL}$ de $\mathrm{MeOH}$ ) se toman $20 \mu \mathrm{L}$ (que llevarán $20 \mu \mathrm{g}$ ) y se adicionan $180 \mu \mathrm{L}$ de $\mathrm{MeOH}$ para tener un volumen final de $200 \mu \mathrm{L}$. De este nuevo stock se tomarán las siguientes cantidades:

\begin{tabular}{|c|c|c|}
\hline [ ] ppm & $\mu \mathrm{L}$ stock & $\mu \mathrm{L}$ de $\mathrm{MeOH}$ \\
\hline 1 & 10 & 990 \\
\hline 2 & 20 & 980 \\
\hline 3 & 30 & 970 \\
\hline 4 & 40 & 960 \\
\hline
\end{tabular}

Del stock (5mg en $5 \mathrm{~mL}$ de $\mathrm{MeOH}$ ) tomar:

\begin{tabular}{|c|c|c|}
\hline [ ] ppm & $\mu \mathrm{L}$ stock & $\mu \mathrm{L} \mathrm{de} \mathrm{MeOH}$ \\
\hline 5 & 5 & 995 \\
\hline 6 & 6 & 994 \\
\hline 7 & 7 & 993 \\
\hline 8 & 8 & 992 \\
\hline 9 & 9 & 991 \\
\hline 10 & 10 & 990 \\
\hline 20 & 20 & 980 \\
\hline 30 & 30 & 970 \\
\hline 40 & 40 & 960 \\
\hline 50 & 50 & 950 \\
\hline 60 & 60 & 940 \\
\hline & & \\
\hline
\end{tabular}




\begin{tabular}{|c|c|c|}
\hline 70 & 70 & 930 \\
\hline 80 & 80 & 920 \\
\hline 90 & 90 & 910 \\
\hline 100 & 100 & 900 \\
\hline 150 & 150 & 850 \\
\hline 200 & 200 & 800 \\
\hline 250 & 250 & 750 \\
\hline 300 & 300 & 700 \\
\hline 400 & 400 & 600 \\
\hline 500 & 500 & 500 \\
\hline 600 & 600 & 400 \\
\hline 700 & 700 & 300 \\
\hline 800 & 800 & 200 \\
\hline 900 & 900 & 100 \\
\hline 1000 & 1000 & 0 \\
\hline
\end{tabular}

\section{Aplicación de sustancias}

En una placa de ELISA se adicionan $50 \mu \mathrm{L}$ de la solución problema a diferentes concentraciones (1-1000 ppm) por triplicado, para agregar posteriormente $150 \mu \mathrm{L}$ de la solución metanólica de DPPH. Inmediatamente se protege de la luz envolviéndola con papel aluminio y se incuba durante 30 minutos a $37^{\circ} \mathrm{C}$. Luego de incubar, se determina la absorbancia a $540 \mathrm{~nm}$ en un lector de ELISA.

\section{Blanco}

Se llenan pozos con $200 \mu \mathrm{L}$ de quercetina a las mismas concentraciones que el compuesto problema. 


\section{Interpretación de resultados}

Los resultados se reportan obteniendo el porcentaje de reducción, que se calcula con la siguiente fórmula:

\section{$\%$ Reducción de DPPH= (C-E/C) 100}

En donde:

$\mathrm{C}=\mathrm{Absorbancia}$ del $\mathrm{DPPH}$ disuelto en $\mathrm{MeOH}$

$\mathrm{E}=$ Absorbancia experimental (Mezcla de DPPH $(150 \mu \mathrm{L})+$ solución problema $(50 \mu \mathrm{L})$. 


\section{Apéndice 7. Conteo de fenoles totales (CFT) (Método modificado de Singleton et}

\section{al., 1999)}

La concentración de fenoles totales (CFT) se mide por espectrofotometría con base a una reacción colorimétrica de óxido-reducción, donde es empleado el reactivo de FolinCiocalteu. El reactivo de color amarillo y $\mathrm{pH}$ ácido, contiene molibdato y tungstatosódico que tienen la capacidad de reaccionar con cualquier tipo de fenol, formando complejos fosfomolíbdico-fosfotúngsticos. La transferencia de electrones a pH básico reduce los complejos fosfomolíbdico-fosfotúngsticos en óxidos, cromógenos de color azul intenso de tunsgteno $\left(\mathrm{W}_{8} \mathrm{O}_{23}\right)$, siendo proporcional este color al número de grupos hidroxilo de las moléculas (Gutiérrez et al., 2008).

Para la curva de calibración se emplea ácido gálico, que es una pequeña molécula que, debido, a su estabilidad y estructura fenólica, presenta un grupo benceno unido a un grupo hidroxilo.

\section{Curva de calibración}

Se utiliza una solución estándar de ácido gálico de $0.2 \mathrm{mg} / \mathrm{mL}$. A partir de esta solución se forman alícuotas correspondientes para obtener las concentraciones seriadas de ácido gálico $(0.00625,0.0125,0.05,0.1,0.2 \mathrm{mg} / \mathrm{mL})$; a cada una se le agrega el volumen correspondiente de agua destilada para obtener las concentraciones mencionadas de en un volumen final de $1 \mathrm{~mL}$.

\section{Preparación del extracto}

Se prepara una solución estándar $(200 \mu \mathrm{g} / \mathrm{mL})$ de la cual se toma una alícuota de 250 $\mu \mathrm{L}$ y se agregan $750 \mu \mathrm{L}$ de agua destilada para obtener las concentraciones mencionadas a un volumen final de $1 \mathrm{~mL}$. 
Se toma $1 \mathrm{~mL}$ de cada concentración y se transfiere a un tubo de ensayo con $7 \mathrm{~mL}$ de agua destilada; a continuación, se adicionan $500 \mu \mathrm{L}$ de reactivo Folin-Ciocalteau.

Después de cinco minutos se añaden $1.5 \mathrm{~mL}$ de una solución de $\mathrm{Na}_{2} \mathrm{CO}_{3}(200 \mathrm{~g} / \mathrm{L})$ y agua hasta completar un volumen de $10 \mathrm{~mL}$. La mezcla resultante se deja reposar durante dos horas, tiempo en el cual todos sus componentes reaccionan a temperatura ambiente, y se lee a $760 \mathrm{~nm}$. Cada concentración se lee por triplicado.

\begin{tabular}{|c|c|c|c|c|c|c|}
\hline Tubo & $\begin{array}{c}\text { Ácido } \\
\text { gálico } \\
(\mathrm{mg} / \mathrm{mL})\end{array}$ & $\begin{array}{c}\text { Patrón } \\
(\text { ácido } \\
\text { gálico } \mu \mathrm{L})\end{array}$ & $\begin{array}{c}\text { Agua } \\
\text { destilada } \\
(\mu \mathrm{L})\end{array}$ & $\begin{array}{c}\text { Agua } \\
\text { destilada } \\
(\mathrm{mL})\end{array}$ & $\begin{array}{c}\text { Folin- } \\
\text { Ciocalteau } \\
(\mu \mathrm{L})\end{array}$ & $\begin{array}{c}\mathrm{Na}_{2} \mathrm{CO}_{3} \\
(\mathrm{~mL})\end{array}$ \\
\hline Blanco & ----- & ------ & ----- & 7 & 500 & 1.5 \\
\hline 1 & 0.00625 & 31.25 & 968.75 & 7 & 500 & 1.5 \\
\hline 2 & 0.0125 & 62.5 & 937.5 & 7 & 500 & 1.5 \\
\hline 3 & 0.0250 & 125 & 875 & 7 & 500 & 1.5 \\
\hline 4 & 0.05 & 250 & 750 & 7 & 500 & 1.5 \\
\hline 5 & 0.1 & 500 & 500 & 7 & 500 & 1.5 \\
\hline 6 & 0.2 & 1000 & 0 & 7 & 500 & 1.5 \\
\hline Problema & ------ & 250 & 750 & 7 & 500 & 1.5 \\
\hline Problema & ------- & 500 & 500 & 7 & 500 & 1.5 \\
\hline
\end{tabular}

\section{Interpretación de resultados}

Se grafica la concentración contra la absorbancia para obtener una curva patrón de ácido gálico. Para conocer la concentración de fenoles del extracto problema, se utiliza un análisis de regresión lineal, interpolando la absorbancia de las muestras evaluadas. Los resultados se reportan como equivalentes de ácido gálico o en porcentaje. 


\section{Apéndice 8. Contenido de flavonoides totales Método Down (Ramamoorthy y}

Bono, 2007)

Este método se basa en el viraje de color de una solución de $\mathrm{AlCl}_{3}$ a color amarillo por la formación de complejos estables ácidos con el grupo ceto en C-4 o bien el grupo hidroxilo C-3 o C-5 de flavonas y flavonoles, así como la formación de complejos lábiles ácidos con los grupos orto-dihidroxil en el anillo A o B de los flavonoides .

\section{Stock de quercetina}

Se pesan $3 \mathrm{mg}$ de quercetina, los cuales se disuelven en $3 \mathrm{~mL}$ de $\mathrm{MeOH}$ grado HPLC.

\section{Curva patrón}

Se toman alícuotas necesarias del stock de quercetina para la preparación de la curva patrón, con las concentraciones de 1, 2, 3, 4, 5, 6, 7, 8, 9, 10, 20, 30, 40, 50, 60, 70, $80,90,100 \mathrm{ppm}$ y se les agrega $1 \mathrm{~mL}$ de $\mathrm{AlCl}_{3}$ al $2 \%$.

Nota: Para las primeras concentraciones (de 1 a 5 ppm), hacer lo siguiente:

Del stock de quercetina tomar $20 \mu \mathrm{L}$ y agregar $180 \mu \mathrm{L}$ de $\mathrm{MeOH}$, teniendo un volumen final de $200 \mu \mathrm{L}$. De este nuevo stock, se toma:

\begin{tabular}{|c|c|c|c|}
\hline [ ] ppm & $\begin{array}{c}\mu \mathrm{L} \text { stock de } \\
\text { quercetina }\end{array}$ & $\mu \mathrm{L}$ de $\mathrm{MeOH}$ & $\mathrm{AlCl}_{3}$ al $2 \%$ \\
\hline 1 & 10 & 990 & 1 \\
\hline 2 & 20 & 980 & 1 \\
\hline 3 & 30 & 970 & 1 \\
\hline 4 & 40 & 960 & 1 \\
\hline 5 & 50 & 950 & 1 \\
\hline
\end{tabular}


Del stock de quercetina ( $3 \mathrm{mg}$ en $3 \mathrm{~mL}$ de $\mathrm{MeOH}$ ) tomar:

\begin{tabular}{|c|c|c|c|}
\hline [ ] ppm & $\begin{array}{c}\mu \mathrm{L} \text { stock de } \\
\text { quercetina }\end{array}$ & $\mu \mathrm{L}$ de $\mathrm{MeOH}$ & $\mathrm{AlCl}_{3}$ al $2 \%$ \\
\hline 6 & 6 & 994 & 1 \\
\hline 7 & 7 & 993 & 1 \\
\hline 8 & 8 & 992 & 1 \\
\hline 9 & 9 & 991 & 1 \\
\hline 10 & 10 & 990 & 1 \\
\hline 20 & 20 & 980 & 1 \\
\hline 30 & 30 & 970 & 1 \\
\hline 40 & 40 & 960 & 1 \\
\hline 50 & 50 & 950 & 1 \\
\hline 60 & 60 & 940 & 1 \\
\hline 70 & 70 & 930 & 1 \\
\hline 80 & 80 & 920 & 1 \\
\hline 90 & 90 & 910 & 1 \\
\hline 100 & 100 & 900 & 1 \\
\hline
\end{tabular}

\section{Stock del extracto}

Se pesan 3mg del látex y se disuelven en $3 \mathrm{~mL}$ de $\mathrm{MeOH}$ grado HPLC

\section{Blanco}

Se toma $1 \mathrm{~mL}$ del stock del látex y $1 \mathrm{~mL}$ de $\mathrm{MeOH}$ grado HPLC.

\section{Problema}

Se toma $1 \mathrm{~mL}$ del stock del látex y se le agrega $1 \mathrm{~mL}$ de $\mathrm{AlCl}_{3}$ al $2 \%$. 
Se vierten $200 \mu \mathrm{L}$ de las soluciones preparadas para la curva patrón, el problema, el blanco y el control negativo en una placa de ELISA, por triplicado.

Después de 10 minutos de reacción a temperatura ambiente se determina la absorbancia a $450 \mathrm{~nm}$.

Interpretación de resultados

Se grafica la concentración contra la absorbancia para obtener la curva patrón de quercetina. Para el problema, se realiza un análisis de regresión lineal y se interpola el promedio de la absorbancia de la muestra a evaluar.

Los resultados de expresan como equivalentes de quercetina/g de extracto. 


\section{Apéndice 9. Cuantificación de carbohidratos (Método de Nelson -Somogy)}

Lo primero que se realiza es la extracción de carbohidratos de la muestra vegetal:

1. Se pesaron $100 \mathrm{mg}$ del látex y se le agregaron $2 \mathrm{~mL}$ de etanol frío al $80 \%$.

2. Se enfría en un baño de hielo por 15 minutos para precipitar proteínas.

3. Se centrifuga a $10000 \mathrm{rpm}$ por 15 minutos, se decanta el sobrenadante y se evapora en vacío a sequedad.

4. Reconstituir en $5 \mathrm{~mL}$ de agua destilada.

Posteriormente se realiza la cuantificación de carbohidratos de la siguiente manera:

Se hace reaccionar un azúcar reductora (como glucosa), se forma óxido cuproso de color rojo, debido a la donación de electrones del reductor al oxidante $\left(I\right.$ ión $\mathrm{Cu}^{+2}$ se transforma en ión $\mathrm{Cu}^{+}$). Ya que el óxido cuproso precipitado insoluble no puede valorarse fotométricamente, se trata con reactivo de arsenomolibdato para transformarse a un ión verdoso que se mide en el fotocolorímetro.

Al estar los reactivos en exceso, el agente reductor es el factor limitante; por lo cual se puede usar para determinar la cantidad de $\mathrm{Cu}_{2} \mathrm{O}$ que es proporcional a la cantidad de glucosa originalmente presente. La sensibilidad es de 25 a $250 \mu \mathrm{g} / \mathrm{mL}$.

Se construye la siguiente serie de tubos:

\begin{tabular}{lllllll}
\hline & 1 & 2 & 3 & 4 & 5 & 6 \\
Patrón de glucosa $(\mathrm{mL})$ & -- & 0.25 & 0.50 & 0.75 & 1.0 & -- \\
Agua destilada $(\mathrm{mL})$ & 1.0 & 0.75 & 0.50 & 0.25 & -- & -- \\
Problema $(\mathrm{mL})$ & -- & -- & -- & -- & -- & 1.0 \\
Reactivo de cobre $(\mathrm{mL})$ & 1.0 & 1.0 & 1.0 & 1.0 & 1.0 & 1.0 \\
\hline
\end{tabular}


1. Se tapan los tubos con papel aluminio y se colocan en baño maría hirviente por 20 minutos, enfriar con agua corriente.

2. Se agrega a cada tubo $1 \mathrm{~mL}$ del reactivo de arsenomolibdato.

3. Agregar a cada tubo $7.5 \mathrm{~mL}$ de agua destilada

4. Mezclar por inversión cada tubo y leer en el fotocolorímetro a $565 \mathrm{~nm}$ utilizando el tubo 1 como blanco.

5. Se construye una curva patrón y se interpola la absorbancia de los tubos problema.

Patrón de glucosa $(200 \mu \mathrm{g} / \mathrm{mL})$ :

Disolver $600 \mu \mathrm{g}$ de glucosa en $3 \mathrm{~mL}$ de agua destilada.

Reactivo de Cobre:

$400 \mathrm{~mL}$ de agua destilada $+40 \mathrm{~g}$ de carbonato de sodio anhidro y disolver. Agregar $7.5 \mathrm{~g}$ de ácido tartárico y disolver otra vez. Enfriar si es necesario, agregar $4.5 \mathrm{~g}$ de sulfato de cobre $\left(\mathrm{CuSO}_{4} .5 \mathrm{H}_{2} \mathrm{O}\right)$ y disolver. Aforar a $1 \mathrm{~L}$ y envasar en frasco ámbar. Dejar madurar por dos semanas.

Reactivo de Arsenomolibdato:

Disolver $50 \mathrm{~g}$ de molibdato de amonio en $900 \mathrm{~mL}$ de agua destilada, agregar $42 \mathrm{ml}$ de $\mathrm{H}_{2} \mathrm{SO}_{4}$ concentrado lentamente y añadir $50 \mathrm{ml}$ de solución de ortoarseniato disódico al $12 \%\left(\mathrm{Na}_{3} \mathrm{AsO}_{4}\right)$. Mezclar bien e incubar a $37^{\circ} \mathrm{C}$ durante 24 a 48 horas. Envasar en frasco ámbar. 


\section{Apéndice 10. Cuantificación de proteínas por el método de Bradford.}

El método está basado en la observación de que el colorante Azul brillante de Coomassie G-250 presenta dos formas coloreadas: azul y rojo. El color rojo pasa a azul cuando el colorante se une a la proteína. La formación del complejo coloranteproteína toma aproximadamente dos minutos y permanecer estable por 1 hora, por lo que el procedimiento es muy rápido y el tiempo para el ensayo no es limitante.

La cuantificación se lleva de la siguiente manera:

Se prepara la siguiente serie de tubos

\begin{tabular}{llllllll}
\hline & 1 & 2 & 3 & 4 & 5 & 6 & 7 \\
Patrón de BSA $(\mathrm{mL})$ & -- & 0.1 & 0.2 & 0.3 & 0.4 & 0.5 & -- \\
Agua destilada $(\mathrm{mL})$ & 1.0 & 0.9 & 0.8 & 0.7 & 0.6 & 0.5 & 1.0 \\
Problema $(\mathrm{mL})$ & -- & -- & -- & -- & -- & -- & $100 \mu \mathrm{L}$ \\
Reactivo de Bradford $(\mathrm{mL})$ & 5.0 & 5.0 & 5.0 & 5.0 & 5.0 & 5.0 & 5.0 \\
\hline Mezclar bien cada tubo y leer en el espectrofotómetro a $595 \mathrm{~nm}$. & \\
Reactivo de Bradford: \\
Pesar $100 \mathrm{mg}$ de Azul de CommassieG-250 y disolver en $500 \mathrm{~mL}$ de etanol AL 96\%, \\
agregar $100 \mathrm{ml}$ de ácido fosfórico al $85 \%$ y aforar a $1 \mathrm{~L}$ con agua destilada, filtrar y \\
almacenar en frasco ámbar, madurar durante 12 horas.
\end{tabular}




\section{REFERENCIAS}

1. Abbas, A., Lichtman, A. and Pillai, S. 2009. Inmunología celular y molecular. Elsevier. Sexta Edición. España. 566p.

2. Acosta A. 2006. El fibroblasto: su origen, estructura, funciones y heterogeneidad dentro del periodonto Universitas Odontológica. Red de Revistas Científicas de América Latina, el Caribe, España y Portugal. 25: 26-33.

3. Aguilar, A., Camacho, J. R., Chino, S. Jacquez, P. López, M. E., 1994. Herbario Medicinal del Instituto Mexicano del Seguro Social. Información Etnobotánica. IMSS. México. 218 pp.

4. Aiyelaagbe, O., Adesogan, K., Ekundayo, O. and Gloer, J. 2007. Antibacterial diterpenoids from Jatropha podagrica Hook. Phytochemistry. 68: 2420-2425.

5. Aljadi A., Kamaruddin M. 2004. Evaluation of the phenolic contents and antioxidant capacities of two Malaysian floral honeys. Food Chemistry. 85: 513-518.

6. Arias, A., Valverde, M., Reyes, J. 2001. Las plantas de la región de Zapotitlán Salinas, Puebla. Instituto Nacional de Ecología - Semarnat. UNAM. 70 pp.

7. Ávalos A., Pérez-Urria E. 2009. Metabolismo secundario de plantas. Reduca (Biología). Serie Fisiología Vegetal. Universidad Complutense. Madrid.2: 119-145.

8. Bairy, K., Ganesh, S., Adiga, M., Shalini, A. 2006. Impaired wound healing due to cyclophosphamide (CLP) alleviated by supplemental Ginkgo biloba. J Nat Rem. 6: 31-34.

9. Baum C., Arpey C. 2005. Normal Cutaneous Wound Healing. Clinical Correlation with Cellular and Molecular Events. Dermatologic Surgery. 31: 674-686. 
10. Benavides J. 2008. Reparación de heridas cutáneas. Revista de la Asociación Colombiana de Dermatología. 16: 29-35.

11. Berlanga, A. Valdéz, C., Savigne, W., Mendoza, Y., Franco, N., Vargas, E., Poll, N., Álvarez, H., Echeverría, H. and Pérez, R. 2010. Cellular and molecular insights into the wound healing mechanism in diabetes. Biotecnología aplicada. 27: 255261.

12. Boulton, A. J. 2004. The diabetic foot - from art to science. Diabetología 47: 134353.

13. Brendan, N., Aquino, J., Codutti, A. 2007. Respuesta inmunitaria. Cátedra de Bioquímica. Facultad de Medicina. UNNE.

14. Can-Ake, R., Erosa, G., May, F., Peña, L and Peraza, S. 2004. Bioactive terpenoids from roots and leaves of Jatropha gaumeri. Revista de la Sociedad de Química de México. 48: 11-14.

15. Canales, M., Hernández, T., Caballero, J., Romo de Vivar, A., Durán, A. y Lira, R. 2005. Informant consensus factor and antibacterial activity of the medicinal plants used by the people of San Rafael Coxcatlán, Puebla, México. Journal of Ethnopharmacology 97: 429-439.

16. Canales, M., Hernández, T., Caballero, J., Romo de Vivar, A., Durán, A. y Lira, R. 2006. Análisis cuantitativo del conocimiento tradicional de las plantas medicinales en San Rafael, Coxcatlán, Valle de Tehuacán-Cuicatlán, Puebla, México. Acta Botánica Mexicana 75: 21-43.

17. Castillo, J. 2004. Trabajos de revisión. Heridas, métodos de tratamiento. Medisan. 8: 33-42. 
18. Céspedes, T. y Sánchez, D. 2000. Algunos aspectos sobre el estrés oxidativo, el estado antioxidante y la terapia de suplementación. Revista Cubana de Cardiología. 14: 55-60.

19. Da Silva, M., Gregori, N., Nunes, P., Ribas-Filho, J., Freire, B., Malafaia, O., Paredes, C., Marcolin, T., Gilberto, S., Maia, J., De Araujo, R. 2006. Evaluación del extracto crudo de Jatropha gossypiifolia L. en la cicatrización de las heridas cutáneas en ratas. Acta Quirurgica Brasileira. 21:1-6.

20.Dandona, P., Aljada, A. and Bandyopadhyay, A. 2004. Inflammation: the link betwen insuline resistnace, obesity and diabetes. Trens Immunology. 25: 4-7.

21.Delaney, C., Dunger, A., Di Matteo, M., Cunningham, J., Green, M., Green, I. 1995. Comparison of inhibition of glucose-stimulated insulin secretion in rat islets of Langerhans by streptozotocin and methyl and ethyl nitrosoureas and methanesulphonates. Lack of correlations with nitric oxide-releasing or 06alkylating ability. Biochem Pharmacol. 50: 2015-2020.

22. Elsner, M., Gudbakke, B., Tiedge, M., Munda, T. and Lenzen, S. 2000. Relative importance of transport and alkylation for pancreatic beta-cell toxicity of streptozotocin. Diabetologia. 43: 1528-1533.

23. Enoch, S. and Leaper, D. 2007. Basic science of wound healing. Elseiver. 26:3137.

24. Fernández, B. M. 1999. Análisis de la dinámica de comunidades vegetales con relación a la evolución del paisaje en la zona semiárida de Coxcatlán, Puebla. Tesis de Maestría. UNAM. México. 98 pp. 
25. Finkel, T. and Holbrook, N. 2000. Oxidants, oxidative stress and the biology of ageing. Nature. 408: 239-247.

26. Flórez, J., Armijo, J. y Mediavilla, A. 2008. Farmacología Humana. 5ta. Edición. Elsevier Masson. Barcelona España.

27. García, A., Delgado, G., 2006a. Cytotoxic cis-fused bicyclic sesquiterpenoids from Jatropha neopauciflora. Journal of Natural Products. 69: 1618-1621.

28. García, A., Delgado, G., 2006b. Uncommon sesquiterpenoids and new triterpenoids from Jatropha neopauciflora (Euphorbiaceae). Helvetica Chemical Acta. 89: 16-28.

29. González, M. y Peñalosa, I. 2000. Biomoléculas (Métodos de Análisis). Ed. Universidad Nacional Autónoma de México. Facultad de Estudios Superiores Iztacala. Edo. de México. 256 pp.

30. Gutiérrez, D., Ortiz, C. y Mendoza, A. 2008. Medición de Fenoles y Actividad Antioxidante en Malezas Usadas para Alimentación Animal. Simposio de Metrología.

31. Haddad, Bruschi, Martins. 2000. The effect of sugar on the process of cicatrization of infected surgical incisions. Revista Latino-Americana de Enfermagem. 8: 57-65.

32. Haque, R., Begum, M., Rahman, S., Karim, R., Begum, T., Uddin, S., Mostofa, R., Hossain, A., Abdel-Daim, M., Begum, R. 2017. Wound healing effect of Euphorbia hirta linn. (Euphorbiaceae) in alloxan induced diabetic rats. BMC Complementary and alternative medicine. 17:423.

33. Harrison 2012. Principios de Medicina Interna. 18 Edición. Mc Graww Hill. Volumen 2. 
34. Havsteen, B. 1983. Flavonoids, a class of natural products of high pharmacological potency. Biochemical Pharmacology. 32: 11411-1148.

35. Hawk, T. C., Leary, S. L. y Morvis, T. H. 1999. Formulary for Laboratory Animals, 2nd edition. Blackwell Publishing. 167 pp.

36. Hernández, H. 2013. Comparación de las propiedades biológicas de dos especies del género Jatropha. Tesis de Maestría. Escuela Superior de Medicina. Instituto Politécnico Nacional. México. 102p.

37. Hernández, A., Alarcón, F., Jiménez, M., Hernández, L., Flores, C., Rodríguez, M. and Canales, M. 2017. Biological properties and chemical composition of Jatropha neopauciflora Pax. African journal of traditional, complementary and alternative medicines. 1: 32-42.

38. Hidalgo, O. 2010. Determinación del efecto cicatrizante del extracto acuoetanólico de la planta Bacopa procumbens en la línea celular 3T3 de fibroblastos de ratón. Tesis de Maestría. Escuela nacional de Medicina y Homeopatía. Instituto Politécnico Nacional. México. 125p.

39. Islas, S. y Revilla, M. 2013. Diabetes mellitus: actualizaciones. Editorial Alfil.

40. Jettanacheawchankit, S., Sasithanasate, S., Sangvanich, P., Banlunara, W., Thunyakitpisal, P. 2009. Acemannan stimulates gingival fibroblast proliferation; expressions of keratinocyte growth factor-1, vascular endotelial growth factor, and type I collagen; and wound healing. J Pharmacol Sci. 109: 525-531.

41. Kanitakis, J. 2002. Anatomy, histology and Inmunohistochemistry of normal human skin. European Journal of Dermatology. 
42. Karodi, R., Jadhav, M., Rub, R. and Bafna, A. 2009. Evaluation of the wound healing activity of a crude extract of Rubia cordifolia L. (Indianmadder) in mice. International Journal of Applied Research in Natural Products. 2: 12-18.

43. Lagunas, V. 2004. Estudio paramétrico para la producción de melanina en Escherichia coli recombinante. Tesis de Licenciatura. Instituto Tecnológico de Celaya. $62 p$.

44. Leighton, F., Urquiaga, I. y Diez, M. 1997. Propiedades antioxidantes del vino y sus componentes. Facultad de Ciencias Biológicas. Pontificia Universidad Católica de Chile. Revista Cubana de Plantas Medicinales Scielo.

45. Lozoya, X. y Zolla, C. 1984. Medicina tradicional en México. Boletín de la oficina sanitaria panamericana.

46. Lynch M. 1988. Métodos de Laboratorio. Editorial Interamericana S.A. de C.V. Segunda edición.

47. Magaña, P. y Villaseñor, J. 2002. La flora de México ¿se podrá conocer completamente? Ciencias 66: 24-26.

48. Maldonado, O., Jiménez, E., Guapillo, M., Ceballos, G. y Méndez, E. 2010. Radicales libres y su papel en las enfermedades crónico-degenerativas. Revista Médica de la Universidad Veracruzana. Diciembre 2010.

49. Merck S.A. 2000. Industrias Químicas. Bioflavonoides: Quercetina y Rutina. Informe a Profesionales.

50. Merino, P.J y Noriega, B.M. 2000. La piel: Estructura y Funciones. Fisiología General. Universidad de Cantabria. 7p. 
51. Monaco J. and Lawrence T. 2003. Acute wound healing An overview. Clinincs in Plastic Surgery. 30: 1-12.

52. Monsonís, B. y Blanco, J. 2012. Abordaje en las heridas de difícil cicatrización. Facultad de Enfermería. Universitat de Lleida. 63 p.

53. Murillo, F. 2006. Actividad antioxidante «in vitro» de las bebidas de frutas. Rev Tecnol. Alfa Editores Técnicos. 27 pp.

54. Nalwaya, N., Pokharna, G., Deb, L. and Kumar, N. 2009. Wound healing activity of látex of Calotropis gigantea. International Journal of Pharmacy and Pharmaceutical Sciences.1: 176-181.

55. Navarrete, F.G. 2003. Histología de la piel. Revista de la Facultad de Medicina. UNAM.

56. Nayak, S., Rodrigues, V., Maharaj, S., Bhogadi, V. 2013. Wound healing activity of the fruit skin of Punica granatum. J Med Food. 16: 857-861.

57. Nelson, N. 1944. A photometric adaptation of the Somogyi method for the determination of glucose. J. Biol. Chem. 153, 375-380.

58. Oskoueian, E., Abdullah, N., Ahmad, S., Zuhainis, W., Rahman, A., Wan, Y. 2011. Bioactive compounds and biological activities of Jatropha curcas L. Kernel meal extract. International Journal of Molecular Sciences. 12: 5955-5970.

59.Papanas, N. y Maltezos, E. 2008. Beclapermin gel in the treatment of diabetic neuropathic foot ulcers. Clinical Interventions in Aging. 3: 233-240.

60. Pickup, J. 2004. Inflammation and activate innate immunity in the pathogenesis of type 2 diabetes. Diabetes Care. 25: 924-932. 
61. Piconi. L. Quaglialioro, L. and Ceriello, A. 2003. Oxidative stress in diabetes. Clinical Chemistry and Laboratory Medicine. 9: 1144-1149.

62. Pieters, L., Bruyne, T., Claeys, M. and Vlietinck, A. 1993. Isolation of a dihydrobenzofuran lignan from South American dragon's blood (Croton spp.) as an inhibitor of cell proliferation. Journal of Natural Products. 56: 899-906.

63. Prieto-González, S., Garrido-Garrido, G., González-Lavaut, J. y Molina-Torres, J. 2004. Actualidad de la medicina tradicional herbolaria. Revista CENIC. Ciencias Biológicas. Centro Nacional de Investigaciones Científicas. Ciudad de la Habana, Cuba. 35: 19-36.

64. Ramamoorthy, P.K., Bono, A., 2007. Antioxidant activity, total phenolic and flavonoid content of Morinda citrifolia fruit extracts from various extraction processes. J. Eng. Sci. Technol. 2, 70-80.

65.Ramos, E., Castañeda, B. e Ibáñez, L. 2008. Evaluación de la capacidad antioxidante de plantas medicinales peruanas nativas e introducidas. Revista de la Academia Peruana de Salud. 15: 42-46.

66. Ramos, M., Batista, C., Gómez, B. y Zamora, A. 2006. Diabetes, estres oxidativo y antioxidantes. Red de Revistas Científicas de América Latina, el Caribe, España y Portugal. Sistema de Información Científica.

67. Risco E., Vila R., Henriques A y Cañigueral S. 2005. Bases químicas y farmacológicas de la utilización de la sangre de grado. Revista de Fitoterapia. 5: 101-114. 
68. Rosas, L. R. 2003. Estudio etnobotánico de San Rafael-Coxcatlán. Tesis Profesional Facultad de Estudios Superiores Iztacala, Universidad Nacional Autónoma de México, México. 94 pp.

69. Rzedowskii, J. 1991. Diversidad y orígenes de la flora fanerogámica de México. Acta Botanica Mexicana. 14: 3-22.

70.Sabandar, C., Ahmat, N., Mohd, F. and Sahidín, I. 2013. Medicinal property, phytochemistry and pharmacology of several Jatropha species (Euphorbiaceae): A review. Phytochemistry. 85: 7-29.

71.Salas, J., Tello, V., Zavaleta, A., Villegas, L., Salas, M., Fernandez, I., Vaisberg, A., 1994. Actividad cicatrizante del látex de Jatropha curcas (Angiospermae: Euforbiaceae). Rev. Biol. Trop. 42, 323-326.

72. Salcedo-Sánchez, B. 1997. Insectos precortesianos de la cueva de Coxcatlán, del Valle de Tehuacán, Puebla. Tesis de Licenciatura. Biología. UNAM Facultad de Ciencias 6-10 pp

73. Scherer, R. and Teixeira, H. 2009. Antioxidant activity index (AAI) by the 2,2diphenyl- 1 -picrylhydrazyl method. Food Chemistry. 112: 654-658.

74. Schnedl, W., Ferber, S., Johnson, J. and Newgard, C. 1994. STZ transport and citotoxicity. Specific enhancement in GLUT 2-expressing cells. Diabetes. 43: 1326-1333.

75. Secretaría de Salud NORMA Oficial Mexicana NOM-015-SSA2-2010, Para la prevención, tratamiento y control de la diabetes mellitus. México D.F. 
76. Singleton, V.L., Orthofer, R., Lamuela-Raventos, R.M., 1999. Analysis of total phenols and other oxidation substrates and antioxidants by means of folinciocalteu reagent. Method. Enzymol. 299, 152-178.

77. Thomas, R., Sah, N. and Sharma, P. 2008. Therapeutic biology of Jatropha curcas: a mini review. Current pharmaceutical biotechnology. 9: 315-324.

78. Vaisberg, A., Milla, M., Planas, M., Cordova, J., De Agusti, E., Ferryra, R., Mustiga, M., Carlin, L. and Hammond, G. 1989. Taspine is the cicatrizant in Sangre de Drago extracted from Croton lechleri. Planta medica. 55: 140-143.

79. Valiente-Banuet, A., Alcantara, A., Dávila, P., Flores-Hernández, N., Arismendi, M. C., Ortega-Ramírez, J., Soriano, J. A. 2000. La vegetación del Valle de Tehuacan-Cuicatlán. Boletín de la Sociedad Botánica de México. 67:25-75.

80. Velioglu, Y., Mazza, G., Gao, L. and Oomah, B. 1998. Antioxidant activity and total phenolics in selected fruits, vegetables and grain products. Journal of Agricultural and Food Chemistry. 46: 4113-4117.

81. Ventura, J., Boone, V., Aguilar,C., Román, R., Vega, E., Campos, E. y Alarcon, F. 2011. Effect of Varying Dose and Administration of Streptozotocin on Blood Sugar in Male CD1 mice. Proc. West. Pharmacol. Soc. 54: 5-9.

82. Vizcaíno, M., Alarcón, I., Sebazco, C., Maceira, M. 2013. Importancia de la sacarosa para la cicatrización de heridas infectadas. Revista Cubana de Medicina Militar. 42: 49-55.

83. Welsh, N. and Sandler, S. 1994. Protective action by hemin against interleukin-1 beta induced inhibition of rat pancreatic islet function. Mol Cell Endocrinol. 103: 109-114. 
84. West, E., Simon, O. y Morrison, E. 1996. Streptozotocin alters pancreatic beta-cell responsiveness to glucose within six hours of injection into rats. West Indian Med J. 45: 60-62. 


\section{PUBLICACIÓN \\ Journal of Ethnopharmacology \\ 2017 vol. 204, 1-7}

\section{Antimicrobial and anti-inflammatory activities, wound-healing effectiveness and chemical characterization of the latex of Jatropha neopauciflora Pax}

A.B. Hernández-Hernández ${ }^{a, d}$, F.J. Alarcón-Aguilar ${ }^{b}$, J.C. AlmanzaPérez $^{b}$, O. Nieto-Yáñez ${ }^{c}$, J.M. Olivares-Sánchez ${ }^{d}$, A. Durán-Díaz ${ }^{d}$, M.A. Rodríguez-Monroy ${ }^{\mathrm{c}}$, M.M. Canales-Martínez ${ }^{\mathrm{d}}$,

a Posgrado en Biología Experimental, División en Ciencias Biológicas y de la Salud (DCBS), Universidad Autónoma Metropolitana Iztapalapa (UAM-I), México

b Laboratorio de Farmacología, Departamento de Ciencias de la Salud, DCBS, UAMI, México, D.F., México

${ }^{c}$ Carrera de Medicina Facultad de Estudios Superiores-Iztacala UNAM, Tlalnepantla, Edo, Mex, México

d Laboratorio de Farmacognosia, UBIPRO Facultad de Estudios Superiores Iztacala UNAM, Tlalnepantla, Edo, Mex, México 


\begin{tabular}{lc|}
\hline ELSEVIER & Contents lists available at ScienceDirect \\
\hline & Journal of Ethnopharmacology \\
\hline
\end{tabular}

\title{
Antimicrobial and anti-inflammatory activities, wound-healing effeetiveness and chemical characterization of the latex of Jatropha neopauciflora Pax

\author{
A.B. Hernandez-Hernandez ${ }^{\mathrm{a}, \mathrm{d}}$, F.J. Alarcon-Aguilar ${ }^{\mathrm{b}}$, J.C. Almanza-Perez ${ }^{\mathrm{b}}$, O. Nieto-Yañez ${ }^{\mathrm{c}}$, \\ J.M. Olivares-Sanchez ${ }^{\mathrm{d}}$, A. Duran-Diaz , M.A. Rodriguez-Monroy ${ }^{\mathrm{c}}$, M.M. Canales-Martinez ${ }^{\mathrm{d}}$, \\ a Posgrado en Biologia Experimental, Division en Ciencias Biologicas y de la Salud (DCBS), Universidad Autonoma Metropolitana Iztapalapa (UAM-I), \\ Mexico
b Laboratorio de Farmacologia, Departamento de Ciencias de la Salud, DCBS, UAM-I, Mexico, D.F., Mexico \\ " Carrera de Medicina Facultad de Estudios Superiores-Iztacala UNAM, Tlalnepantla, Edo, Mex, Mexico \\ d Laboratorio de Farmacognosia, UBIPRO Facultad de Estudios Superiores Iztacala UNAM, Tlainepantla, Edo, Mex, Mexico
}

\section{A R T I C L E I N F O}

Keywords:

Euphorbiacea

Jatropha

Latex

Wound healing

Medicinal plant

\begin{abstract}
A B S T R A C T
Ethnopharmacological relevance: Jatropha neopauciflora Pax is an endemic species to Mexico, and its latex is used in traditional medicine to treat mouth infections when there are loose teeth and to heal wounds. In this research, we evaluated the antimicrobial activity, wound healing efficacy and chemical characterization of $J$. neopauciflora latex in a murine model.

Materials and methods: The antibacterial activity was determined using Gram positive and negative strains, the antifungal activity was determined using yeast and filamentous fungi, and the wound healing efficacy of the latex was determined using the tensiometric method. The anti-inflammatory activity was evaluated using the plantar oedema model in rats, administering the latex orally and topically. Cytotoxic activity was determined in vitro in two different cell lines. Antioxidant capacity, total phenolics, total flavonoids, reducing carbohydrates and latex proteins were quantified. The latex analysis was performed by High Performance Liquid Chromatography (HPLC). Finally, molecular exclusion chromatography was performed.

Results: The latex demonstrated antibacterial activity. The most sensitive strains were Gram positive bacteria, particularly $S$. aureus (MIC=2 mg/mL), and the latex had bacteriostatic activity. The latex did not show antifungal activity. The latex demonstrated a wound-healing efficacy, even the positive control (Recoveron). The orally administered latex demonstrated the best anti-inflammatory activity and was not toxic to either of the 2 cell lines. The latex had a high antioxidant capacity $\left(\mathrm{SA}_{\overline{5} 0}=5.4 \mathrm{\mu g} / \mathrm{mL}\right)$, directly related to the total phenolic (6.9 $\mathrm{mg} \mathrm{GAE} / \mathrm{mL})$ and flavonoid $(12.53 \mu \mathrm{g} \mathrm{QE} / \mathrm{mL})$ concentration. The carbohydrate concentration was $18.52 \mu \mathrm{g} / \mathrm{mL}$, and fructose was the most abundantly expressed carbohydrate in the latex $(14.63 \mu \mathrm{g} / \mathrm{mL}$ $79.03 \%)$. Additionally, the latex contained proteins $(7.62 \mu \mathrm{g} / \mathrm{mL})$ in its chemical constitution. As secondary metabolites, the HPLC analysis indicated the presence of phenols and flavonoids.

Conclusions: The $J$. neopauciflora latex promotes the wound healing process by avoiding microorganism infections, inbibiting inflammation and acting as an antioxidant.
\end{abstract}

\section{Introduction}

Several genera of the Euphorbiaceae family have diverse biological activities, such as antibacterial, antioxidant, anti-inflammatory and wound healing activities. The genus Croton, belonging to this family, is one of the most studied. It was observed that the latex of various species of this genus have healing properties, such as $C$. lechleri Müll. Arg. and C. draconoides Müll. Arg., where the alkaloid taspine has been identified as a healing product, increasing fibroblast migration and accelerating the wound healing process. The chemical and pharmacological activities of $C$. lechleri latex have also been studied, and the presence of various molecules with biological properties was detected (Salas et al., 1994). The alkaloid taspine was one of those molecules, showing wound healing and anti-inflammatory activity by promoting fibroblast migration during the first $60 \mathrm{~h}$ after injury and inflammation, and three inflammation models showed significant anti-inflammatory activity. An investigation of the mechanism of action in cell culture demonstrated that the hydrochloride salt of alkaloid is not toxic

" Correspondence to: Laboratorio de Farmacognosia, Unidad de Biotecnologia y Prototipos (UBIPRO) Facultad de Estudios Superiores Iztacala, Universidad Nacional Autonoma de Mexico, Av. De los Barrios No.1, Los Reyes Iztacala, Tlalnepantla, Edo. Mex C.P. 54090, Mexico.

E-mail address: magacm @yahoo.com.mx (M.M. Canales-Martinez).

http://dx.doi.nrg/10.1016/j.jep.2017.04.003

Received 10 Janury 2017; Received in revised form 27 March 2017; Accented 2 April 2017

Available online 06 April 201

0378-8741/ (C 2017 Published by Elsevier Ireland Lte. 
(Vaisberg et al.,, 1989).

Another genus that presents similar biological activities is Jatropha L., which has been studied phytochemically. Compounds isolated from Jatropha, such as cyclic peptides, have biological activity, acting on the proliferation of $\mathrm{T}$ cells, and have antimalarial activity (Baraguey et al., 2000). Different species of this genus, such as $J$. curcas L. and $J$. gaumeri Greenm, have also been shown to have antibacterial, antiinflammatory, wound healing and antioxidant activity (Can-Ake et al., 2004).

Jatropha neopauciflora (common name: "sangre de grado") is an endemic species of the Valley of Tehuacan-Cuicatlan, Puebla, Mexico. Ethnobotanical records report that the latex of this species is often white but may also have shades of orange and red with a milky appearance. Latex is used to treat wounds, scarring, oral infections and when there are loose teeth (Canales et al., 2006 and Canales et al., 2005b; Arias et al., 2001).

There are a few phytochemical studies about $J$. neopauciflora; for example, Garcia and Delgado (2006a, 2006b) obtained two unknow sesquiterpenes and reported the cytotoxicity of two triterpenoids from the bark of this species. On the other hand, Canales (2005a) reported the antibacterial activity of this species on Gram positive and negative bacteria. However, this species may present different medicinal properties, such as antibacterial, antioxidant and anti-inflammatory activities. These properties can help or intervene in the process of wound healing, which consists of three phases: inflammatory, proliferative and repair, each lasting for a certain amount of time and involving the participation of various tissues and cell types (Karodi et al., 2009). This process may occur after a microbial infection, and free radical products from cells of the immune system and the inflammatory phase can change from acute to chronic, causing a delay in the wound healing process.

Therefore an ideal wound healing would be that in addition to intervene in the healing process, also present antimicrobial, antiinflammatory and antioxidant activity, in order to have a good healing efficiency, since drugs currently used for wound healing only have a specific activity, also produce harmful side effects and some have very high costs. For these reasons, this work studied the biological properties of latex, such as antimicrobial, anti-inflammatory and antioxidant activities, which involve or promote the wound healing process.

\section{Material and methods}

Latex of J. neopauciflora was collected in January 2014 in San Rafael Coxcatlan, Puebla. The specimens were collected in the field with permission from the "Secretaria de Medio Ambiente y Recursos Naturales" (SGPA/DGVS/1266). Voucher specimens were deposited in the National Herbarium of Mexico (MEXU) at the Universidad Nacional Autonoma de Mexico, and the herbarium IZTA at the Facultad de Estudios Superiores Iztacala (voucher no. IZTA 29284)

San Rafael is a village in the municipality of Coxcatlan, which is located southeast of the Tehuacan-Cuicatlan Valley at $18^{\circ} 12^{\prime}$ to $18^{\circ} 14^{\prime}$ north and $97^{\circ} 07^{\prime}$ to $97^{\circ} 09^{\prime}$ west, $957 \mathrm{~m}$ above sea level. The climate is dry or arid with summer rains and a mean temperature of $22^{\circ} \mathrm{C}$ (Fernandez, 1999).

\subsection{Test microorganisms}

Bacteria strains: Staphylococcus aureus ATCC 29213, S. aureus (clinical case), S. epidermidis, Bacillus subtilis, Enterococcus faecalis ATCC 29212, Streptococcus pneumoniae, Micrococcus luteus, Vibrio cholerae CDC V 12 El Tor, Vibrio cholerae INDRE 206, Vibrio cholerae (clinical case), Enterobacter aerogenes, Yersinia enterocolitica, Escherichia coli (clinical case), Pseudomonas aeruginosa ATCC 27853, Proteus mirabilis and Enterobacter cloacae.

Fungal strains: Yeast: Candida albicans ATCC 14065, Candida albicans ATCC 10231, Candida albicans ATCC 14065 and Cryptococcus neoformans.
Filamentous fungi: Aspergillus niger CDBB-H-179, Aspergillus sp., Trichophyton mentagrophytes CDBB-H-1112, Fusarium sporotrichioides NRLL3299, Fusarium moniliforme CDBB-H-265 and Rhizoctonia lilacina CDBB-H-306.

Each bacterial and levadura strains were suspended in nutrient broth and incubated for $24 \mathrm{~h}$ before testing at $37^{\circ} \mathrm{C}$. Müeller Hinton agar (Bioxon, Edo. de Mexico, Mexico) and potato-dextrose agar (PDA) (Bioxon, Edo. de Mexico, Mexico) were used to test the antibacterial and antifungal activity, respectively.

\subsection{Antibacterial activity assay}

The antibacterial activity was measured using the Kirby-Baüer disc diffusion agar method (Vanden Berghe and Vlietinck, 1991). The bacterial inoculum was incubated in $10 \mathrm{~mL}$ Müeller Hinton broth at $37^{\circ} \mathrm{C}$ for $24 \mathrm{~h}$. The cultures were adjusted to a turbidity comparable to McFarland standard no. 0.5 with a sterile saline solution $\left(1.5 \times 10^{8}\right.$ $\mathrm{CFU} / \mathrm{mL}$ ). The microbial suspensions were plated on Müeller Hinton agar plates (BD Bioxon). Five mm diameter discs (Whatman no. 5) were impregnated with $10 \mu \mathrm{L}$ of latex, and discs with $25 \mu \mathrm{g}$ chloramphenicol were used as positive controls. The tests were performed in triplicate.

The minimal inhibitory concentration (MIC) was estimated using the broth dilution method (Vanden Berghe and Vlietinck, 1991). The concentrations used were $0.125-20 \mathrm{mg} / \mathrm{mL}$. The tubes were inoculated with a $10^{5} \mathrm{CFU} / \mathrm{mL}$ microorganism suspension. The MIC values were defined as the lowest latex concentration that prevented visible bacterial growth after $24 \mathrm{~h}$ of incubation at $37^{\circ} \mathrm{C}$. Each experiment was repeated at least three times. The bactericidal kinetic assay was performed using the appropriate concentrations of the latex (corresponding to $1 / 2$ MIC, MIC and MBC) (Muroi et al., 1993).

\subsection{Antifungal activity assay}

For qualitative analysis, the radial growth inhibition method (Wang and Bun, 2002) was used. Petri dishes with PDA were inoculated with mycelium by point deposition ( $5 \mathrm{~mm}$ diameter) and incubated at $28^{\circ} \mathrm{C}$ for $72 \mathrm{~h}$. After mycelium growth, paper filter discs saturated with $10 \mu \mathrm{L}$ of latex were placed over these plates. A positive control disc with ketoconazole antibiotic was used $(7.0 \mu \mathrm{g})$ (Sigma-Aldrich, St. Louis, MO, USA). Mycelium reduction or changes in colour, sporulation or morphology was reported as antifungal activity. No antifungal activity was reported when the fungi grew similar to the control and grew over the discs. The tests were performed in triplicate.

\subsection{Wound-healing efficacy}

Seven-week-old CD1 male Mus musculus were employed and were handled in accordance with Mexican Federal regulations for animal use and care (Nom-062-Zoo-1999).

Wound healing activity was performed using the tensiometric method based on measuring wound resistance to tension (Salas et al., 1994). The experimental groups were: latex 50\%, 75\% and $100 \%$, negative control (gel), and positive control (Recoveron) (Armstrong laboratorios, Mexico). Treatments were applied topically every $12 \mathrm{~h}$ for 10 days. Later, the mice were sacrificed using a $\mathrm{CO}_{2}$ chamber, and the force with which the wound is opened was measured using a dynamometer (Acrylic tubular, Montcello, N.Y., USA).

\subsection{Anti-inflammatory activity}

The anti-inflammatory activity was evaluated using the carrageenan-induced oedema model $(100 \mu \mathrm{L} 1 \%$ dissolved in $\mathrm{NaCl} 0.9 \%)$ in Wistar rats.

The experimental groups for oral administration were latex (250, 500 and $750 \mathrm{mg} / \mathrm{kg}$ bodyweight) and positive control (Dexamethasone 
$10 \mathrm{mg} / \mathrm{kg}$, Chinoin, S.A. Mexico, and Naproxen sodium $25 \mathrm{mg} / \mathrm{kg}$, Siegfried Rhein, S.A. de C.V. Mexico); these treatments were administered orally via a cannula (Sengar et al., 2015). The experimental groups for topical administration were latex $100 \%$ and the positive control (Naproxen sodium gel; Bayer, Mexico and Dexamethasone; Alcon-Couvreur NV, Belgica). The volume of the paw was measured thickness gage ID-C112/1012X (Mitutoyo, Kawasaki-shi, Japan) at 0 $1,2,3$ and $4 \mathrm{~h}$ after the injection of carrageenan (Sigma-Aldrich, St Louis, MO, USA).

\subsection{Cytotoxic activity}

A human cervical carcinoma cell line (Ca Ski ATCC CRL-1550) and fibroblast cell line 3T3-L1 (ATCC CL-173) obtained from mouse embryos ( $M$. musculus) were used. The cells were maintained in DMEM (GIBCO, Grand Island, N.Y. USA) supplemented with $10 \%$ foetal bovine serum (GIBCO, The Grand Island, New York, USA) and $100 \mu \mathrm{g} / \mathrm{mL}$ gentamycin (GIBCO). The cells were cultured under humidified atmosphere containing $5 \% \mathrm{CO}_{2}$ in an incubator kept at $37^{\circ} \mathrm{C}$. An in vitro cell cytotoxicity test was performed using the crystal violet method (Badisa, 2003). Briefly, the cells $\left(3 \times 10^{4} /\right.$ well) were seeded in 96-well plates and allowed to grow for $24 \mathrm{~h}$ before treatment. After, the cells were treated with different concentrations (10$0.004 \mathrm{mg} / \mathrm{mL}$ ) of latex in three replicates. Doxorubicin was used as the positive control. Wells containing untreated cells were the negative control. The results of the cytotoxic activity assay were interpreted according to the criteria of the National Cancer Institute (NCI), which states that concentrations considered as active or toxic substances are $\leq 20 \mu \mathrm{g} / \mathrm{mL}$ for extracts and $\leq 4 \mu \mathrm{g} / \mathrm{mL}$ for pure compounds (CLSI, 2012).

\subsection{Antioxidant activity (DPPH free radical scavenging)}

The antioxidant activity was determined according to the method by Mensor et al. (2001) Ninety-six-well ELISA plates were filled with latex concentrations ranging from 1 to $100 \mu \mathrm{g} / \mathrm{mL}$; HPLC grade methanol served as a blank sample and a DPPH solution $(100 \mu \mathrm{M})$ served as a control. The plates were incubated for $30 \mathrm{~min}$ at $37^{\circ} \mathrm{C}$, and the absorbance values were determined at $540 \mathrm{~nm}$ using an ELISA plate reader (Multiskan-Ex Thermo Scientific, Waltham, MA, USA) The antioxidant activity values were determined according to the following equation: \% inhibition=[(absorbance of control-absorbance of sample)/ absorbance of control] ${ }^{*} 100$. The concentration leading to $50 \%$ inhibition $\left(\mathrm{SC}_{50}\right)$ was determined graphically. Quercetin was used as a reference (positive control).

\subsection{Total phenolic content}

The Folin-Ciocalteu method (Singleton et al., 1999) was used to determine the total phenolic content of the latex. The amount of phenols was measured spectrophotometrically at $760 \mathrm{~nm}$. The mean of three readings was used to interpolate the gallic acid curve $(6.25,12.5$, $25,50,100,200 \mu \mathrm{g} / \mathrm{mL}$ ), and the total phenolic content was expressed in $\mathrm{mg}$ of gallic acid equivalents (GAE)/mL of latex.

\subsection{Total flavonoid content}

The Dowd method (adapted by Ramamoorthy and Bono, 2007) was used to determine the flavonoid content of latex. A quercetin (1$100 \mu \mathrm{g} / \mathrm{mL}$ ) calibration curve was used as the standard. A solution of $2 \%$ aluminium trichloride $\left(\mathrm{AlCl}_{3}\right)$ in HPLC grade methanol was used. The amount of flavonoids was measured spectrophotometrically at $415 \mathrm{~nm}$. The mean of three readings was expressed as $\mu \mathrm{g}$ of quercetin equivalent $\mathrm{QE} / \mathrm{mL}$ of latex.

\subsection{Qualitative detection of saponins}

The latex was diluted in water, stirred vigorously to produce foam that remained for $5 \mathrm{~min}$, resulting in a positive detection (Hernandez et al., 2005).

\subsection{Quantification of carbohydrates}

First, carbohydrate extraction was performed, and then these carbohydrates were quantified using the Nelson-Somogyi method. A glucose $(200 \mu \mathrm{g} / \mathrm{mL})$ calibration curve was used as the standard. The mean of three readings was expressed as mg of glucose equivalent GE/ $\mathrm{mL}$ of latex (Nelson, 1944; Somogyi, 1952).

2.12. Determination of carbohydrate using high performance liquid chromatography (HPLC)

Carbohydrate sample was injected into the HPLC Agilent Technologies 1100 (Atlanta, USA), with a column for carbohydrates, Supelcogel $7.8 \mathrm{~cm} \times 30 \mathrm{~cm}$ inside diameter, with a detector for light refraction. The mobile phase was water. The standards used were glucose, fructose and sucrose.

\subsection{Quantification of proteins}

Protein content was determined using the Bradford method (Bradford, 1976). The amount of proteins was measured spectrophotometrically at $595 \mathrm{~nm}$. The total protein content was expressed in $\mu \mathrm{g}$ of albumin equivalents (BSAE) $/ \mathrm{mL}$ of latex.

2.14. Bioassay guided fractionation size exclusion chromatography (SEC)

Five millilitres of latex was used. Sephadex LH-20 was used as the stationary phase, and increasing concentrations of hexane, methanol, and water were used as eluents. Fifty-eight fractions were obtained, and the antioxidant capacity of the higher yielding (24) fractions were measured using the DPPH method.

\subsection{High performance liquid chromatography (HPLC)}

The latex was loaded onto the HPLC HP Series 1100 separations module from Hewlett-Packard (Wilmington, DE, USA), equipped with a Allphere ODS- 1 column of $250 \times 4.6 \mathrm{~mm}$, with a particle size of $5 \mu \mathrm{m}$ The mobile phase consisted of methanol: acetonitrile: $\mathrm{H}_{2} \mathrm{O}(25: 25: 50)$ for $25 \mathrm{~min}$, flow $1 \mathrm{~mL} / \mathrm{min}$. A diode array detector (DAD) wavelength of $260 \mathrm{~nm}$ with a full scan of $200-400 \mathrm{~nm}$ was used.

\subsection{Statistical analysis}

Results were expressed as the mean \pm standard error of the mean (S.E.M.). Analysis of the data was done using the one-way analysis of variance (ANOVA) with a Tukey-Kramer Multiple Comparison post hoc test $(\mathrm{P}<0.05)$ using GraphPad Prism 6 software.

\section{Results}

The latex displayed activity on Gram-positive and Gram-negative bacteria. Bacillus subtilis FES-C showed the highest diameter inhibition zones $(12.33 \pm 1.15 \mathrm{~mm})$. Statistical analysis showed significant differences. Gram positive bacteria showed inhibition halos with a larger diameter $(\mathrm{p}=0.0001)$. Regarding MIC and MBC, most bacteria were sensitive to latex; however, the bacterial strain with the highest sensitivity was $Y$. enterocolitica (CUSI) (CMI: $1.0 \mathrm{mg} / \mathrm{mL}$ and CBM: $2.0 \mathrm{mg} / \mathrm{mL}$ ) (Table 1). Figs. 1 and 2 demonstrate the effects of the latex on the survival curves against $S$. aureus (cc) and $E$. coli (cc). The 
Table 1

Antibacterial activity of $J$. neopauciflora latex.

\begin{tabular}{|c|c|c|c|c|}
\hline Bacteria & $\begin{array}{l}\text { Halos of } \\
\text { inhibition } \\
(\mathrm{mm})\end{array}$ & $\begin{array}{l}\text { MIC } \\
\text { (mg/ } \\
\mathrm{mL})\end{array}$ & $\begin{array}{l}\text { MBC } \\
(\mathrm{mg} / \\
\mathrm{mL})\end{array}$ & $\begin{array}{l}\text { Positive } \\
\text { control (mm) }\end{array}$ \\
\hline S. aureus (cc) & $10.33 \pm 0.57$ & 4.0 & 6.0 & $28.0 \pm 0.00$ \\
\hline S. aureus 29213 & $9.66 \pm 0.57$ & 4.0 & 6.0 & $20.0 \pm 0.00$ \\
\hline $\begin{array}{l}\text { S. epidermidis } \\
\text { FES-C }\end{array}$ & $9.33 \pm 1.15$ & 2.0 & 4.0 & $30.3 \pm 0.57$ \\
\hline B. subtilis FES-C & $12.33 \pm 1.15$ & 2.0 & 4.0 & $32.6 \pm 0.57$ \\
\hline B. subtilis & $8.00 \pm 1.00$ & 6.0 & $>6.0$ & $24.0 \pm 1.00$ \\
\hline E. faecalis & $10.00 \pm 0.00$ & 2.0 & 4.0 & $24.3 \pm 0.57$ \\
\hline M. luteus & $10.33 \pm 1.15$ & 4.0 & 6.0 & $25.3 \pm 0.57$ \\
\hline S. pneumonie & $10.33 \pm 1.52$ & 4.0 & 6.0 & $30.0 \pm 0.00$ \\
\hline P. mirabilis & $8.33 \pm 2.30$ & na & na & $17.3 \pm 0.57$ \\
\hline P. mirabilis (cc) & $9.00 \pm 1.00$ & 2.0 & 4.0 & $14.6 \pm 0.57$ \\
\hline E. aerogenes & $9.66 \pm 0.57$ & 4.0 & 6.0 & $22.0 \pm 0.00$ \\
\hline $\begin{array}{l}\text { V. cholerae. El } \\
\text { Tor }\end{array}$ & $10.66 \pm 0.57$ & 4.0 & 6.0 & $25.0 \pm 0.00$ \\
\hline V. cholerae. (cc) & $10.00 \pm 1.00$ & na & na & $23.3 \pm 1.00$ \\
\hline V.cholerae. Agua & $9.66 \pm 0.57$ & 4.0 & 6.0 & $22.0 \pm 0.00$ \\
\hline E. coli $(\mathrm{cc})$ & $7.00 \pm 0.00$ & 4.0 & 6.0 & $30.0 \pm 0.00$ \\
\hline $\begin{array}{l}\text { Y. enterocolitica } \\
\text { CUSI }\end{array}$ & $12.00 \pm 1.00$ & 1.0 & 2.0 & $20.0 \pm 0.00$ \\
\hline $\begin{array}{l}\text { Y. enterocolitica } \\
\text { HA }\end{array}$ & $10.00 \pm 0.00$ & na & na & $14.0 \pm 0.00$ \\
\hline E. cloacae & na & na & na & $20.0 \pm 0.00$ \\
\hline
\end{tabular}

na: no activity; positive control: chloramphenicol; ce: clinical case; halos of inhibition mean data and standard deviation.

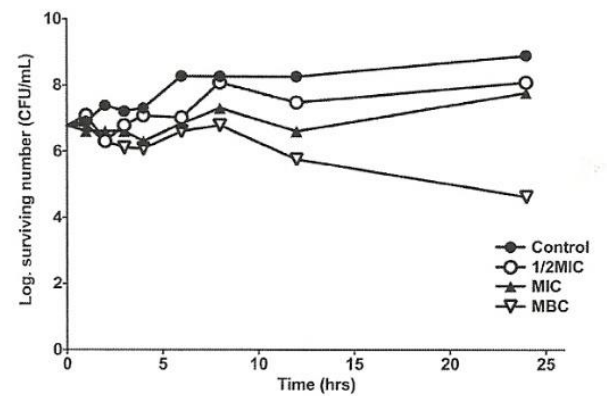

Fig. 1. Survival curve for S. aureus (cc) exposed to $J$. neopauciflora latex. The latex was added to each experimental culture at time zero. The concentrations were: $1 / 2 \mathrm{MIC}$ $1 \mathrm{mg} / \mathrm{mL}$; MIC: $2 \mathrm{mg} / \mathrm{mL}$; MBC: $4 \mathrm{mg} / \mathrm{mL}$. The control tube did not contain latex.

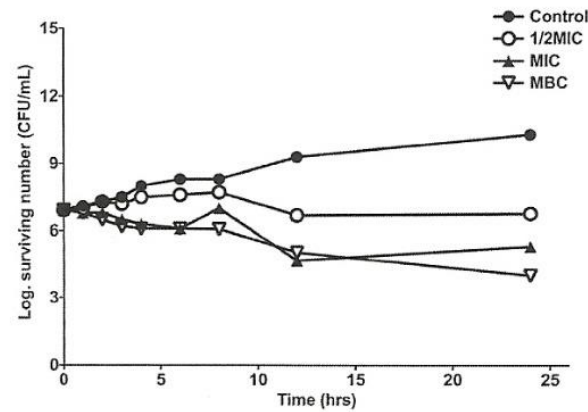

Fig. 2. Survival curve for $E$. coli (cc) exposed to J. neopauciflora. The latex was added to each experimental culture at time zero. The concentrations were: $1 / 2 \mathrm{MIC}: 7 \mathrm{mg} / \mathrm{mL}$. MIC: $14 \mathrm{mg} / \mathrm{mL}$; MBC: $20 \mathrm{mg} / \mathrm{mL}$. The control tube did not contain latex.

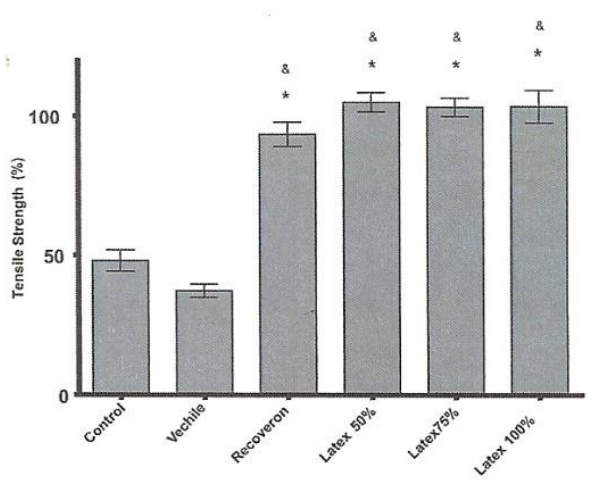

Fig. 3. Tensile strength of $J$. neopauciflora latex. The data are represented as means \pm S.E.M. $(\mathrm{n}=6)$. " Significant difference compared to the control group $(\mathrm{P}<0.05)$. ${ }^{\text {\& }}$ Significant difference compared to the vehicle group $(\mathrm{P}<0.05)$

minimum bactericidal concentration ( $\mathrm{MBC}=4 \mathrm{mg} / \mathrm{mL}$ ) had a bacteriostatic effect. A similar activity was demonstrated against $E$. coli (cc) MBC $(20 \mathrm{mg} / \mathrm{mL})$. The latex did not inhibit the growth of yeast strains or filamentous fungi.

In the wound healing activity assay, the three concentrations used $(50 \%, 75 \%$ and $100 \%)$ showed $100 \%$ cicatrizing efficacy, and there was no significant difference between the concentrations used $(P<0.05)$ and the control group in which the skin was uninjured. These percentages were above the positive control (Recoveron), which had an efficiency of $85 \%$. The group with gel was not significantly different from the untreated group. For this reason, the gel that dissolves the latex was not involved in the healing process (Fig. 3).

Concerning the anti-inflammatory activity, in the topical administration (Fig. 4), the inhibition of inflammation with latex was only $25 \%$, while the concentrations of 500 and $750 \mathrm{mg} / \mathrm{kg}$ of orally administered latex (Fig. 5) exhibited similar behaviours by decreasing inflammation between $65 \%$ and $70 \%$ and compared to the control (naproxen sodium) was not significant differences $(\mathrm{P}<0.05)$.

Based on the criterion of the NCI, the latex of $J$, neopauciflora was not toxic to either of the 2 cell lines (Ca Ski $\mathrm{IC}_{50}=1250 \mu \mathrm{g} / \mathrm{mL}$ fibroblasts $\mathrm{IC}_{50}=1000 \mu \mathrm{g} / \mathrm{mL}$ ).

In terms of antioxidant activity, the latex had a $\mathrm{SC}_{50}=5.4 \mu \mathrm{g} / \mathrm{mL}$, and the positive control quercetin had a $\mathrm{SC}_{50}=4.3 \mu \mathrm{g} / \mathrm{mL}$. These results demonstrate that the latex is able reduce DPPH. This result is related to the concentration of phenols $(6.9 \mathrm{mg} \mathrm{eAG} / \mathrm{mL})$ and flavonoids

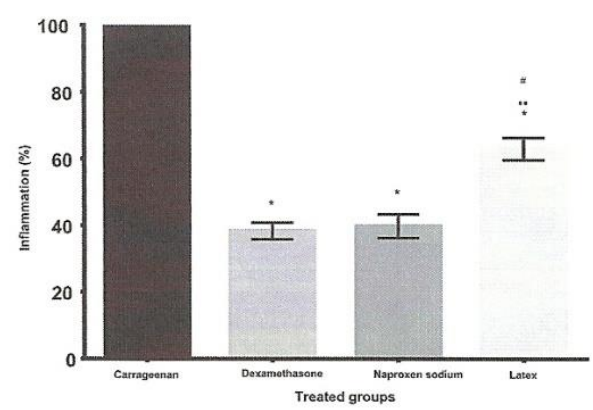

Fig. 4. Effect of $J$. neopauciflora latex administered topically on the plantar oedema in Wistar rats. The data are represented as means \pm S.E.M. $(n=6)$. "Significant difference compared to the carrageenan group ( $\mathrm{P}<0.05)$." Significant difference compared to the dexamethasone group $(\mathrm{P}<0.05)$. "Significant difference compared to the naproxen sodium group $(\mathrm{P}<0.05)$ 


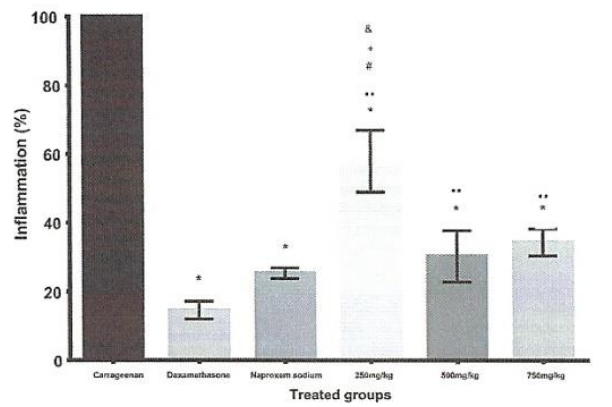

Fig. 5. Effect of $J$. neopauciflora latex administered orally on plantar oedema in Wistar rats. The data are represented means \pm S.E.M. $(n=6)$. *Significant difference compared to the carrageenan group $(\mathrm{P}<0.05)$. "Significant difference compared to the dexamethasone group $(\mathrm{P}<0.05)$. "Significant difference compared to the naproxen sodium group $(\mathrm{P}<0.05)$. ${ }^{\mathrm{E}}$ Significant difference compared to the $750 \mathrm{mg} / \mathrm{kg}$ group $(\mathrm{P}<0.05)$ ${ }^{+}$Significant difference compared to the $500 \mathrm{mg} / \mathrm{kg}$ group $(\mathrm{P}<0.05)$.

Table 2

Total concentration of phenols, flavonoids, proteins and carbohydrates per $\mathrm{mL}$ of latex

\begin{tabular}{ll}
\hline Molecules & Concentration \\
\hline Phenols & $6.9 \mathrm{mg}$ (GAE) \\
Flavonoids & $12.53 \mu \mathrm{gg}$ (QE) \\
Proteins & $7.62 \mu \mathrm{g}$ (AE) \\
Carbolydrates & $18.52 \mu \mathrm{g}$ (GE)
\end{tabular}

GAE: gallic acid equivalent, $\mathrm{QE}$ : quercetin equivalent, $\mathrm{AE}$ : albumin equivalent, $\mathrm{GE}$ glucose equivalent.

$(12.53 \mu \mathrm{g} \mathrm{eQ} / \mathrm{mL})$ contained in the latex. In the qualitative test, the latex contains saponins. Proteins and reducing carbohydrates were also determined. Of these molecules, carbohydrates showed a higher concentration (Table 2). HPLC analysis of the carbohydrates showed the presence of fructose $(79.03 \%)$ in the latex of $J$. neopauciflora.

Fifty-eight fractions were obtained by SEC of which 24 fraction showed the highest yields, and antioxidant capacity was measured using the reduction of DPPH method (Table 3).

Alternatively, for the HPLC analysis of the latex, the chromatogram showed two peaks. The first was identified as catechin (retention time $2.46 \mathrm{~min}$ ) and the second was catechol (retention time $3.46 \mathrm{~min}$ ). These compounds were identified with respect to standards.

\section{Discussion}

The results of antibacterial activity showed that Gram positive bacteria were more sensitive to latex (Table 1). These data are

Table 3

$\mathrm{SC}_{50}$ fractions of $J$. neopauciflora latex.

\begin{tabular}{llll}
\hline Fraction & $\mathbf{S C}_{5 \mathbf{0}}(\boldsymbol{\mu g} / \mathbf{m L})$ & Fraction & $\mathbf{S C}_{\mathbf{5 0}}(\boldsymbol{\mu g} / \mathbf{m L})$ \\
\hline 2 & $>50$ & 14 & $\mathbf{4 5}$ \\
3 & $>50$ & 15 & $>50$ \\
4 & $>50$ & 16 & $>50$ \\
5 & $>50$ & 17 & $>50$ \\
6 & $>50$ & 19 & $\mathbf{3 5}$ \\
7 & $>50$ & 20 & $>50$ \\
8 & $>50$ & 21 & $>50$ \\
9 & $\mathbf{1 0}$ & 23 & $>50$ \\
10 & $\mathbf{1 4}$ & 24 & $>50$ \\
11 & $\mathbf{2 6}$ & 25 & $>50$ \\
12 & $\mathbf{2 2}$ & 26 & $>50$ \\
13 & $\mathbf{3 0}$ & 35 & $>50$ \\
\hline
\end{tabular}

$\mathrm{SC}_{50}$ of the latex $=5.4 \mu \mathrm{g} / \mathrm{mL}$. consistent with the ethnobotanical use of $J$. neopauciflora for wound healing and skin infections (Canales et al., 2005), which are mainly caused by Gram positive bacteria. This fact is due to the structural characteristics and composition of the wall of this bacterial group. The peptide-glucans are inside a matrix of teichoic, teichuronic and lipoteichoic acids, which provide a negative charge to assimilate divalent cations. This feature makes Gram positive bacteria more sensitive to the polar compounds of latex, unlike Gram negative bacteria, which structurally presents as more resistant to organic solvents (Cimanga et al., 2002). A previous study demonstrated that the latex of African spirostachys Sond (Euphorbiaceae) has activity against Staphylococcus aureus, Salmonella typhi, Vibrio cholera, Escherichia coli and Shigella dysenteriae (MIC $=50 \mu \mathrm{g} / \mathrm{mL}$ ) (Mathabe et al., 2008). On the other hand, the essential oil and methanol extract of $J$. neopauciflora have activity against Staphylococcus aureus, Vibrio cholera, Escherichia coli and Pseudomas aeruginosa (Hernández et al., 2017).

The latex has a bacteriostatic effect on the bacterial growth curve of S. aureus (cc) (Fig. 1) and E. coli (cc) (Fig. 2). At $4 \mathrm{~h}$, the greatest decline in bacterial population was observed, but at $5 \mathrm{~h}$, the population begins to recover, thus creating the bacteriostatic effect. This observation is very important because the latex decreases the bacterial population, allowing the host to develop an immune response against these pathogens.

The latex has a wound-healing efficacy of $100 \%$ with all three concentrations tested (Fig. 3). However, there were differences in the appearance of the wound. The scar treated with $100 \%$ latex had a coarse appearance, similar to that of a keloid scar, while the $50 \%$ latex treatment presented the best repair because the scar was thin and well defined. The same concentration (50\%) was reported using J. curcas latex in a wound-healing model (Salas et al., 1994). C. lechleri and C. draconoides were studied, and the alkaloid taspine was identified as a wound healing principle because it increases the migration of fibroblasts (Vaisberg et al., 1989). The latex of Euphorbia nivulia Buch Ham., was evaluated using the excision wound model in albino mice by applying latex topically on the area of the wound, showing a significantly enhanced rate of wound contraction and period of epithelialization Phytochemical analysis revealed the presence of alkaloids, cyanogenic glycosides, phenolics, tannins and saponins (Badgujar et al. 2009).

Furthermore, in the wound healing process, inflammation occurs. For this reason, the anti-inflammatory activity of latex was evaluated by two routes of administration: topical and oral (Figs. 4 and 5). The results demonstrated that the anti-inflammatory effect was greater with the oral administration; this fact is because this route of administration is faster and more effective. For drugs to reach their site of action, they need to be transported through the bloodstream. The routes of administration according to their site of application are classified into enteral and parenteral. Enteral routes include drug application along the digestive tract. Orally, the drug can be absorbed in two sites, the stomach lining and the intestinal mucosa, which have the greatest absorption rate. In parenteral routes, in particular topical, drugs are deposited in the tissue and must be dissolved in the tissue fluids and cross-different biological barriers with different structures, so the absorption rate is slower (Florez et al., 2013).

Also, there are no significant differences between two concentrations of latex (500 and $750 \mathrm{mg} / \mathrm{kg}$ ) and naproxen sodium (positive control) (Fig. 5); a non-steroidal anti-inflammatory drugs (NSAIDs) which inhibits cyclooxygenase enzymes I and II (COX), resulting in decreased formation of prostaglandins and thromboxane from arachidonic acid (Meek et al., 2010).

The latex showed no cytotoxic activity against Ca Ski cells $\left(\mathrm{IC}_{50}\right.$ $=1250 \mu \mathrm{g} / \mathrm{mL}$ ) or fibroblasts (IC ${ }_{50}=1000 \mu \mathrm{g} / \mathrm{mL}$ ). In addition to this result, the ethno-medicinal use by people in the region (San Rafael, Coxcatlan) confirms that it does not cause any side effects.

The latex showed $\mathrm{SA}_{50}=5.4 \mu \mathrm{g} / \mathrm{mL}$. Comparing this result with 
quercetin, which has a $\mathrm{SA}_{50}=4.3 \mu \mathrm{g} / \mathrm{mL}$, the latex has a very good antioxidant capacity because the value of the $\mathrm{SA}_{50}$ is very similar to quercetin, and the latter is a pure compound. Extracts with $\mathrm{SA}_{50}$ less than $96.6 \mu \mathrm{g} / \mathrm{mL}$ have a good antioxidant capacity (Al-fatimi et al., 2007). The latex of $J$. curcas has a $\mathrm{SA}_{50}=5.9 \mu \mathrm{g} / \mathrm{mL}$ (Oskoneian et al., 2011). This result is similar to $J$. neopauciflora. Furthermore, of the fractions obtained from the SEC (Table 3), only 7 fractions showed a $\mathrm{SA}_{50}$ less than $50 \mu \mathrm{g} / \mathrm{mL}$. With these results, we can say that there is a synergism of all of the components of the latex as the latex $\mathrm{SA}_{50}$ was very high $(5.4 \mu \mathrm{g} / \mathrm{mL})$ while the fractions have very low antioxidant capacities.

The results obtained in the total quantification of phenols and total flavonoids content are closely related with the antioxidant activity of latex. Flavonoids have a proven antioxidant activity, which can protect cells against oxidative damage and therefore limit the risk of several degenerative diseases associated with oxidative stress caused by free radicals. These cytoprotective effects have been observed in human skin fibroblasts, keratinocytes and endothelial cells. In addition to the antioxidant activity, flavonoids exhibit a wide range of therapeutic effects, such as cardiotonic, anti-inflammatory, antimicrobial, hepatoprotective, antineoplastic activity, etc. (Martinez-Florez et al., 2002). Some chalcones and flavonoids have been reported to inhibit severa enzymes involved in inflammatory processes. Experiments have shown a dose-dependent inhibitory effect on COX-2 in a range of 4-190 $\mu \mathrm{M}$ Additionally, these flavonoids showed a cytoprotective capacity on the gastric mucosa, an antioxidant capacity, $\mathrm{COX}$ inhibition activity and anti-inflammatory activity (Alberto et al., 2007).

Saponins are recognized for their ability to produce a soapy lather when shaken with water. Saponins possess a variety of biological activities, such as antioxidant, immune-stimulant, anti-hepatotoxic anticarcinogenic, anti-diarrhoeal, anti-ulcerogenic, antioxytoxic, hypocholesterolemic, anticoagulant, hepatoprotective, hypoglycaemic, neuroprotective, and anti-inflammatory activity while inhibiting denta caries and platelet aggregation (Guclu-ustundag and Mazza, 2007; Rao and Gurfinkel, 2000). The qualitative test to detect saponins in the latex was positive, which may help explain the biological properties present in the latex of $J$. neopauciflora.

Alternatively, cyclic peptides with biological activity have been isolated from the latex of several species of Jatropha. For example, curcacycline A, isolated from $J$. curcas, has immunomodulatory activity inhibiting the classical complement pathway and proliferation of $\mathrm{T}$ cells. Additionally, curcacycline $\mathrm{B}$ has antimalarial activity (Baraguey et al., 2000). For this reason, protein quantification was performed on the latex of $J$. neopauciflora $(7.62 \mu \mathrm{g} / \mathrm{mL}$ of latex). Most likely, the latex has similar molecules responsible for its biological activity.

Carbohydrate quantification was performed, obtaining a concentration of $18.52 \mathrm{mg} / \mathrm{mL}$ latex, of which $79 \%$ was fructose. When there is wound, sugar creates a medium with low water content (high osmolarity) plasma and lymph migrate outside the tissue into the solution and inhibit bacterial growth in the decreased concentration of water (Haddad et al., 2000). Additionally, sugar attracts macrophages that phagocytose detritus and accelerate the release of devitalized, necrotic or gangrenous tissue, providing a local energy source and forming a protective layer on the wound. Honey contains various sugars, including fructose, promoting wound healing and acting on cell division, synthesis and the maturation of collagen, contraction and epithelialization of the wound (Gonzalez et al., 2004).

Fructans are fructose polymers distributed as carbohydrate storage polymers in the vegetative tissue of many families of plants, bacteria and fungi (Hosono et al., 2003). Fructans may be involved in the positive modulation of the immune system, mainly increasing resistance to infections and microbicidal activity and reducing allergic reactions and cancer in experimental models (Choque et al., 2010). Some plants with biological activity contains high fructans content as the case of Psacalium peltatum (Kunth) Cass, the aqueous fraction of roots may produce hypoglycemic, anti-inflammatory and antioxidant effects in mice with streptozotocin-induced diabetes (Alarcon-Aguilar et al., 2010). Therefore, it is very probable that the fructose present in $J$. neopauciflora latex is involved in the wound healing process.

Catechin and catechol were detected by HPLC analysis. Catechin has a good antioxidant potential, provides a reliable defence against free radicals and protects against neurological disorders, inflammation and apoptosis. Epigallocatechin-3-gallate (EGCG) has anti-inflammatory and antioxidant properties, reducing reactive oxygen species in the inflamed tissues. This antioxidant and radical scavenging activity, as shown in vitro and in vivo, can be attributed to the presence of the phenolic hydroxyl groups on the $\mathrm{B}$ and $\mathrm{D}$ rings of the catechin molecule (Nanjo et al., 1996)

These compounds are associated with acute and chronic inflammatory disorders. Some flavonoids inhibit chronic inflammation through enzymatic inhibition of cyclooxygenase and 5-lipoxygenase, considered one of the most important anti-inflammatory cell mechanisms (Surh et al., 2001). In vitro, polyhydroxylated flavonoids preferably involved by the lipoxygenase pathway, while less hydroxylated inhibit cyclooxygenase pathway, however, they act in vivo of both forms (Ferrandiz and Alcazar, 1991). Quercetin, in particular, inhibits both cyclooxygenase and lipoxygenase activities, thus diminishing the formation of these inflammatory metabolites. Flavonoids also inhibit eicosanoid biosynthesis, which are involved in various immunologic responses and the end products of the cyclooxygenase and lipoxygenase pathways (Nijveldt et al., 2001) Flavonoids extracted from medicinal plants of Spain and India were involved in the metabolism of arachidonic acid, noting that flavones and flavonols inhibited 12-lipoxygenase. In assessing the anti-inflammatory activity in mouse ear oedema, the researchers found that flavone, chrysin and apigenin are good inhibitory agents in addition to flavonols and isoflavones (Kim et al., 1993).

\section{Conclusion}

In this research, the data support that the Jatropha neopauciflora latex promotes the wound-healing process, probably by avoiding microorganism infections, inhibiting inflammation and acting as an antioxidant.

\section{Acknowledgements}

This research was funded by the UNAM PAPIIT 211614 project. Ana Bertha Hernández Hernández is a doctoral student from Programa de Doctorado en Biología Experimental, Universidad Autónoma Metropolitana (UAM) Unidad Iztapalapa and received fellowship 376294 from CONACYT.

\section{References}

Alarcon-Aguilar, F.J., Fortis-Barrera, A., Angeles-Mejia, S., Banderas-Dorantes, T.R., lasso-Villagomez, E.I., Almanza-Perez, J.C., Blancas-Flores, G., Zamilpa, A., 2010. Anti-inflammatory and antioxidant effects of a hypoglycemic rructan fraction fron sacalum pellatim (H.B.K.) (3)

Nieva, M.M.I., Zampini, C., Isla, M.I, I., 2007. Actividad antiinflamatoria de flavonoides naturales estrueturalmente relacionados. Bol. Iatinoam. Caribe Plant. Med. Aromat, $6,312-314$.

Al-Fatimi, M., Wurster, M., Schröder, G., Lindequist, U., 2007. Antioxidant, antimicrobial and cytotoxic activitios of selected medicinal plants from $Y_{\text {emen }} \mathrm{J}$ Fthnopharmacol. 111, 657-666.

Arias, T.A.A., Valverde, V.M.T. Reyes, S.J., 2001. Las plantas de la región de Zapotitlán Salinas. Puebla. Semarnat - Instituto Nacional de Ecologia. UNAM.

Badgujar, S.B., Mahajan, R.T., Chopda, M.Z., 2009. Wound healing activity of latex of Euphorbia nivulia Buch.-ham. in mice. Res. J. Pharmacol. Pharmacodyn. 1, 90-92 Badisa, R.B., Trakou, O., Couladis, M., Pilarinou, E.,2003. Cytotoxic activities of some Greek Labiatae herbs. Phytother, Res. 17, 472-476.

Baraguey, C., Blond, A., Correia, L, Pousset, J.L., Bodo, B., Auvin-Guette, C., 2000 Mahafacyclin A, a cyclic heptapeptide from. Jatropha mahafalensis exhibiting $\beta$ bulge conformation. Tetrahedron Lett. 41, 325-329. 
$72,248-254$.

Can-Ake, R., Erosa-Rejon, G., May-Pat, F., Peña-Rodriguez, L.M., Peraza-Sanchez, S.R., 2004. Bioactive terpenoids from roots and leaves of Jatropha gaumeri. Rev. Soc. Quim. Mex. 48, 11-14.

Canales, M., Hernandez, T., Caballero, J., Romo de Vivar, A., Avila, G., Duran, A., Lira, R., 2005b. Informant consensus factor and antibacterial activity of the medicinal plants used by the people of San Rafael CoxcatlanJ. Ethnopharmacol 97. Puebla, Nexico, $429-439$.

Canales, M.M., Hernandez, D.T., Caballero, N.J., Romo de Vivar, R.A., Duran, D.A., Lira, S.R., 2006. Analisis cuantitativo del conocimiento tradicional de las plantas medicinales en San Rafael, Coxeatlan, Valle de Tehuacan-Cuicatlan (Acta Bot. Mex) 75. Prebla, Mexico, $21-43$.

Canales, M.M.M., 2005a. Base fitoguimica del uso tradicional de plantas para el ratamiento de enfermedades de posible origen bacteriano en San Rafael Coxcatlar Mexico, 145 .

Choque, D.G.T., Tamashiro, W.M.S.C., Pastore, G.M., 2010. Immunomodulatory effects of fructans. Food Res. Int. 43, 1231-1236.

Cimanga, K., Kambu, K., Tona, L, Apers, S., De Bruyne, T, Hermans, N. Totte, J. Pielers, L., vlietinck, A.J., 2002. Correlation between chemical composition and Pielers, L., Vlietinck, A.J., 2002. Correlation between chemical composition and the Democratic Rebublic of Congo. J. Ethnopharmacol. 79, 213-220.

CLSI, 2012. Clinical and Laboratory Standards Institute. Performance standards for antimicrobial susceptibility testing; twentieth informational supplement. Tech. Rep. M100-S22, Clinical and Laboratory Standards Institute (CLSI). Pennsylvania, USA

$$
184 \mathrm{p} \text {. }
$$

Fernandez, B.M., 1999. Analisis de la dinamica de comunidades vegetales con relacion a la evolucion del pais

Ferrandiz, M.L., Alcazar, M.J., 1991. Anti-inflammatory activity and inhibition of arachidonic acid metabolism by flavonoids. Agents Actions 32, 283-288.

Florez, J., Armijo, J., Mediavilla, A., 2013. Farmacologia Humana sixth ed. Masson, España.

Garcia, A., Delgado, G., 2006a. Cytotoxic cis-fused bicyclic sesquiterpenoids fron Jatropha neopauciflora. J. Nat. Prod. 69, 1618-1621.

Garcia, A., Delgado, G., 2006b. Uncommon sesquiterpenoids and new triterpenoids from

Jatropha neopauciflora (Euphorbiaceae). Helv. Chim. Acta 89, 16-29.
Gonzalez, T.J.H., Rodriguez, R.R., Machado, P.P.M., Gonzalez, Q.J., Cabrera, S.I., 200-1 Heridas. Metodos de tratamiento. Medisan 8, 33-42.

Guclu-Ustundag, O., Mazza, G., 2007. Saponins: properties, applications and processing Crit. Rev. Food Sci. Nutr. 47, 231-258.

Haddad, M.C., Bruschi, L.C., Martins, E.A., 2000. The effect of sugar on the process of cicatrization of infected surgical incisions. Rev. Lat. Am. Enferm. 8, 57-65.

Hernandez, R., Lugo, E.C., Diaz, L., Villanueva, S., 2005. Extraccion y cuantificacion indirecta de las saponinas de Agave lechuguilla Torrey, e-Gnos. 3, 1-9.

Hosono, A., Ozawa, A., Kato, R., Ohnishi, Y., Nakanishi, Y., Kimura, T., Nakamura, R., 2003. Dietary fructooligosaccharides induce immunoregulation of intestinal IgA secretion by murine Peyer's patch cells. Biosci. Biotechnol. Biochem. 67, 758-764. Karodi, R., Jadhav, M., Rub, R., Bafna, A., 2009. Evaltation of the wound healing activity of a crude extract of Rubia cordifolia L. (lndian madder) in mice. Int. J. Appl. Re Nat. Prod. 2, 12-18.
Kim, H.K., Namgoong, S.Y., Kim, H.P., 1993. Anti-inflammatory activity of flavonoids: mouse ear edema inhibition. Arch. Pharm. Res. 16, 18-24.

Martinez-Florez, S., Gonzalez-Gallego, J., Culebras, I.M., Tuñon, M.J., 2002. Los flavonoides: propiedades y acciones antioxidantes. Nutr. Hosp. 17, 271-278.

Mathabe, M.C., Hussein, A.A., Nikolova, R.V., Basson, A.E., Meyer, J.J., Lilll, N., 2008 Antibacterial activities and cytotoxicity of terpenoids isolated from Spirostachys

Meek, I.L., de Iaar, Van, Vonkeman, H,E, M.A.F.J., 2010. Non-steroidal antiinflammatory drugs: an overview of cardiovascular risks. Pharmaceuticals 3 $2146-2162$

Mensor, L., Menezes, F., Leitao, G., Reis, A., Santos, T., Coube, C., Leitao, S., 2001. Screening of Brazilian plant extracts for antioxidant activity by the use of DPPH free mudical method. Phytother. Res. 15, 127-130.

Muroi, H., Kubo, A., Kubo, 1., 1993. Antimicrobial activity of cashew apple flavor compounds. J. Agric. Food Chem. 41, 11.06-1109.

Nanjo, F., Goto, K., Seto, R., Suzuki, M., Sakai, M., Hara, Y., 1996. Scavenging effects of on 1,-diphenyl-2- picryllhydrazyl radical. Free

elson, N., 1944. A photometric adaptation of the Somogyi method for the

lucose. J. Biol. Chem. 153, 375-380.

Nijveldt, R.J., Nood, E., Hoorn, D.E., Boelens, P.G., Norren, K., Leetwen, P.A.M., 2001. Flavonoids: a review of probable mechanisms of action and potential applications. Am. J. Clin. Nutr. 74, 418-425.

Oskoueian, E., Adbullah, N., Saad, W.Z., Omar, A.R., Ahmad, S., Kuan, W.B., Zolkifli, N.A., Hendra, R., Ho, Y.W., 2011. Antioxidant, anti-inflammatory and anticancer activities of methanolic extracts from Jatropha cureas Linn. J. Med. Plants Res. 5 , 49-57.

Ramamoorthy, P.K., Bono, A., 2007. Antioxidant activity, total phenolic and flavonoid content of Morinda citr

Rao, A.V., Gurfinkel, D.M., 2000. The bioactivity of saponins: triterpenoid and steroidal glycosides. Drug. Metabol. Drug, Interact. 17, 211-235.

Salas, J., Tello, V., Zavaleta, A., Villegas, L., Salas, M., Fernandez, 1., Vaisberg, A., 1994 Actividad cicattizante del latex de Jatropha curcas (Angiospermae: Euforbiaceae). Rev. Biol. Trop. 42, 323-326.

Singleton, V.I., Orthofer, R., Lamuela-Raventos, R.M., 1999. Analysis of total phenols and other oxidation substrates and antioxidants by means of folin-ciocalteu reagen Method. Enzymol. 299, 152-178.

Somogvi, M., 1952. Noles on sugar delermination. J. Biol. Chem. 195, 19-2.3.

Surh, Y.J., Chun, K.S., Cha, H.H., Han, S.S., Keum, Y.S., Park, K.K., Lee, S.S., 2001 Molecular mechanisms underlving chemopreventive activities of antiinflammatory phytochemicals: down-regulation of COX-2 and iNOS through suppression of NFkappa B activation. Mutat. Res. 1, 243-268.

Vaisberg, A.J., Milla, M., Planas, M.C., Cordova, J.L., De Agusti, E.R., Ferreyra, R., Mustiga, M.C., Carlin, L., Hammond, G.B., 1989. Taspine is the cicatrizant principle in sangre de grado extracted from Croton lechleri. Planta Med. 55, 140-143.

Vanden Berghe, D.A., Vlietnick, A.J., 1991. Screening methods for antibacterial agents from higher plants. In: Hostettmann, K. (Ed.), Methods in Plant Biochemistry (Assay

Wang, H., Bun, N.T., 2002. Isolation of an antifungal thaumatin-like protein from kiwl fruits. Phytochemistry $61,1-6$ 


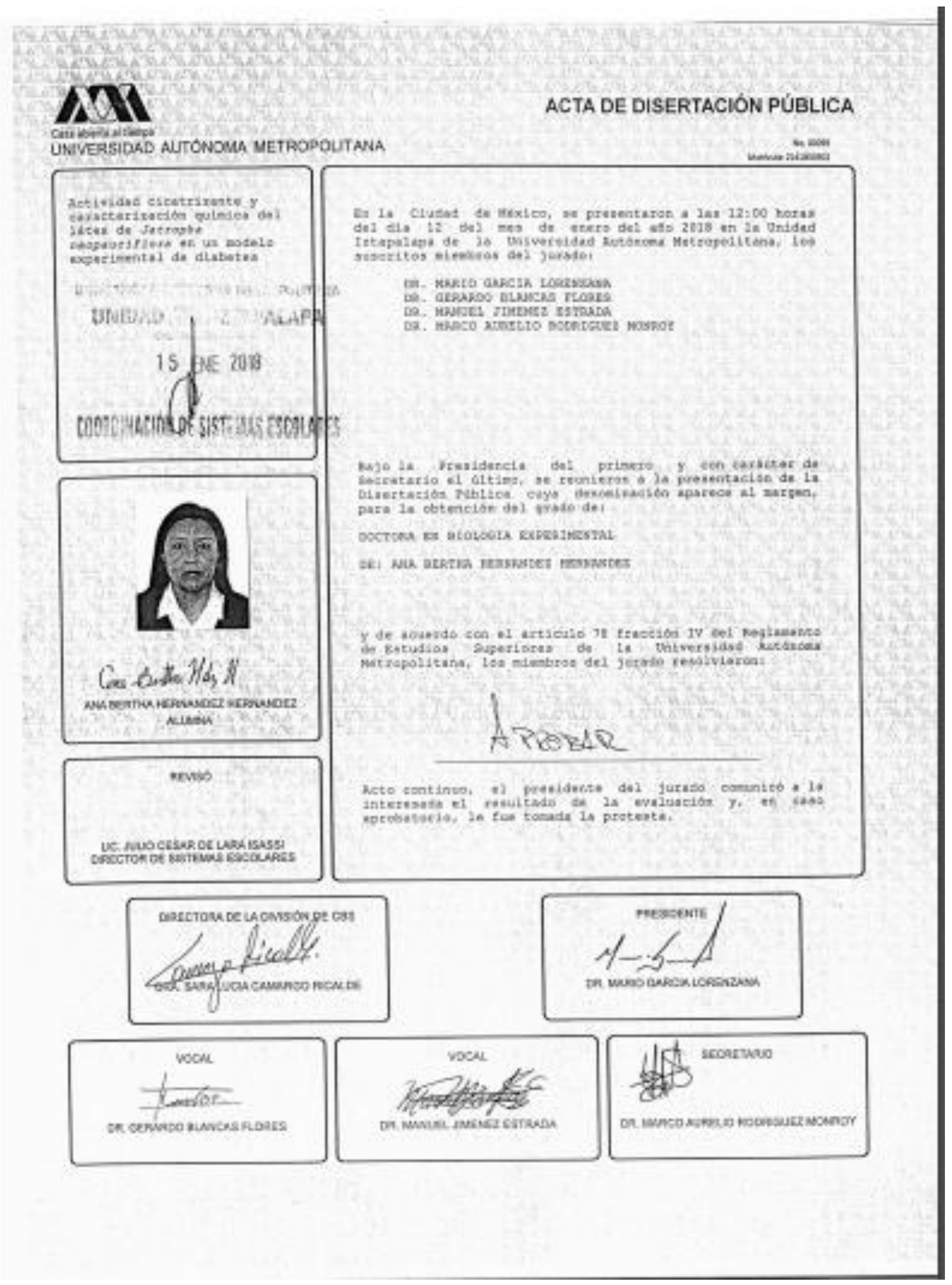

